\author{
UNIVERSIDADE DE SÃO PAULO \\ ESCOLA DE ENGENHARIA DE SÃO CARLOS \\ Departamento de Engenharia Elétrica e de Computação
}

Felipe José de Carvalho

\title{
Circuitos elétricos equivalentes para polímeros piezoelétricos termo-formados
}





\title{
FELIPE JOSÉ DE CARVALHO
}

\section{Circuitos elétricos equivalentes para polímeros piezoelétricos termo-formados}

\begin{abstract}
Dissertação apresentada à Escola de Engenharia de São Carlos da Universidade de São Paulo para obtenção do título de Mestre em Ciências, Programa de Engenharia Elétrica.
\end{abstract}

Área de Concentração: Sistemas Elétricos de Potência.

Orientador: Prof. Tit. Ruy Alberto Corrêa Altafim

Trata-se da versão corrigida da dissertação. A versão original se encontra disponível na EESC/USP que aloja o programa de Pós-graduação de Engenharia Elétrica.

São Carlos 
AUTORIZO A REPRODUÇÃO TOTAL OU PARCIAL RESTE TRABALHO, POR QUALQUER MEIO COONVENCIONAL OU ELETRONICO, PARA FINS DE ESTUDO E PESQUISA, DESDE QUE CITADA A FONTE.

C313c Carvalho, Felipe Jose de

eletricos equivalentes para polimeros pieroeletricos termo-formados / Felipe Jose de Carvalho; orientador Ruy Alberto Corré Altafim. SAo Carlos, 2016.

Dissertaçlo (Mestrado) - Programa de Pos-Graduaçlo em Engenharia Eletrica e Area de Concentraçlo em Bistemas Eletricos de Potencia -- Escola de Engenharia de SIo Carlos da Universidade de SIo Paulo, 2016.

1. circuitos eletricos equivalentes. 2 . pieroeletretos. 3. transdutores pieroeletricos. 4. polimeros pieroeletricos. I. Título. 


\section{FOLHA DE JULGAMENTO}

Candidato: Engenheiro FELIPE JOSÉ DE CARVALHO.

Título da dissertação: "Circuitos elétricos equivalentes para polímeros piezoelétricos termo-formados".

Data da defesa: 30/09/2016.

\section{Comissão Julgadora:}

Prof. Titular Ruy Alberto Correa Altafim (Orientador)

(Escola de Engenharia de São Carlos/EESC)

Prof. Dr. Antônio Adilton Oliveira Carneiro (Faculdade de Filosofia, Ciências e Letras de Ribeirão Preto/FFCLRP-USP)

Prof. Dr. Dante Luis Chinaglia

(Universidade Estadual Paulista "Júlio de Mesquita Filho"/UNESP - Rio

Coordenador do Programa de Pós-Graduação em Engenharia Elétrica:

Presidente da Comissão de Pós-Graduação:

Prof. Associado Luís Fernando Costa Alberto

\section{Resultado:}
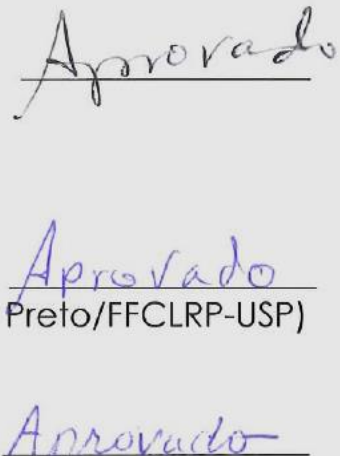



\section{AGRADECIMENTOS}

Agradeço primeiramente a toda minha família, meus pais e irmãos, que sempre estiveram ao meu lado em todas as etapas da minha vida.

À minha namorada Larissa, que me apoiou incondicionalmente durante a realização de todo este trabalho.

Ao professor Ruy Alberto Corrêa Altafim pelos ensinamentos ao longo dos cinco anos da graduação e pela oportunidade de ser seu orientado neste trabalho de mestrado.

Ao professor Ruy Alberto Pisani Altafim pelas ideias e pelo suporte para a realização dos experimentos.

Ao pessoal do GIIMUS da Faculdade de Filosofia, Ciências e Letras de Ribeirão Preto, em especial ao professor Antônio Adilton Oliveira Carneiro e ao técnico Agnelo Bastos pela estrutura laboratorial cedida e pelo apoio durante a realização dos experimentos.

Aos companheiros de laboratório do Grupo de Alta Tensão e Materiais: Daniel Ferreira, Felipe Souza, Luís Guilherme, Thamyres Tâmulla e Yuri Olivato, pelas opiniões e amizades.

À FIPAI pela concessão da bolsa de mestrado, dentro do projeto Piezoeletretos/EESC/ELEKTRO/ANEEL.

A todos os funcionários do Departamento de Engenharia Elétrica e de Computação da EESC/USP pelo apoio concedido.

A todos que contribuíram de alguma maneira para a realização deste trabalho. 



\section{RESUMO}

CARVALHO, F. J. Circuitos elétricos equivalentes para polímeros piezoelétricos termo-formados. 2016. 110 f. Dissertação (Mestrado) - Escola de Engenharia de São Carlos, Universidade de São Paulo, São Carlos, 2016.

Os circuitos ou modelos elétricos equivalentes destinam-se à modelagem de transdutores piezoelétricos, incluindo todo seu comportamento eletromecânico. Os modelos elétricos convencionais e clássicos foram elaborados inicialmente para materiais cerâmicos e cristalinos e só posteriormente adaptados para a simulação de polímeros piezoelétricos. Seguindo estes estudos, este trabalho apresenta um circuito elétrico equivalente para transdutores construídos com a tecnologia dos piezoeletretos termo-formados, desenvolvida no Grupo de Alta Tensão e Materiais da Escola de Engenharia de São Carlos (EESC-USP). Este circuito, baseado em um modelo proposto por Fiorillo (2000) para simular um transdutor curvo de fluoreto de polivinilideno (PVDF), foi aprimorado para melhor representar o comportamento em baixas frequências. Nele existem dois ramos: um mecânico e um elétrico. Os parâmetros do ramo mecânico foram calculados nas proximidades da frequência de ressonância das amostras, enquanto que os componentes do ramo elétrico foram determinados pelos ajustes das curvas de condutância e de susceptância para frequências distantes da ressonância. Esta etapa compreendeu o desenvolvimento de um algoritmo baseado na taxa de variação da condutância pela frequência, o qual permitiu determinar um método para separação do espectro de frequência em uma região próxima e outra distante da frequência de ressonância. Após a determinação de todos os parâmetros do modelo elétrico, circuitos para simulação no software Pspice foram elaborados para cada transdutor. Os resultados das simulações da condutância, da susceptância, do módulo da impedância e do ângulo de fase dos circuitos mostraram relevante concordância com as medições quando comparados grafica e numericamente. Esta última análise foi feita através da expressão de erro relativo percentual médio. Neste trabalho, empregou-se a metodologia fundamentada nas medidas da condutância e da susceptância de diferentes amostras, incluindo filmes de polipropileno (PP), de PVDF e de piezoeletretos de canais tubulares abertos de Teflon®FEP.

Palavras-chave: circuitos elétricos equivalentes, piezoeletretos, transdutores piezoelétricos, polímeros piezoelétricos. 



\begin{abstract}
CARVALHO, F. J. Equivalent electric circuits for thermo-formed piezoelectric polymers. 2016. 110f. Dissertação (Mestrado) - Escola de Engenharia de São Carlos, Universidade de São Paulo, São Carlos, 2016.

Equivalent electric circuits or models are regularly employed in piezoelectric transducers modeling, including its electromechanical behavior. Conventional and classic electric models were initially developed for ceramic and crystalline materials and later adapted for simulating piezoelectric polymers. Following these studies, this work presents an equivalent electric circuit for transducers built with the piezoelectret thermo-formed technology, developed by the High Voltage and Materials Group of São Carlos Engineering School (EESC-USP). This circuit, based on a model proposed by Fiorillo (2000) for simulating a curved polyvinylidene fluoride (PVDF) transducer, was improved to represent the behavior at low frequencies. There are two branches in this circuit: a mechanical and an electrical branches. The mechanical branch parameters were calculated in the vicinity of the resonance frequency, whereas the components of the electrical branch were determined by conductance and susceptance curves fittings for frequencies far from resonance. This stage included the development of an algorithm based on the rate of change of conductance, which allowed determining a method to separate the frequency spectrum in near resonance and far from resonance. After determining all parameters, electrical circuits were designed to perform simulations using Pspice software. The results for conductance, susceptance, impedance magnitude and phase angle simulations presented relevant agreement with measurements when compared graphically and numerically. This latter analysis was done by error relative expression. In this work, the methodology was based on conductance and susceptance measurements for different samples, including porous polypropylene (PP), PVDF and Teflon®FEP piezoelectrets with open-tubular channels films.
\end{abstract}

Keywords: Equivalent electric circuits, piezoelectrets, piezoelectric transducers, piezoelectric polymers. 



\section{LISTA DE FIGURAS}

Figura 2.1 - Dispositivo ultrassônico desenvolvido por Langevin. Fonte: Adaptado de Sherman e

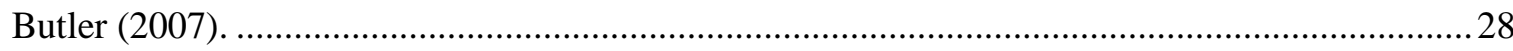

Figura 2.2 - Sistema de coordenadas utilizado na orientação de polarização e da excitação mecânica de um material piezoelétrico. Fonte: Altafim (2006).

Figura 2.3 - Representação da célula unitária de uma peroviskita. Fonte: Adaptado de Haerteling (1999).

Figura 2.4 - Representação da cadeia molecular do polifluoreto de vinilideno (PVDF). Fonte:

Adaptado de Fiorillo e Pullano (2011).

Figura 2.5 - Representação dos polímeros celulares e suas cavidades internas carregadas eletricamente. Fonte: Adaptado de Gerhard-Multhaupt (2002).

Figura 2.6 - Piezoeletretos com camadas empilhadas de filmes de Teflon ${ }^{\circledR F E P}$ e alumínio. Fonte:

Adaptado de Altafim et al. (2003).

Figura 2.7 - Procedimento utilizado para a formação de piezoeletretos com distribuição homogênea de bolhas de ar. Fonte: Adaptado de Altafim et al. (2006).

Figura 2.8 - Procedimento para moldar as bolhas de ar do piezoeletreto e sua vista lateral. Fonte:

Adaptado de Zhang, Hillenbrand e Sessler (2006).

Figura 2.9 - Método de fabricação dos piezoeletretos com várias camadas e imagem lateral de uma amostra. Fonte: Adaptado de Zhang, Hillenbrand e Sessler (2007).

Figura 2.10 - Procedimento de fabricação de piezoeletretos com estruturas padronizadas de canaletas e micrografia ótica da seção transversal de uma amostra. Fonte: Adaptado de Altafim (2010).

Figura 2.11 - Espectroscopia de amostras de piezoeletretos de canaletas com diferentes espessuras. Fonte: Adaptado de Altafim (2010).

Figura 2.12 - Espectroscopia de amostras de piezoeletretos de canaletas com diferentes larguras.

Fonte: Adaptado de Altafim et al. (2010)...

Figura 2.13 - Método de fabricação de filmes com domos simetricamente espaçados e laminação

dos filmes de FEP. Fonte: Adaptado de Falconi et al. (2010).

Figura 2.14 - Esquema utilizado na produção de piezoeletretos com dois filmes selados de FEP contendo água e imagem de uma abertura lateral de uma amostra. Adaptado de Assagra; Altafim,

R. A. C; Altafim, R. A. P. (2015).

Figura 2.15 - Representação esquemática de um sistema massa-mola. Fonte: Adaptado de Sherman e Butler (2007).

Figura 2.16 - Circuito elétrico RLC série e seu equivalente mecânico. Fonte: Adaptado de Kynsler et al. (2000).

Figura 2.17 - Gráfico da potência pela frequência de um circuito RLC. Fonte: Adaptado de Sherman e Butler (2007).

Figura 2.18 - Modelo de um transdutor com dois terminais. Fonte: Adaptado de Sherman e Butler (2007).

Figura 2.19 - Circuito elétrico equivalente de um transdutor recíproco. Fonte: Adaptado de Kynsler et al. (2000).

Figura 2.20 - Circuito elétrico equivalente proposto por Van Dyke para um cristal piezoelétrico nas proximidades de uma ressonância. Fonte: Adaptado de Van Dyke (1928).

Figura 2.21 - Representação do cristal piezoelétrico e suas dimensões utilizadas nos cálculos dos parâmetros do circuito equivalente. Fonte: Adaptado de Van Dyke (1928). 
Figura 2.22 - Circuito equivalente de um cristal piezoelétrico para frequências múltiplas da ressonância fundamental. Fonte: Adaptado de Van Dyke (1928)

Figura 2.23 - Circuito equivalente de KLM para transdutores do tipo espessura. Fonte: Adaptado

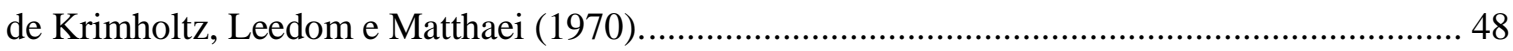

Figura 2.24 - Circuito equivalente proposto por Leach. Fonte: Adaptado de Leach (1994)......... 49

Figura 2.25 - Circuito equivalente com perdas adaptado do modelo de Van Dyke. Fonte:

Adaptado de Brown e Carlson (1989)

Figura 2.26 - Circuito equivalente contendo apenas componentes complexos. Fonte: Adaptado de

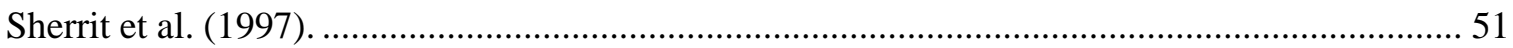

Figura 2.27 - Representação do transdutor curvo de PVDF e seu circuito equivalente para

frequências entre 1 e 150 kHz. Fonte: Adaptado de Fiorillo (2000)........................................... 52

Figura 2.28 - Circuitos equivalentes contendo apenas componentes reais e constantes. Em: (a)

Modelo proposto por Guan e Liao (2004); (b) Modelo proposto por Kim et al. (2008). Fonte:

Adaptado de Guan e Liao (2004) e Kim et al. (2008), respectivamente......................................... 53

Figura 3.1- Diagrama de blocos da metodologia proposta...................................................... 55

Figura 3.2 - Transdutores utilizados no experimento. Da esquerda para a direita: filme de PVDF,

piezoeletreto poroso de PP e piezoeletreto de canaletas de teflon FEP. .........................................56

Figura 3.3 - Detalhe do analisador de impedância conectado à interface de teste dielétrico. ....... 56

Figura 3.4 - Representação esquemática dos eletrodos utilizados nas medições e a foto lateral

mostrando o contato com os eletrodos da interface de teste dielétrico......................................... 57

Figura 3.5 - Circuito equivalente para simulação dos transdutores piezoelétricos, dividido em

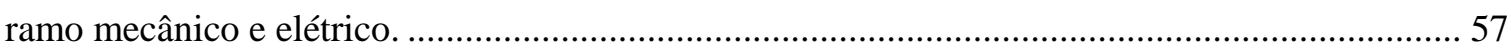



Figura 3.7 - Circuito equivalente para a modelagem dos dielétricos. Fonte: Adaptado de Zaengl

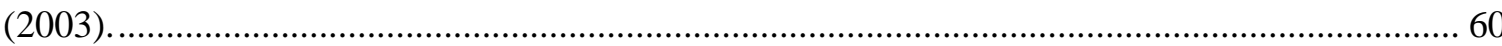

Figura 3.8 - Circuitos RLC paralelos para representação de $\mathbf{n}$ ressonâncias no espectro da

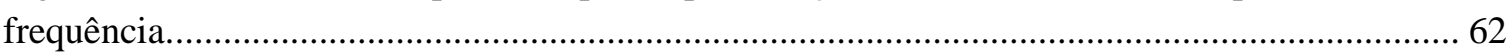

Figura 3.9 - Circuito equivalente para simulação dos transdutores, com $\mathbf{n}$ ramos RC na parte

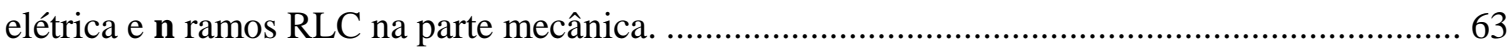

Figura 3.10 - Exemplo de circuito simulado no software Pspice, contendo três ramos RC na parte

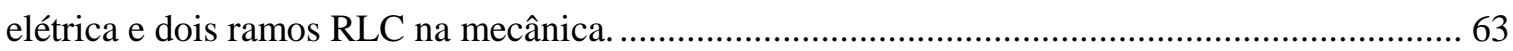

Figura 4.1 - Gráfico da condutância pela frequência do filme de PVDF. ...................................... 66

Figura 4.2 - Gráfico da susceptância pela frequência do filme de PVDF. ...................................... 66

Figura 4.3 - Gráfico do módulo da impedância pela frequência do filme de PVDF...................... 67

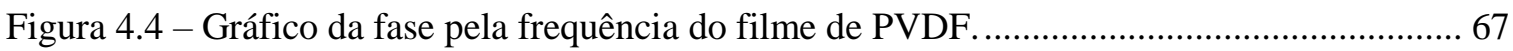

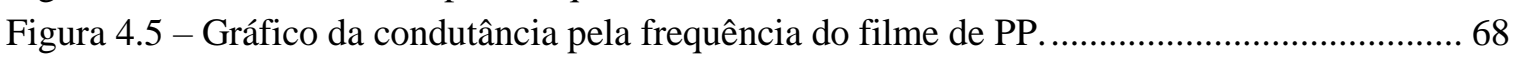

Figura 4.6 - Gráfico da susceptância pela frequência do filme de PP........................................... 68

Figura 4.7 - Gráfico do módulo da impedância pela frequência do filme de PP............................. 69

Figura 4.8 - Gráfico da fase pela frequência do filme de PP......................................................... 69

Figura 4.9 - Gráfico da condutância pela frequência dos piezoeletretos de canaletas. ................... 70

Figura 4.10 - Gráfico da susceptância pela frequência dos piezoeletretos de canaletas................. 71

Figura 4.11 - Gráfico do módulo de impedância pela frequência dos piezoeletretos de canaletas.

Figura 4.12 - Gráfico da fase pela frequência dos piezoeletreto de canaletas.............................. 72

Figura 4.13 - Gráfico da condutância pela frequência do piezoeletreto de canaletas com duas

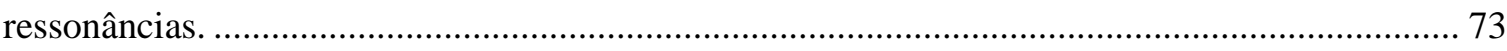

Figura 4.14 - Gráfico da susceptância pela frequência do piezoeletreto de canaletas com duas ressonâncias. 
Figura 4.15 - Gráfico do módulo da impedância pela frequência do piezoeletreto de canaletas com duas ressonâncias.

Figura 4.16 - Gráfico da fase pela frequência do piezoeletreto de canaletas com duas ressonâncias.

Figura 4.17 - Gráfico da taxa de variação da condutância pela sua posição no vetor medido, com $\Delta \mathrm{i}=28$, para o piezoeletreto de canaletas com cavidades de $25 \mu \mathrm{m}$ de altura.

Figura 4.18 - Gráfico da taxa de variação da condutância pela sua posição no vetor medido, com $\Delta \mathrm{i}=28$, para o piezoeletreto de canaletas com cavidades de $50 \mu \mathrm{m}$ de altura.

Figura 4.19 - Gráfico da taxa de variação da condutância pela sua posição no vetor medido, com $\Delta \mathrm{i}=22$, para o piezoeletreto de canaletas com cavidades de $70 \mu \mathrm{m}$ de altura.

Figura 4.20 - Gráfico da taxa de variação da condutância pela sua posição no vetor medido, com

$\Delta \mathrm{i}=28$, para o piezoeletreto de canaletas com larguras de 2,0 e $2,5 \mathrm{~mm}$.

Figura 4.21 - Gráfico da taxa de variação da condutância pela sua posição no vetor medido, com $\Delta \mathrm{i}=30$, para o filme de PP.

Figura 4.22 - Gráfico da taxa de variação da condutância pela sua posição no vetor medido, com $\Delta \mathrm{i}=20$, para o filme de PVDF.

Figura 4.23 - Ajustes da curva de condutância para a amostra de piezoeletreto com canaletas de $25 \mu \mathrm{m}$ de altura

Figura 4.24 - Ajustes da curva de condutância para a amostra de piezoeletreto com canaletas de $50 \mu \mathrm{m}$ de altura.

Figura 4.25 - Ajustes da curva de condutância para a amostra de piezoeletreto com canaletas de $70 \mu \mathrm{m}$ de altura.

Figura 4.26 - Ajustes da curva de condutância para a amostra de piezoeletreto com canaletas de 2,0-2,5 mm de largura.

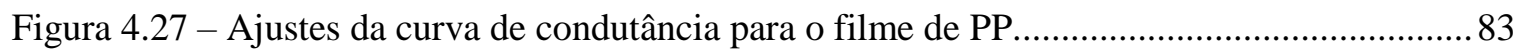

Figura 4.28 - Ajustes da curva de condutância para o filme de PVDF............................................ 83

Figura 4.29 - Gráficos da condutância do piezoeletreto de canaletas $(70 \mu \mathrm{m})$ e da função polinomial de ajuste para frequências distantes da ressonância.

Figura 4.30 - Resultado da subtração ponto a ponto dos dados experimentais pela função polinomial de ajuste dos pontos distantes da ressonância para o piezoeletreto de canaletas de 70

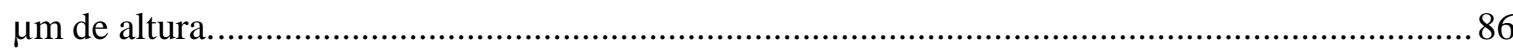
Figura 4.31 - Ajuste do ramo mecânico do piezoeletreto de canaletas $25 \mu \mathrm{m}$ de altura................. 87 Figura 4.32 - Ajuste do ramo mecânico do piezoeletreto de canaletas $50 \mu \mathrm{m}$ de altura.................. 87 Figura 4.33 - Ajuste do ramo mecânico do piezoeletreto de canaletas $70 \mu \mathrm{m}$ de altura.................. 88 Figura 4.34 - Ajuste do ramo mecânico do piezoeletreto de canaletas com 2,0-2,5 mm de largura.

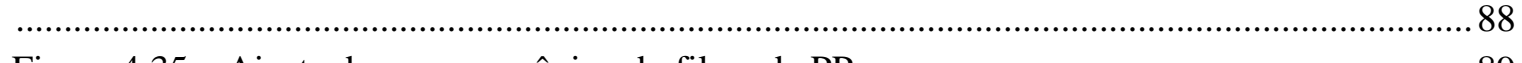

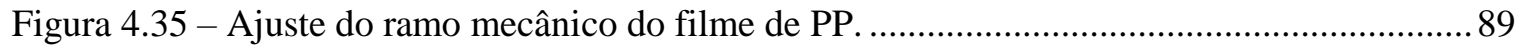

Figura 4.36 - Ajuste do ramo mecânico do filme de PVDF. .......................................................... 89 Figura 4.37 - Simulação do circuito equivalente e medição do piezoeletreto de canaletas $(25 \mu \mathrm{m}$

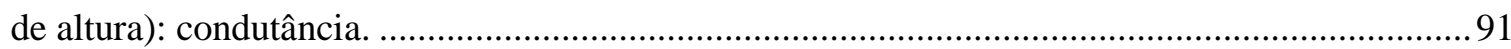
Figura 4.38 - Simulação do circuito equivalente e medição do piezoeletreto de canaletas ( $25 \mu \mathrm{m}$

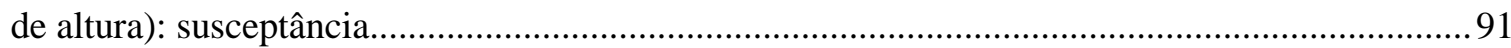
Figura 4.39 - Simulação do circuito equivalente e medição do piezoeletreto de canaletas ( $25 \mu \mathrm{m}$ de altura): módulo da impedância.

Figura 4.40 - Simulação do circuito equivalente e medição do piezoeletreto de canaletas $(25 \mu \mathrm{m}$ de altura): fase. 
Figura 4.41 - Simulação do circuito equivalente e medição do piezoeletreto de canaletas $(50 \mu \mathrm{m}$ de altura): condutância.

Figura 4.42 - Simulação do circuito equivalente e medição do piezoeletreto de canaletas $(50 \mu \mathrm{m}$ de altura): susceptância.

Figura 4.43 - Simulação do circuito equivalente e medição do piezoeletreto de canaletas $(50 \mu \mathrm{m}$ de altura): módulo da impedância.

Figura 4.44 - Simulação do circuito equivalente e medição do piezoeletreto de canaletas (50 $\mu \mathrm{m}$ de altura): fase.

Figura 4.45 - Simulação do circuito equivalente e medição do piezoeletreto de canaletas $(70 \mu \mathrm{m}$ de altura): condutância.

Figura 4.46 - Simulação do circuito equivalente e medição do piezoeletreto de canaletas $(70 \mu \mathrm{m}$ de altura): susceptância.

Figura 4.47 - Simulação do circuito equivalente e medição do piezoeletreto de canaletas $(70 \mu \mathrm{m}$ de altura): módulo da impedância.

Figura 4.48 - Simulação do circuito equivalente e medição do piezoeletreto de canaletas $(70 \mu \mathrm{m}$ de altura): fase.

Figura 4.49 - Simulação do circuito equivalente e medição do piezoeletreto de canaletas (2,0-2,5 mm de largura): condutância.

Figura 4.50 - Simulação do circuito equivalente e medição do piezoeletreto de canaletas $(2,0-2,5$ mm de largura): susceptância.

Figura 4.51 - Simulação do circuito equivalente e medição do piezoeletreto de canaletas (2,0-2,5

mm de largura): módulo da impedância.

Figura 4.52 - Simulação do circuito equivalente e medição do piezoeletreto de canaletas (2,0-2,5

$\mathrm{mm}$ de largura): fase.

Figura 4.53 - Simulação do circuito equivalente e medição do filme de PP: condutância............. 99

Figura 4.54 - Simulação do circuito equivalente e medição do filme de PP: susceptância............ 99

Figura 4.55 - Simulação do circuito equivalente e medição do filme de PP: módulo da impedância.

Figura 4.56 - Simulação do circuito equivalente e medição do filme de PP: fase.

Figura 4.57 - Simulação do circuito equivalente e medição do filme de PVDF: condutância.... 101

Figura 4.58 - Simulação do circuito equivalente e medição do filme de PVDF: susceptância... 101

Figura 4.59 - Simulação do circuito equivalente e medição do filme de PVDF: módulo da impedância.

Figura 4.60 - Simulação do circuito equivalente e medição do filme de PVDF: fase. 


\section{LISTA DE TABELAS}

Tabela 2.1 - Resumo dos principais circuitos equivalentes utilizados na simulação de transutores piezoelétricos

Tabela 4.1 - Valores de $\mathrm{f}_{1}$ e $\mathrm{f}_{2}$ determinados a partir das medidas de condutância dos transdutores

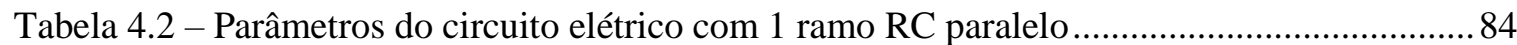

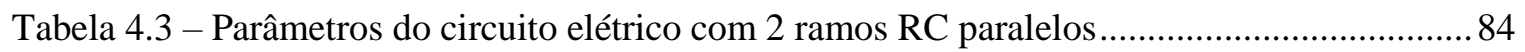

Tabela 4.4 - Parâmetros do circuito elétrico com 3 ramos RC paralelos ....................................... 84

Tabela 4.5 - Componentes referentes à parte mecânica dos circuitos equivalentes.........................90

Tabela 4.6 - Valores dos erros relativos percentuais médios (\%) entre os parâmetros simulados

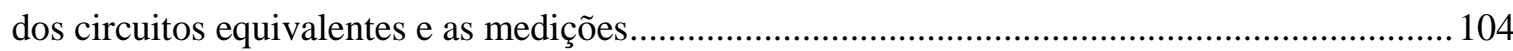





\section{LISTA DE ABREVIATURAS E SIGLAS}

CEIDP Conference on Electrical Insulation and Dielectric Phenomena

EESC Escola de Engenharia de São Carlos

FFCLRP Faculdade de Filosofia, Ciências e Letras de Ribeirão Preto

FIPAI Fundação para o Incremento da Pesquisa e Aperfeiçoamento Industrial

GATM Grupo de Alta Tensão e Materiais

GIIMUS Grupo de Inovação em Instrumentação Médica e Ultrassom

PP Polipropileno

PTFE Politetrafluoretileno

PVDF Polifluoreto de vinilideno

PZT Titanato zirconato de chumbo

$\mathrm{RC} \quad$ Resistor e capacitor

RLC Resistor, indutor e capacitor

USP Universidade de São Paulo 



\section{SUMÁRIO}

Introdução

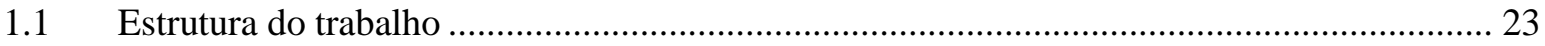

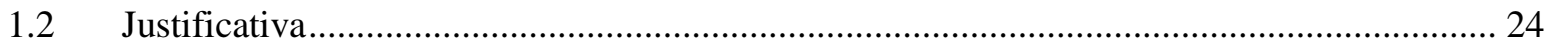

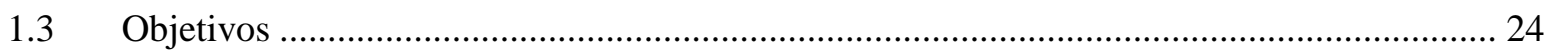

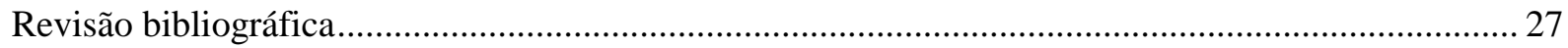

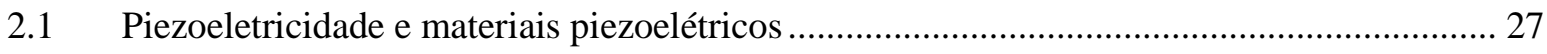

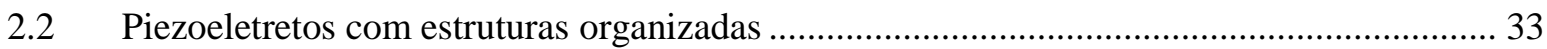

2.3 Modelos elétricos equivalentes de transdutores ................................................................. 39

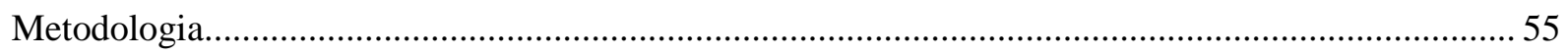

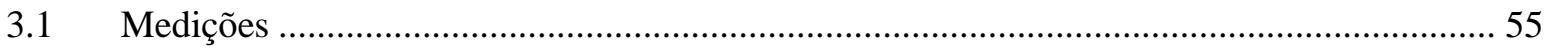

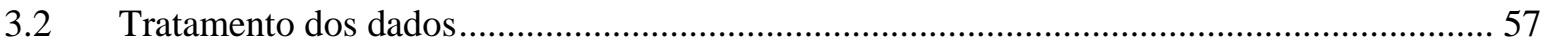

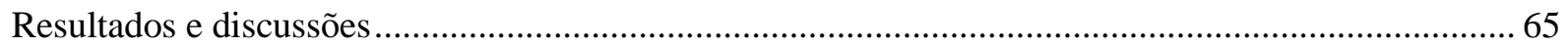

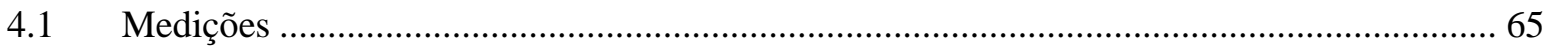

4.2 Algoritmo para separação das regiões no espectro de frequência .......................................... 76

4.3 Determinação dos parâmetros dos circuitos elétrico e mecânico ............................................. 80

4.4 Comparação: simulação e medição .................................................................................... 90

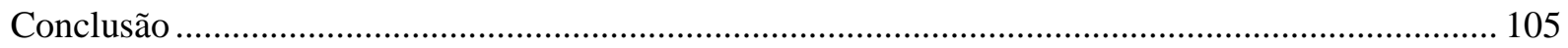

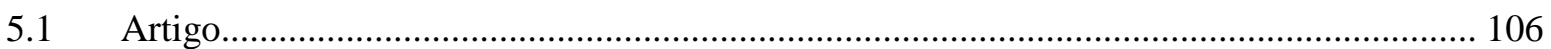

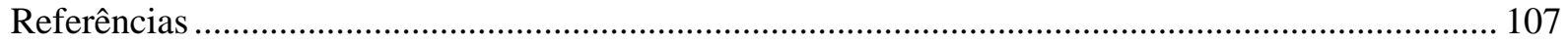





\section{Capítulo 1}

\section{Introdução}

Na década de 1980, foi constatado que determinados polímeros celulares ou com cavidades internas quando eletricamente carregados passavam a apresentar grandes coeficientes piezoelétricos, algumas vezes superiores aos das cerâmicas e cristais. Tais materiais foram denominados de piezoeletretos e, por serem poliméricos, apresentam características vantajosas em relação às tradicionais cerâmicas piezoelétricas, como a baixa densidade e a grande flexibilidade. Características estas desejáveis em muitas aplicações, como por exemplo, em detectores de movimento, transdutores ultrassônicos, microfones piezoelétricos e transdutores de pressão (GERHARD-MULTHAUPT, 2002).

Seguindo esta linha de pesquisa, o Grupo de Alta Tensão e Materiais da Escola de Engenharia de São Carlos (GATM/EESC) vem desenvolvendo ao longo dos últimos anos uma nova tecnologia de piezoeletretos denominados piezoeletretos termo-formados, que permite um total controle sobre a geometria das cavidades internas do transdutor.

Junto ao aperfeiçoamento das técnicas de fabricação destes materiais, o GATM desenvolveu um microfone que utiliza o piezoeletreto como elemento transdutor. $\mathrm{O}$ dispositivo foi utilizado como hidrofone na formação de imagens médicas pelo método da vibroacustografia (MEDEIROS, 2014) e na detecção acústica de descargas parciais (PALITÓ, 2015), o que mostra a grande aplicabilidade destes materiais. Neste contexto verificou-se a necessidade de se criar um modelo para simulação dos piezoeletretos, modelo este que auxiliará no projeto de novas aplicações e no entendimento do comportamento eletromecânico destes transdutores.

\subsection{Estrutura do trabalho}

O trabalho está dividido em cinco capítulos, sendo que o primeiro compreende a introdução do trabalho. 
O segundo capítulo refere-se à revisão bibliográfica. Serão abordados assuntos fundamentais à pesquisa, como a piezoeletricidade, materiais piezoelétricos e modelos elétricos equivalentes de transdutores.

O terceiro capítulo, por sua vez, compreenderá a metodologia utilizada no trabalho. Nele serão focados as medições realizadas, os equipamentos utilizados e o procedimento de determinação do circuito equivalente.

Já no quarto capítulo, que trata dos resultados obtidos, serão apresentadas as medições realizadas em laboratório, os resultados da determinação dos componentes do circuito equivalente e as comparações entre as medições e as simulações.

O quinto e último capítulo trata das análises e das conclusões do trabalho.

\subsection{Justificativa}

A modelagem dos piezoeletretos termo-formados é de grande importância no projeto de novas aplicações. Com o modelo é possível determinar parâmetros que aperfeiçoem a operação de novos dispositivos que utilizem o piezoeletreto como elemento transdutor, como a escolha de materiais de retaguarda (backing material), estruturas de casamento de impedância acústica, circuitos elétricos de sintonia e de amplificação, entre outras características. Já o transdutor como circuito elétrico facilita a simulação destes dispositivos devido à existência de uma grande variedade de softwares aplicados a circuitos elétricos. Outro fator importante é que o modelo auxiliará no entendimento do comportamento do transdutor devido à existência das analogias eletromecânicas presentes nos circuitos equivalentes.

\subsection{Objetivos}

O objetivo principal deste trabalho é determinar um circuito elétrico equivalente que represente as características eletromecânicas dos piezoeletretos termo-formados de canaletas desenvolvidos pelo GATM.

Como objetivos específicos deste trabalho têm-se: 
- Fazer um estudo na literatura sobre piezoeletricidade e materiais pieozoelétricos com a finalidade de apresentar conceitos introdutórios sobre o tema;

- Realizar pesquisa bibliográfica sobre os principais modelos elétricos de transdutores a fim de se obter um circuito que se adapte satisfatoriamente às características dos piezoeletretos;

- Detalhar a metodologia para obtenção do modelo. Esta parte compreenderá as etapas de preparação da amostra, os equipamentos utilizados, as configurações de medição e o tratamento dos dados obtidos. 


\section{Capítulo 2}

\section{Revisão bibliográfica}

Neste capítulo será feita uma revisão sobre os assuntos fundamentais para esta pesquisa. A seção 2.1 abordará a piezoeletricidade e os materiais piezoelétricos, a seção 2.2 será focada nos piezoeletretos com estruturas organizadas e a seção 2.3, na modelagem dos transdutores por meio de circuitos elétricos equivalentes.

\subsection{Piezoeletricidade e materiais piezoelétricos}

A piezoeletricidade foi descoberta pelos irmãos Pierre e Jacques Curie em $1880 \mathrm{em}$ estudos realizados com cristais de quartzo. Eles observaram o aparecimento de uma diferença de potencial quando estes materiais eram submetidos a pressões mecânicas, o que é denominado de efeito piezoelétrico direto. A palavra piezoeletricidade foi sugerida primeiramente por Hermann Hankel em 1881, sendo derivada do grego "piezen", que significa pressionar. No mesmo ano, Gabriel Lipmann sugeriu a existência do efeito piezoelétrico inverso, no qual a aplicação de uma diferença de potencial elétrica resulta em uma deformação mecânica do material. $\mathrm{O}$ efeito inverso foi confirmado experimentalmente pelos irmãos Curie em 1882 (TRAINER, 2003).

O uso da piezoeletricidade foi impulsionado durante a Primeira Guerra Mundial (1914-1918), em virtude da necessidade de detecção acústica submarina. Em 1917, Paul Langevin utilizou transdutores de quartzo para gerar pulsos de ultrassom e receber ecos. $\mathrm{O}$ dispositivo criado por Langevin, apresentado na Figura 2.1, consistia de cristais de quartzo empilhados, envolvidos por placas de metal (SHERMAN; BUTLER, 2007). Outras aplicações desenvolvidas no início do século XX foram o interferômetro ultrassônico, controladores de frequência de circuitos osciladores e filtros seletivos, estes últimos como resultado do alto fator de qualidade dos cristais. Estima-se que aproximadamente 10 milhões de cristais foram utilizados em circuitos de controle de comunicação durante a Segunda Guerra Mundial (MASON, 1981). 


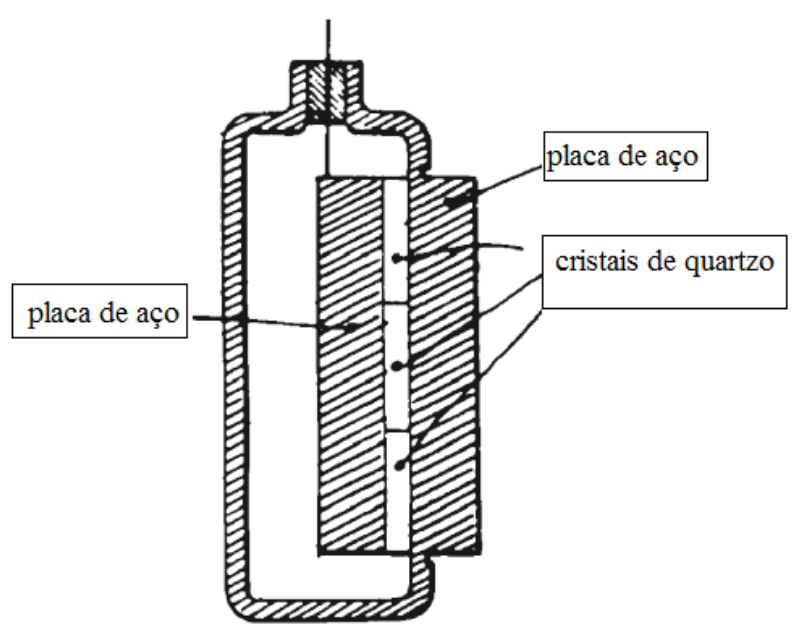

Figura 2.1 - Dispositivo ultrassônico desenvolvido por Langevin. Fonte: Adaptado de Sherman e Butler (2007).

As equações que descrevem o efeito piezoelétrico relacionam grandezas mecânicas e grandezas elétricas que são representadas por matrizes, cujos parâmetros obedecem a uma convenção de orientação espacial. Basicamente, as relações lineares de um meio piezoelétrico podem ser descritas por (HAERTLING, 1999):

$$
\begin{aligned}
& S=s^{E} T+d E \\
& D=d T+\varepsilon^{T} E
\end{aligned}
$$

sendo S a taxa de deformação mecânica, D o vetor deslocamento elétrico, T a tensão mecânica, E o vetor campo elétrico, $\mathrm{s}^{\mathrm{E}} \mathrm{o}$ coeficiente elástico, $\varepsilon^{\mathrm{T}}$ a permissividade dielétrica e d a constante piezoelétrica. Os sobrescritos E e T significam que as grandezas são obtidas a um campo elétrico constante e a uma tensão mecânica constante, respectivamente.

A matriz d é dada por (TRAINER, 2003):

$$
d_{i j}=\left(\begin{array}{llllll}
d_{11} & d_{12} & d_{13} & d_{14} & d_{15} & d_{16} \\
d_{21} & d_{22} & d_{23} & d_{24} & d_{25} & d_{26} \\
d_{31} & d_{32} & d_{33} & d_{34} & d_{35} & d_{36}
\end{array}\right)
$$

Os subscritos dos termos são interpretados de acordo com a orientação espacial da polarização quando o campo elétrico externo for igual à zero (subscrito i) e com o sentido da 
excitação externa aplicada (subscrito j). Os números 1,2 e 3 se referem às direções paralelas aos eixos da Figura 2.2, enquanto que os números 4, 5 e 6 são relacionados com as direções de cisalhamento. Em transdutores piezoelétricos do tipo espessura (do inglês, thickness mode) a polarização coincide com a direção do eixo Z do sistema de coordenadas da Figura 2.2 e seu coeficiente piezoelétrico é caracterizado por $\mathrm{d}_{33}$ (ALTAFIM, 2006).



Figura 2.2 - Sistema de coordenadas utilizado na orientação de polarização e da excitação mecânica de um material piezoelétrico. Fonte: Altafim (2006).

Como dito anteriormente, os cristais foram os primeiros materiais utilizados em aplicações piezoelétricas. Como vantagens frente aos outros materiais, eles apresentam maiores temperaturas de Curie $^{1}$, alta estabilidade térmica e alto fator de qualidade mecânico. Como exemplo de cristais piezoelétricos, pode-se citar o quartzo $\left(\mathrm{SiO}_{2}\right)$, o niobato de lítio $\left(\mathrm{LiNbO}_{3}-\mathrm{LN}\right)$ e o tantalato de lítio $\left(\mathrm{LiTaO}_{3}\right.$-LT) (EIRAS). Porém devido à escassez de fontes naturais dos cristais, alternativas começaram a ser exploradas, a exemplo das cerâmicas ferroelétricas (TRAINER, 2003).

O primeiro material cerâmico a ser utilizado como transdutor piezoelétrico foi o titanato de bário $\left(\mathrm{BaTiO}_{3}\right)$ cujas propriedades piezoelétricas foram constatadas pela primeira vez por Wainer e Salomon no início da década de 1940. Quando amostras desta cerâmica foram polarizadas por meio da aplicação de um forte campo elétrico DC, elas passaram a apresentar ressonâncias no espectro de frequências, característica atribuída ao efeito piezoelétrico (ROBERTS, 1947).

O titanato de bário foi amplamente utilizado até o final da década de 1950, quando começou a ser substituído pelas cerâmicas de titanato zirconato de chumbo (PZT) e suas composições. Comparando-se os dois materiais, o PZT suporta maiores temperaturas e

\footnotetext{
${ }^{1}$ Temperatura acima da qual a estrutura do material se modifica e deixa de apresentar propriedades piezoelétricas.
} 
apresenta efeitos piezoelétricos mais intensos (BERLINCOURT, 1981). Ademais, as cerâmicas de PZT possuem maiores coeficientes de acoplamento eletromecânico, são facilmente polarizadas e formam composições com diferentes constituintes químicos, tornando várias das suas propriedades manipuláveis (HAERTLING, 1999).

Além do PZT e do titanato de bário, outras cerâmicas apresentam atividades piezoelétricas como, por exemplo, o titanato de chumbo e magnésio (PMN), o titanato zirconato de chumbo-lantânio (PLZT) e o titanato de chumbo (PT). Estas cerâmicas pertencem à família das peroviskitas, cuja unidade cristalina é chamada de ABO3 (Figura 2.3). Quando um campo elétrico externo é aplicado à unidade, o íon central se move para uma nova posição na direção do campo. Este movimento provoca uma alteração na dimensão da célula e, consequentemente, da cerâmica como um todo (HAERTLING, 1999).

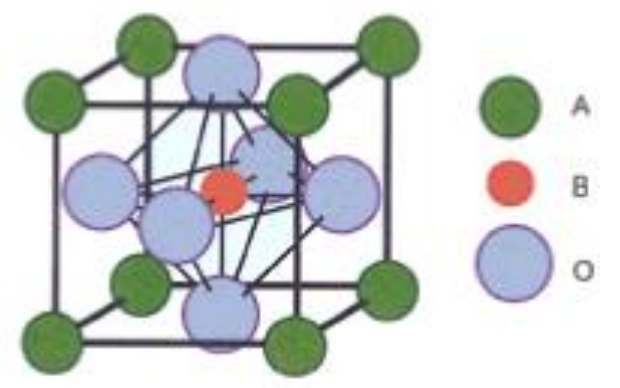

Figura 2.3 - Representação da célula unitária de uma peroviskita. Fonte: Adaptado de Haerteling (1999).

Além dos cristais e das cerâmicas, determinados polímeros também podem apresentar atividade piezoelétrica. Em 1969, Heiji Kawai realizou um estudo sobre a piezoeletricidade de alguns materiais poliméricos após o processo de polarização. Neste trabalho, as características piezoelétricas do polifluoreto de vinilideno (PVDF ou PVF2) obtiveram destaque (KAWAI, 1969).

O PVDF é um polímero composto por longas cadeias moleculares em que cada mero $\left(\mathrm{CH}_{2}-\mathrm{CF}_{2}\right)$ apresenta um dipolo elétrico, como apresentado na Figura 2.4 (FIORILLO; PULLANO, 2011). Ele pode ser sintetizado em diferentes formas, sendo estas chamadas de fases. As fases mais conhecidas do PVDF são as fases $\alpha, \beta, \delta$ e $\gamma$. A fase $\alpha$ é a fase mais comum e é apolar enquanto que as fases $\beta, \delta$ e $\gamma$ são polares. Do ponto de vista tecnológico, a fase $\beta$ é mais interessante, pois oferece melhores propriedades piroelétricas e piezoelétricas. 
Ela é geralmente obtida pelo estiramento mecânico de filmes da fase $\alpha$ (GREGÓRIO FILHO, 1993).

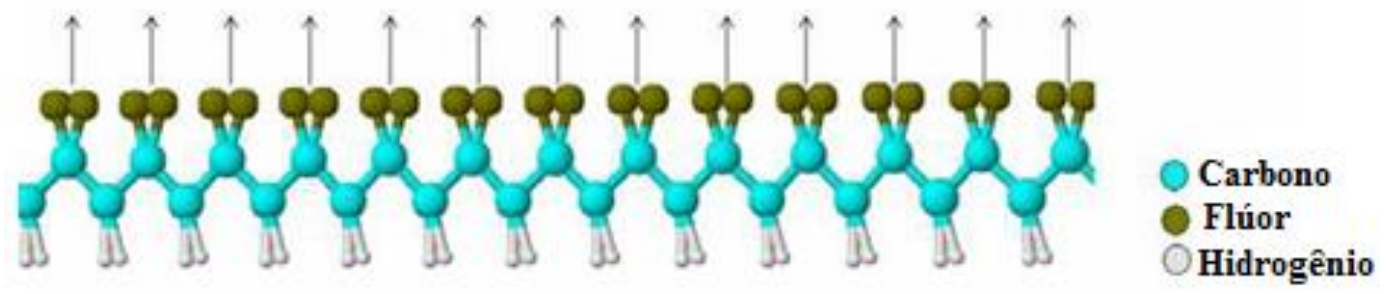

Figura 2.4 - Representação da cadeia molecular do polifluoreto de vinilideno (PVDF). Fonte: Adaptado de Fiorillo e Pullano (2011).

A descoberta de Kawai impulsionou a pesquisa sobre piezoeletricidade em polímeros. Na década de 1980, foi descoberto que copolímeros ferroelétricos de PVDF podiam apresentar polarizações remanescentes mais intensas do que o PVDF. Como exemplo destes materiais pode-se citar os copolímeros polifluoreto de vinilideno trifluoretileno $\mathrm{P}(\mathrm{VDF}-\mathrm{TrFE})$ e tetrafluoretileno $\mathrm{P}(\mathrm{VDF}-\mathrm{TeFE})$. $\mathrm{O}$ fator de acoplamento e o fator de qualidade mecânico destes são maiores se comparados com os valores do PVDF. Outra característica destes copolímeros é que eles não necessitam do processo de estiramento para alcançar a sua forma polarizada (BROWN, 2000).

Comparando-se os polímeros com as cerâmicas piezoelétricas, verifica-se que os dois materiais apresentam suas vantagens e desvantagens. No trabalho de Lancee et al. (1985) é feito um estudo comparativo entre as características piezoelétricas de um filme de PVDF e de uma cerâmica PZT-5A. O polímero apresenta uma menor impedância acústica, resultando em melhor casamento de impedância e maior transferência de potência em aplicações no ar e na água. Outra característica positiva do PVDF é que ele possui um maior amortecimento interno, fato que reflete em uma maior largura de banda em suas aplicações. Como características positivas, a cerâmica apresenta um maior fator de acoplamento mecânico, maior coeficiente piezoelétrico e menores perdas dielétricas do que os polímeros.

Tradicionalmente, o efeito piezoelétrico era relacionado com a estrutura dipolar das moléculas dos materiais. Entretanto, no decorrer da história foi verificado que um efeito similar à piezoeletricidade poderia ser observado em dielétricos polarizados com cargas 
elétricas aprisionadas. Wada e Hayakawa (1976) utilizaram o efeito piezoelétrico proveniente do aprisionamento de cargas na construção de transdutores com camadas de eletretos ${ }^{2}$.

Com a constatação de que polímeros não polares poderiam apresentar efeito similar à piezoeletricidade, novos materiais e métodos de produção começaram a ser estudados, a exemplo dos polímeros celulares ou espumas poliméricas. Na década de 80 , foi constatado que filmes porosos de polipropileno (PP), quando carregados eletricamente, passaram a apresentar elevados coeficientes piezoelétricos. Estes materiais, devido a sua porosidade, apresentam cavidades internas (Figura 2.5) que permitem a formação de grandes dipolos quando os filmes são submetidos a intensos campos elétricos. As cavidades internas do material também facilitam a deformação da estrutura com a aplicação de uma força externa, fato que resulta em grandes coeficientes piezoelétricos (GERHARD-MULTHAUPT, 2002).

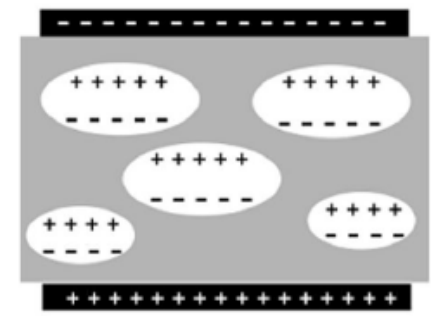

Figura 2.5 - Representação dos polímeros celulares e suas cavidades internas carregadas eletricamente. Fonte: Adaptado de Gerhard-Multhaupt (2002).

Os filmes de polipropileno (ou espuma polimérica) receberam o nome de piezoeletreto devido à similaridade com os eletretos e aos elevados coeficientes piezoelétricos. A diferença entre os eletretos e os piezoeletretos ocorre basicamente no processo de polarização. Durante o carregamento dos piezoeletretos, ocorre a ruptura dielétrica do gás no interior dos poros da estrutura, levando à ionização das moléculas gasosas que pela ação do campo elétrico, são deslocadas em direções opostas, criando os macrodipolos (QIU, 2005).

${ }^{2} \mathrm{O}$ termo eletreto foi criado por Oliver Heaviside para denominar materiais que apresentavam cargas elétricas permanentes e de sinais opostos em suas extremidades. Os primeiros eletretos foram feitos por Eguchi, derretendo quantidades iguais de cera de carnaúba e resina com uma pequena quantidade de cera de abelha. A mistura era então resfriada e solidificava, sujeita a um intenso campo elétrico (GUTMANN, 1948). 


\subsection{Piezoeletretos com estruturas organizadas}

Seguindo a linha de pesquisa com piezoeletretos, o Grupo de Alta Tensão e Materiais da Escola de Engenharia de São Carlos vem desenvolvendo, desde o início dos anos 2000, uma nova tecnologia de transdutores. Estes, assim como os piezoeletretos porosos, apresentam cavidades internas eletricamente carregadas, fato que se reflete no elevado coeficiente piezoelétrico. A diferença entre eles, porém, encontra-se no processo de fabricação. Os transdutores desenvolvidos pelo GATM apresentam cavidades internas com geometrias completamente controladas durante o processo de fabricação.

O processo de fabricação que permite este controle das cavidades internas foi primeiramente desenvolvido por Altafim et al. (2003). Tal método consiste na união de dois filmes circulares de Fluoretileno Propileno (Teflon®FEP) por meio de uma tinta sintética e posterior metalização com folhas laminadas de alumínio para compor os eletrodos, conforme apresentado na Figura 2.6. A tinta sintética borrifada formava pequenas gotículas com dimensões da ordem de $10 \mu \mathrm{m}$ distribuídas uniformemente entre os filmes poliméricos, formando cavidades na estrutura. Após o carregamento, as amostras passaram a apresentar coeficientes piezoelétricos de até $270 \mathrm{pC} / \mathrm{N}$.

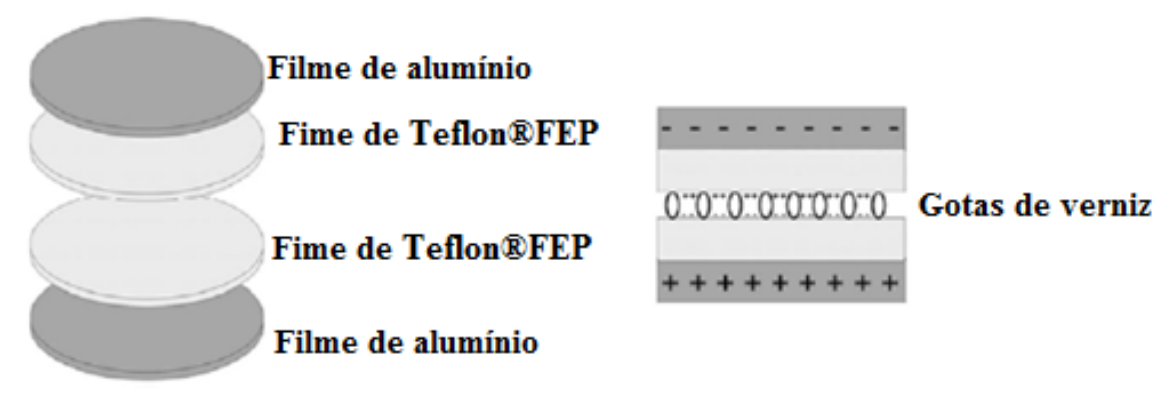

Figura 2.6 - Piezoeletretos com camadas empilhadas de filmes de Teflon®FEP e alumínio. Fonte: Adaptado de Altafim et al. (2003).

Altafim et al. (2006) propuseram um sistema formado por uma prensa aquecida conectada a uma bomba a vácuo utilizado para moldar dois filmes de FEP, sendo um deles com pequenas bolhas uniformemente distribuídas (Figura 2.7). O procedimento inicia-se com o pré-aquecimento dos discos da prensa, seguida da disposição de uma película do filme sobre a grade do sistema. Aplica-se então o vácuo, resultando na formação de bolhas no filme. Por fim, a outra película é colocada sobre a primeira de modo que as duas películas sejam pressionadas entre as duas placas da prensa, fundindo os dois filmes. As amostras deste 
processo apresentaram coeficientes piezoelétricos da ordem de $500 \mathrm{pC} / \mathrm{N}$, após o carregamento. Por compreender o aquecimento no processo de fabricação, estes piezoeletretos foram denominados de piezoeletretos termo-formados.

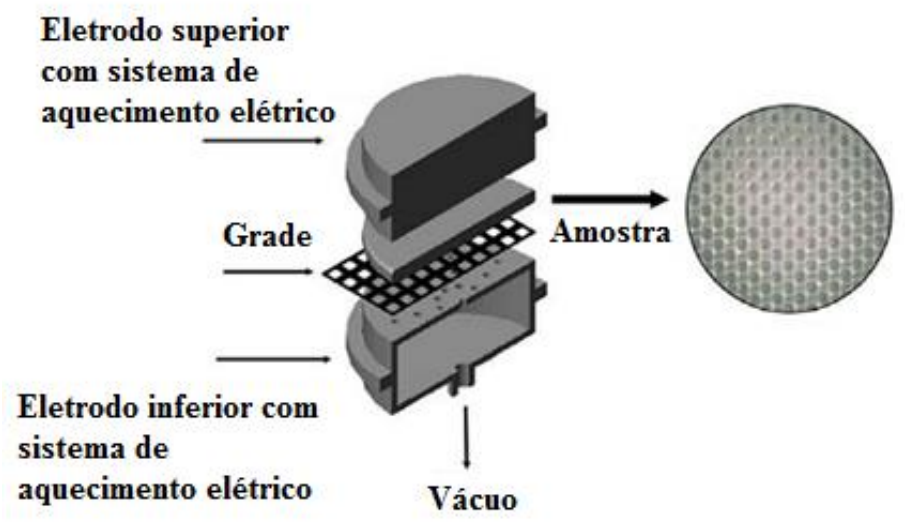

Figura 2.7 - Procedimento utilizado para a formação de piezoeletretos com distribuição homogênea de bolhas de ar. Fonte: Adaptado de Altafim et al. (2006).

Zhang et al. (2006) apresentaram um novo processo de produção de ferroeletretos, semelhante ao de Altafim et al. (2006). No processo, uma grade pré-aquecida a $280{ }^{\circ} \mathrm{C}$ pressiona por uma hora, à força constante de $20 \mathrm{~N}$, a estrutura do transdutor composta de uma película de FEP entreposta por duas camadas de politetrafluoretileno Teflon®PTFE, conforme Figura 2.8. Ocorre então a fusão dos filmes nas regiões de contato com grade e o estiramento destes nas regiões vazadas, resultando no aparecimento de bolhas. As amostras resultantes deste processo apresentaram coeficientes piezoelétricos superior a $1000 \mathrm{pC} / \mathrm{N}$ após o carregamento.

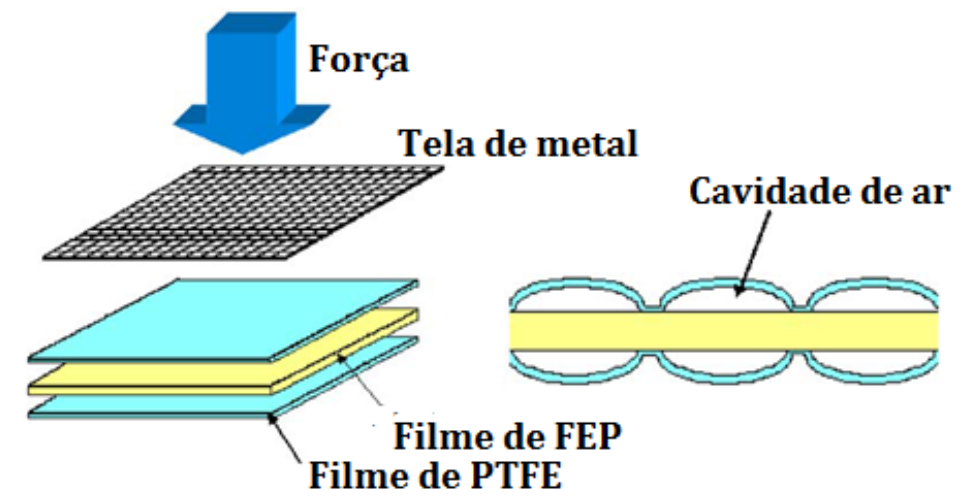

Figura 2.8 - Procedimento para moldar as bolhas de ar do piezoeletreto e sua vista lateral. Fonte: Adaptado de Zhang, Hillenbrand e Sessler (2006). 
Zhang et al. (2007) aplicaram o mesmo processo, empilhando desta vez múltiplas camadas de fluopolímeros. As amostras atingiram coeficientes piezoelétricos da ordem de $1000 \mathrm{pC} / \mathrm{N}$ com estabilidade térmica até $90^{\circ} \mathrm{C}$. Para temperaturas maiores até $120^{\circ} \mathrm{C}$, os coeficientes ficaram em torno de $500 \mathrm{pC} / \mathrm{N}$. Uma das desvantagens que pode ser observada no processo foi que mesmo com a possibilidade de se empilhar diversas camadas de polímeros, não houve nenhum controle da distribuição e do formato das cavidades internas do piezoeletreto, como pode ser observado pelas deformações da estrutura vista na Figura 2.9.
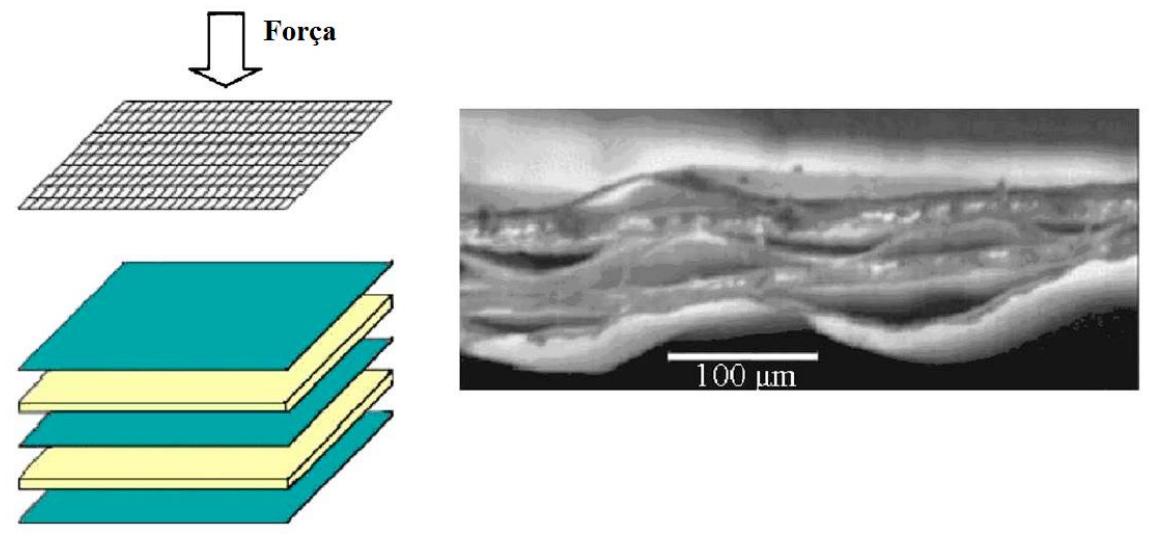

Figura 2.9 - Método de fabricação dos piezoeletretos com várias camadas e imagem lateral de uma amostra. Fonte: Adaptado de Zhang, Hillenbrand e Sessler (2007).

Altafim (2010) desenvolveu uma estrutura com formas padronizadas de canaletas. O processo consiste da laminação a quente de uma pilha de materiais poliméricos formada por dois filmes externos de FEP e uma camada intermediária de PTFE, este último servindo como molde. Esta pilha de polímeros é submetida ao processo de laminação a $300{ }^{\circ} \mathrm{C}$, descrito na Figura 2.10. Durante a laminação, as camadas de FEP fundem-se nas regiões vazadas dos moldes e, após o resfriamento da pilha, a camada de PTFE é facilmente retirada mediante o corte em uma de suas extremidades. Como resultado deste processo é obtido uma estrutura com canais tubulares bem definidos. Após a metalização e o carregamento, as amostras apresentaram um coeficiente piezoelétrico da ordem de 160 pC/N. 


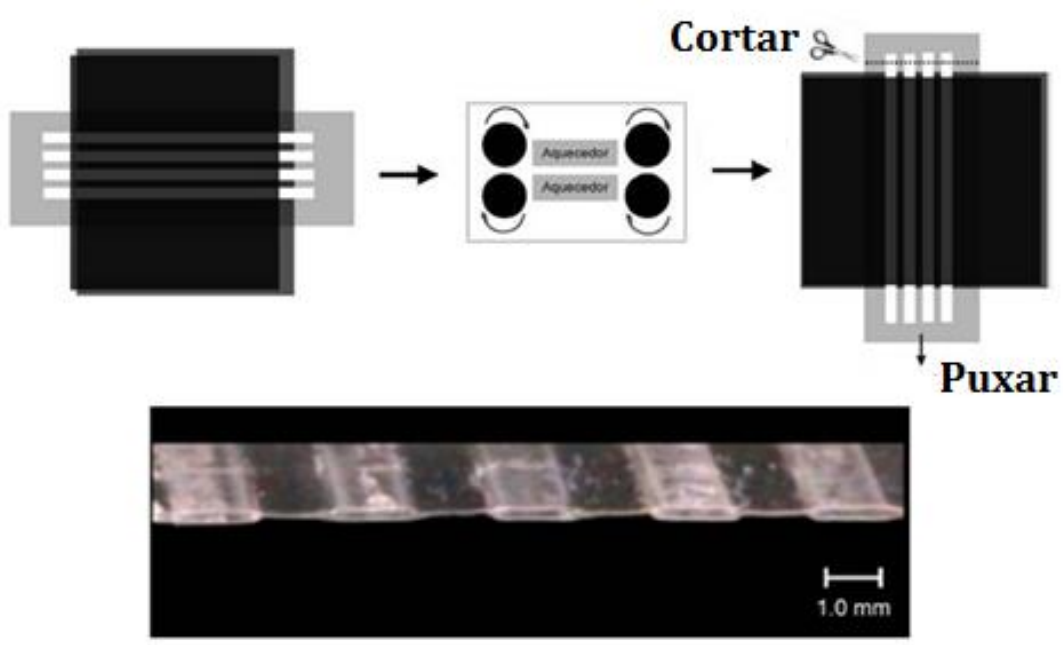

Figura 2.10 - Procedimento de fabricação de piezoeletretos com estruturas padronizadas de canaletas e micrografia ótica da seção transversal de uma amostra. Fonte: Adaptado de Altafim (2010).

Uma característica que pode ser observada no trabalho de Altafim é a correlação entre a frequência de ressonância e a altura das canaletas. Deste modo, a frequência de ressonância das amostras pode ser controlada pela espessura do molde de PTFE. A Figura 2.11 apresenta a espectroscopia do fator de dissipação de amostras com cavidades variando de 25 a $100 \mu \mathrm{m}$, cujas frequências de ressonância variam entre 25 e $44 \mathrm{kHz}$, aproximadamente (ALTAFIM, 2010).

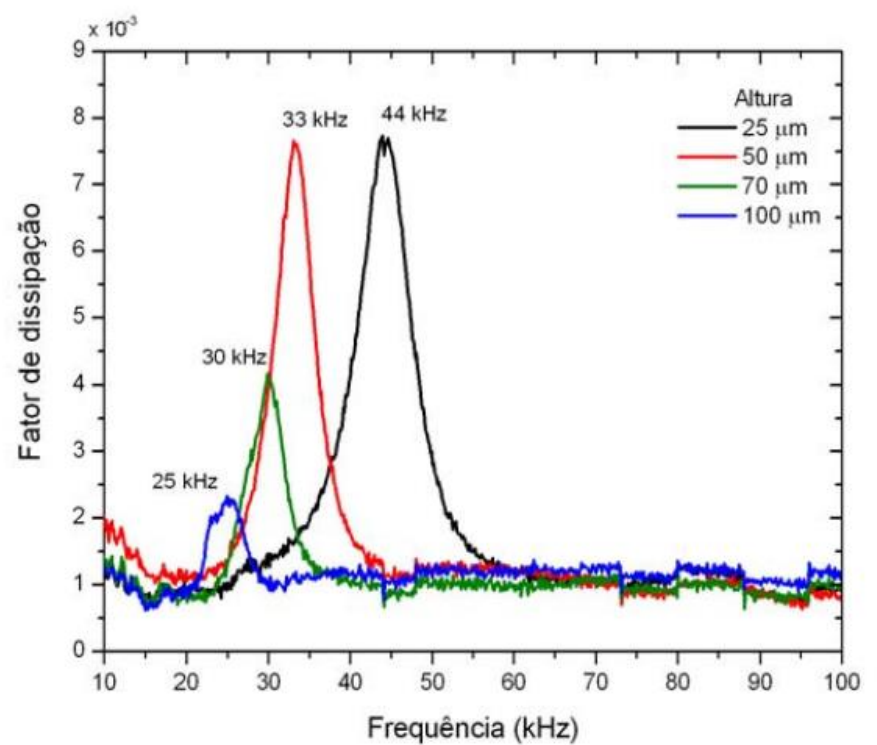

Figura 2.11 - Espectroscopia de amostras de piezoeletretos de canaletas com diferentes espessuras. Fonte: Adaptado de Altafim (2010). 
Outra característica que influencia na ressonância das amostras é largura das canaletas. Como pode ser observado na Figura 2.12, amostras com cavidades de mesma altura (100 $\mu \mathrm{m})$ e canaletas de larguras variáveis apresentam diferentes frequências de ressonância (ALTAFIM, 2010).

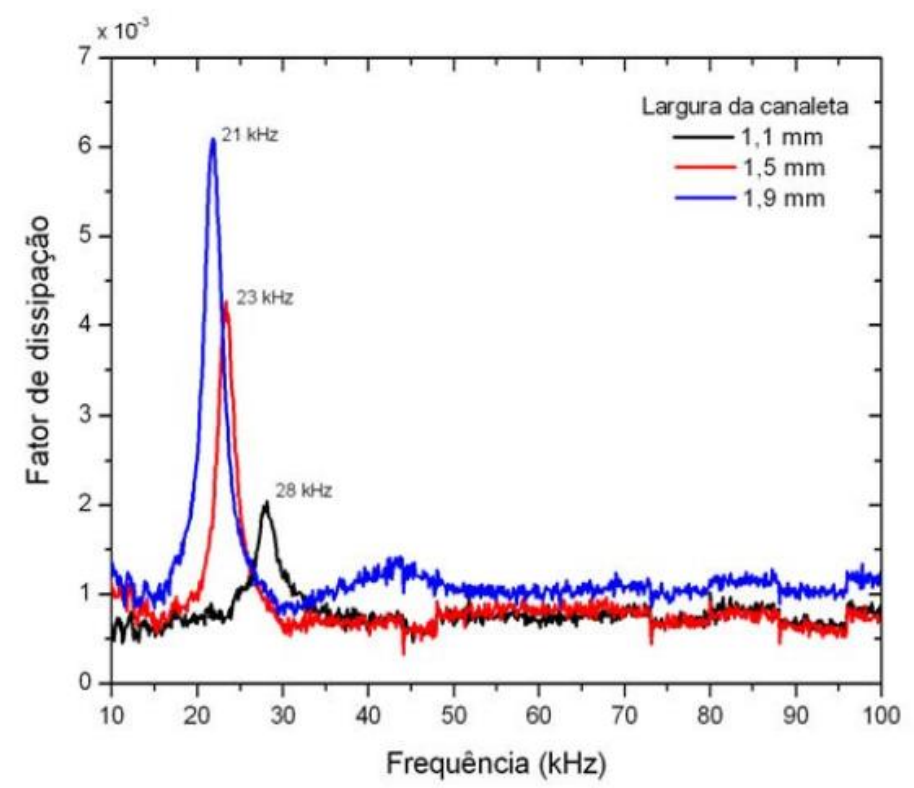

Figura 2.12 - Espectroscopia de amostras de piezoeletretos de canaletas com diferentes larguras. Fonte: Adaptado de Altafim (2010).

Falconi et al. (2010) desenvolveram outra tecnologia de produção de piezoeletretos termo-formados. O processo, apresentado na Figura 2.13, consiste em uma etapa de prémoldagem de um filme de FEP em pequenos domos, feito por uma prensa hidráulica e uma matriz metálica contendo orifícios simetricamente espaçados. Após a pré-moldagem, a matriz junto com o filme modificado pela prensa são cobertos por outro filme de FEP não modificado. Por fim o conjunto passa pelo processo de laminação a quente. Neste processo, amostras com bolhas de $4 \mathrm{~mm}$ de diâmetro e espaçadas de 5,5 $\mathrm{mm}$ apresentaram coeficientes piezoelétricos de até $215 \mathrm{pC} / \mathrm{N}$. 

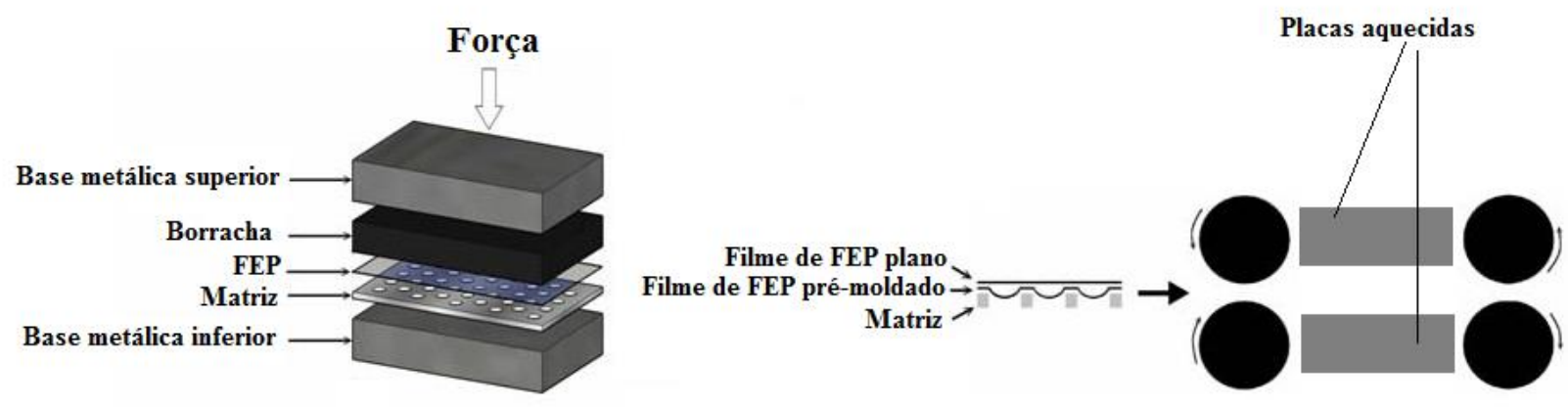

Figura 2.13 - Método de fabricação de filmes com domos simetricamente espaçados e laminação dos filmes de FEP. Fonte: Adaptado de Falconi et al. (2010).

Zhang et al. (2010) produziram piezoeletretos com cavidades organizadas de filmes de FEP e PTFE de 3 e 5 camadas intercaladas, utilizando uma matriz rígida e um processo de ligação por fusão. No processo um filme poroso de PTFE (90\% de porosidade) é modelado por uma matriz rígida, sendo colocado logo após em entre dois filmes planos de FEP. Em seguida a amostra passa por um processo de fusão dos filmes poliméricos com o uso de um forno. Após o carregamento, as amostras exibiram coeficientes piezoelétricos de até 500 $\mathrm{pC} / \mathrm{N}$.

Zhang et al. (2012) desenvolveram um novo método para produção de piezoeletretos com cavidades organizadas. $O$ processo consiste da moldagem de filmes poliméricos de FEP por meio de uma matriz metálica e uma espuma. O arranjo é prensado a uma temperatura de $90{ }^{\circ} \mathrm{C}$. Após o processo de moldagem, os dois filmes moldados passam por um processo de fusão em um forno a uma temperatura de $290^{\circ} \mathrm{C}$. As amostras atingiram coeficientes de até $1000 \mathrm{pC} / \mathrm{N}$.

Assagra et al. (2015) apresentaram um método alternativo para produção de piezoeletretos de canais tubulares. Primeiramente, dois filmes de FEP de $50 \mu \mathrm{m}$ são selados em suas extremidades e preenchidos com água, de maneira a formar um colchão de água, conforme apresentado na Figura 2.14. O colchão de água é então colocado em uma prensa formada por duas matrizes de alumínio, uma superior e outra inferior. As placas então são aquecidas para que a água no interior do colchão evapore, aumentando a pressão até ser expelida por uma das extremidades do colchão, moldando o filme nos padrões tubulares da matriz metálica. No estudo, foram obtidas amostras com $300 \mu \mathrm{m}$ de altura e $2 \mathrm{~mm}$ de largura que após o carregamento apresentaram coeficientes piezoelétricos da ordem de $450 \mathrm{pC} / \mathrm{N}$. 


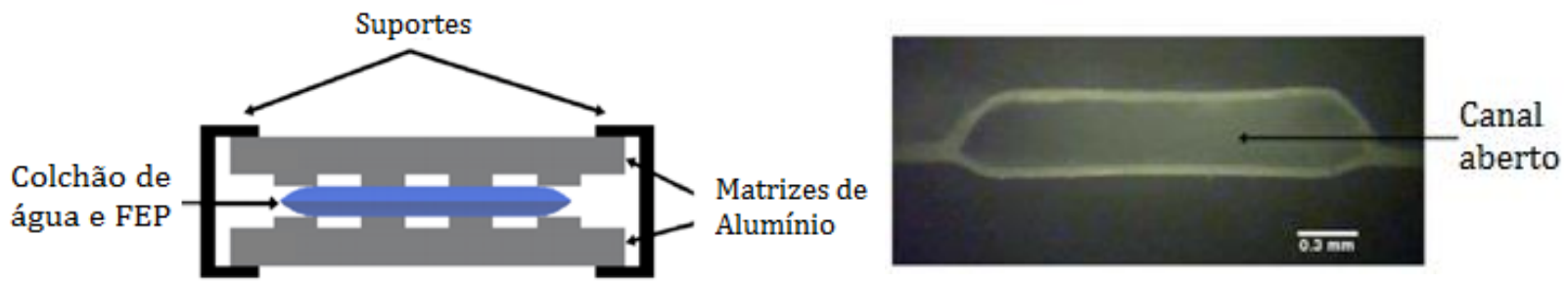

Figura 2.14 - Esquema utilizado na produção de piezoeletretos com dois filmes selados de FEP contendo água e imagem de uma abertura lateral de uma amostra. Adaptado de Assagra; Altafim, R. A. C; Altafim, R. A. P.

(2015).

\subsection{Modelos elétricos equivalentes de transdutores}

\section{Sistema massa-mola e seu equivalente elétrico}

Uma das formas mais simples de se representar um transdutor é compará-lo a um sistema oscilador (massa-mola). Considerando-se um sistema formado por uma massa $\mathrm{M}$ acoplada a uma mola de constante elástica $\mathrm{K}$ e amortecimento $\mathrm{R}_{\mathrm{m}}$, sendo a ele submetida uma força externa senoidal (variável no tempo) de amplitude $\mathrm{F}\left(\operatorname{Re}\left\{\mathrm{Fe}^{\mathrm{j} \omega \mathrm{t}}\right\}\right)$ aplicada na direção $\mathrm{x}$ a uma frequência angular $\omega$, como exemplificado na Figura 2.15.

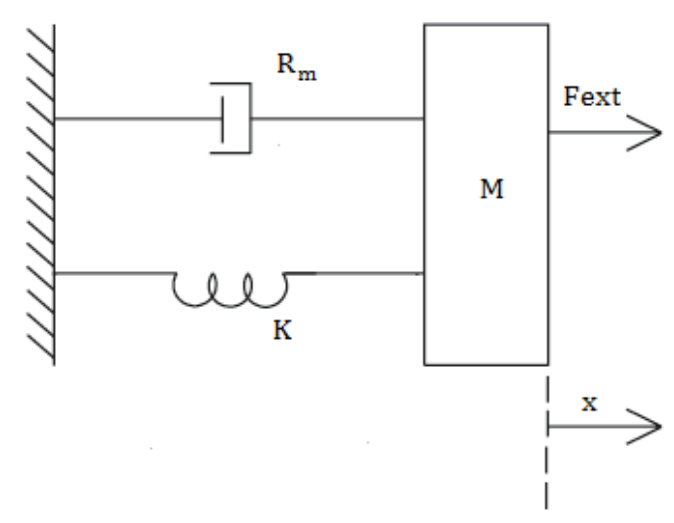

Figura 2.15 - Representação esquemática de um sistema massa-mola. Fonte: Adaptado de Sherman e Butler (2007).

Considerando-se x e $\ddot{x}$ como as derivadas temporais do deslocamento x de ordem 1 e 2 , respectivamente. Ao se aplicar a Segunda Lei de Newton ao sistema da Figura 2.15, tem-se: 


$$
\mathrm{Fext}=\operatorname{Re}\left\{\mathrm{Fe}^{\mathrm{j} \omega \mathrm{t}}\right\}=\mathrm{M} \ddot{\mathrm{x}}+\mathrm{R}_{\mathrm{m}} \dot{\mathrm{x}}+\mathrm{Kx}
$$

Considerando $\mathrm{u}=\dot{\mathrm{x}}=\mathrm{j} \omega \mathrm{x}$ (velocidade da massa), a equação pode ser reescrita por:

$$
R e\left\{\mathrm{Fe}^{\mathrm{j} \omega \mathrm{t}}\right\}=\left(\mathrm{j} \omega \mathrm{M}-\frac{\mathrm{jK}}{\omega}+\mathrm{R}_{\mathrm{m}}\right) \mathrm{u}
$$

A ressonância do sistema ocorre quando $\mathrm{j} \omega \mathrm{M}-\mathrm{jK} / \omega=0$. Sendo assim, a frequência de ressonância (em Hz) do sistema é calculada por:

$$
f_{r}=\frac{1}{2 \pi} \sqrt{\frac{K}{M}}
$$

Seja um circuito elétrico composto de uma resistência $R$, uma indutância L e uma capacitância $\mathrm{C}$, dispostos em série, alimentado por uma fonte de tensão alternada de amplitude V $\left(\operatorname{Re}\left\{\mathrm{Ve}^{\mathrm{j} \omega \mathrm{t}}\right\}\right)$. Aplicando-se a Lei de Kirchhoff das tensões ao circuito, tem-se:

$$
R e\left\{V \mathrm{e}^{\mathrm{j} \omega \mathrm{t}}\right\}=\left(\mathrm{j} \omega \mathrm{L}-\frac{\mathrm{j}}{\omega \mathrm{C}}+\mathrm{R}\right) \mathrm{I}
$$

sendo I a corrente elétrica do circuito.

Comparando-se as equações 2.5 e 2.7 verifica-se que as duas são matematicamente análogas. Desta forma, o sistema massa-mola da Figura 2.15 pode ser representado por um circuito elétrico equivalente, como indicado na Figura 2.16. 

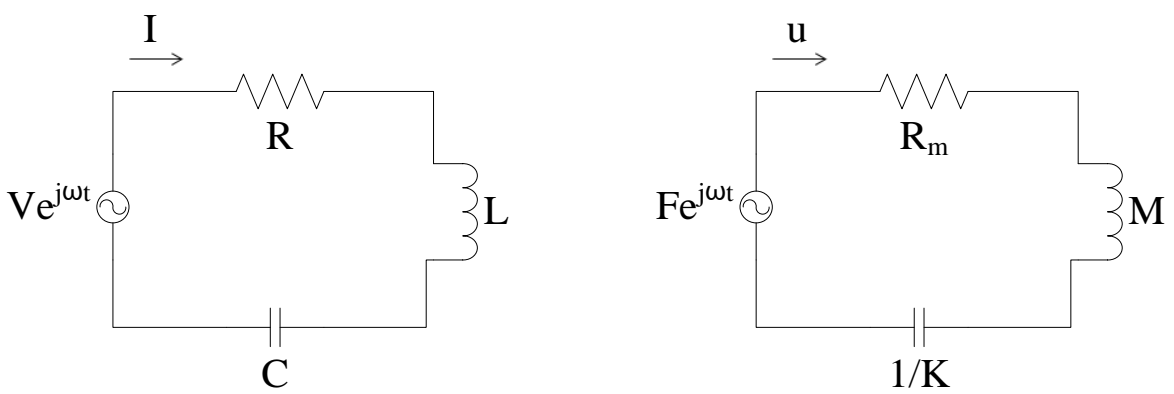

Figura 2.16 - Circuito elétrico RLC série e seu equivalente mecânico. Fonte: Adaptado de Kynsler et al. (2000).

De maneira análoga ao sistema massa-mola, pode-se calcular a frequência de ressonância do circuito elétrico quando a reatância deste é nula. A frequência em $\mathrm{Hz}$ é calculada por:

$$
\mathrm{f}_{\mathrm{r}}=\frac{1}{2 \pi \sqrt{\mathrm{LC}}}
$$

Uma grandeza associada à frequência de ressonância do sistema é o fator de qualidade (Q), que é calculado por (SHERMAN; BUTLER, 2007):

$$
\mathrm{Q}=\frac{\omega_{\mathrm{r}}}{\omega_{1}-\omega_{2}}
$$

em que $\omega_{\mathrm{r}}$ é a frequência de ressonância, e $\omega_{1}$ e $\omega_{2}$ as frequências abaixo e acima da ressonância cuja potência do sistema atinge metade do valor máximo. O fator de qualidade pode ser calculado por meio da análise da curva de potência pela frequência (Figura 2.17).

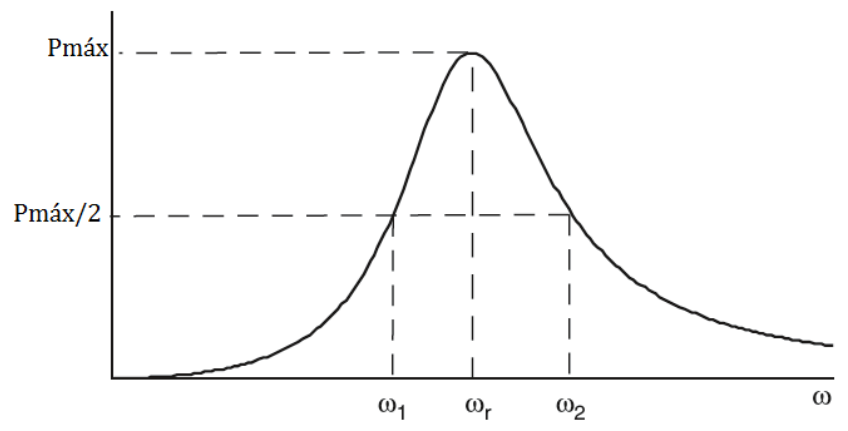

Figura 2.17 - Gráfico da potência pela frequência de um circuito RLC. Fonte: Adaptado de Sherman e Butler (2007). 
Outra forma de se calcular o fator de qualidade é através das relações existentes entre os parâmetros de circuito. Sendo um circuito RLC alimentado por uma tensão senoidal de amplitude $\mathrm{V}$, a potência média dissipada pelo circuito é dada por:

$$
\mathrm{P}_{\text {med }}(\omega)=\mathrm{I}_{\text {eficaz }}^{2}(\omega) \mathrm{R}
$$

sendo a $\mathrm{I}_{\text {eficaz }}$ a corrente eficaz do circuito, calculada por:

$$
I_{\text {eficaz }}(\omega)=\frac{1}{\sqrt{2}} \frac{V}{\sqrt{R^{2}+\left(\omega L-\frac{1}{\omega C}\right)^{2}}}
$$

Substituindo 2.11 em 2.10, tem-se:

$$
\mathrm{P}_{\text {med }}(\omega)=\frac{\mathrm{V}^{2} \mathrm{R}}{2\left[\mathrm{R}^{2}+\left(\omega \mathrm{L}-\frac{1}{\omega \mathrm{C}}\right)^{2}\right]}
$$

Na ressonância, como a reatância do circuito é nula, a potência média é:

$$
\mathrm{P}_{\text {med }}\left(\omega_{0}\right)=\frac{\mathrm{V}^{2}}{2 \mathrm{R}}
$$

Para metade da potência de ressonância, igualam-se as expressões 2.12 e 2.13: 


$$
\frac{\mathrm{P}_{\mathrm{med}}\left(\omega_{0}\right)}{2}=\frac{\mathrm{V}^{2}}{4 \mathrm{R}}=\frac{\mathrm{V}^{2} \mathrm{R}}{2\left[\mathrm{R}^{2}+\left(\omega \mathrm{L}-\frac{1}{\omega \mathrm{C}}\right)^{2}\right]}
$$

A expressão 2.14 pode ser reduzida a:

$$
\mathrm{R}^{2}=\left(\frac{\mathrm{LC} \omega^{2}-1}{\omega \mathrm{C}}\right)^{2}
$$

Desenvolvendo 2.15, chega-se a duas expressões de segundo grau:

$$
\begin{aligned}
& \mathrm{LC} \omega^{2}+\mathrm{RC} \omega-1=0 \\
& \mathrm{LC} \omega^{2}-\mathrm{RC} \omega-1=0
\end{aligned}
$$

As raízes positivas das equações 2.16 e 2.17 são, respectivamente:

$$
\begin{aligned}
& \omega_{1}=-\frac{\mathrm{R}}{2 \mathrm{~L}}+\frac{\sqrt{(\mathrm{RC})^{2}+4 \mathrm{LC}}}{2 \mathrm{LC}} \\
& \omega_{2}=\frac{\mathrm{R}}{2 \mathrm{~L}}+\frac{\sqrt{(\mathrm{RC})^{2}+4 \mathrm{LC}}}{2 \mathrm{LC}}
\end{aligned}
$$

Subtraindo $\omega_{2}$ de $\omega_{1}$, o resultado é:

$$
\omega_{2}-\omega_{1}=\frac{\mathrm{R}}{\mathrm{L}}
$$


Substituindo 2.20 na relação do fator de qualidade, dada por 2.9, tem-se:

$$
\mathrm{Q}=\frac{\mathrm{L} \omega_{\mathrm{r}}}{\mathrm{R}}
$$

Pela relação 2.8 , a expressão 2.21 pode ser reescrita por:

$$
\mathrm{Q}=\frac{1}{\omega_{\mathrm{r}} \mathrm{RC}}
$$

\section{Modelo elétrico de transdutores}

Os transdutores são sistemas ou dispositivos que convertem uma forma de energia em outra. Os transdutores eletromecânicos, por exemplo, convertem energia elétrica em mecânica e vice-versa. Eles podem ser representados por uma rede formada por dois terminais (Figura 2.18), sendo um relacionado com as grandezas elétricas, dadas pela tensão (V) e pela corrente elétrica (I), e o outro com as grandezas mecânicas: força (F) e velocidade (u) (SHERMAN; BUTLER, 2007).

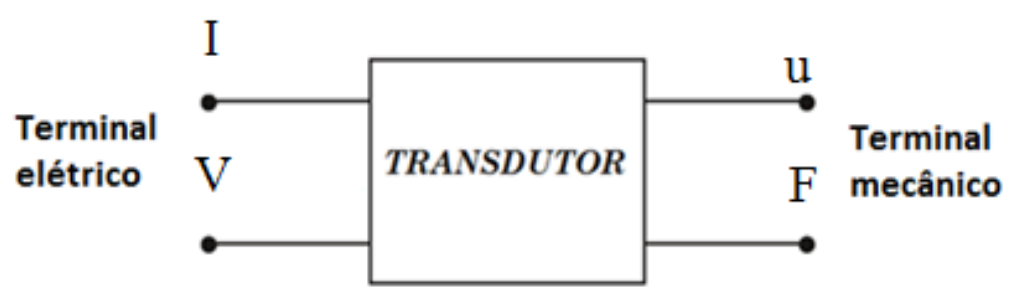

Figura 2.18 - Modelo de um transdutor com dois terminais. Fonte: Adaptado de Sherman e Butler (2007).

Existem dois tipos de analogias referentes a esta rede eletromecânica. Na primeira, a tensão elétrica é análoga à força, enquanto que a corrente é análoga à velocidade. Na outra, a tensão é análoga à velocidade e a corrente é análoga à força. Neste sistema estão relacionados quatro tipos de impedâncias, sendo duas impedâncias elétricas e duas impedâncias mecânicas. Uma impedância elétrica refere-se ao transdutor bloqueado $\left(\mathrm{Z}_{\mathrm{EB}}\right)$ e outra ao transdutor livre para vibrar $\left(\mathrm{Z}_{\mathrm{EF}}\right)$. Em relação às impedâncias mecânicas, uma é medida com o terminal 
elétrico em curto-circuito $\left(Z_{\mathrm{ms}}\right)$ e a outra com o terminal elétrico em aberto $\left(Z_{\mathrm{mo}}\right)$ (KYNSLER et al., 2000).

As equações canônicas do comportamento eletromecânico de um transdutor são dadas por (KYNSLER et al., 2000):

$$
\begin{aligned}
& \mathrm{V}=\mathrm{Z}_{\mathrm{EB}} \mathrm{I}+\mathrm{T}_{\mathrm{em}} \mathrm{u} \\
& \mathrm{F}=\mathrm{T}_{\mathrm{me}} \mathrm{I}+\mathrm{Z}_{\mathrm{mo}} \mathrm{u}
\end{aligned}
$$

sendo $\mathrm{T}_{\mathrm{me}}$ e $\mathrm{T}_{\mathrm{em}}$ os coeficientes de transdução.

Os transdutores são chamados de recíprocos quando é válida a relação $\mathrm{T}_{\mathrm{me}}=\mathrm{T}_{\mathrm{em}}=\mathrm{T}$. Já quando $\mathrm{T}_{\mathrm{me}}=-\mathrm{T}_{\mathrm{em}}$, os transdutores são chamados de anti-recíprocos. São recíprocos os transdutores piezoelétricos e os transdutores eletrostáticos, enquanto que os transdutores de bobina móvel e os magnetoestritivos são anti-recíprocos. As equações canônicas para os transdutores recíprocos podem ser reduzidas a (KYNSLER et al., 2000):

$$
\begin{gathered}
\mathrm{V}=\mathrm{Z}_{\mathrm{EB}} \mathrm{I}+\phi \mathrm{Z}_{\mathrm{EB}} \mathrm{u} \\
\mathrm{F}=\phi \mathrm{Z}_{\mathrm{EB}} \mathrm{I}+\mathrm{Z}_{\mathrm{mo}} \mathrm{u} \\
\phi=\mathrm{T} / \mathrm{Z}_{\mathrm{EB}}
\end{gathered}
$$

sendo $\phi$ um número real e constante para a maioria das frequências de interesse e chamado de fator de transformação. A partir da analogia força-tensão e velocidade-corrente e das equações 2.25, 2.26 e 2.27, é derivado o circuito elétrico equivalente da Figura 2.19. Neste circuito, o fator de transformação $\phi$ tem o significado físico da relação de espiras de um transformador ideal que liga a parte mecânica à parte elétrica (KYNSLER et al., 2000).

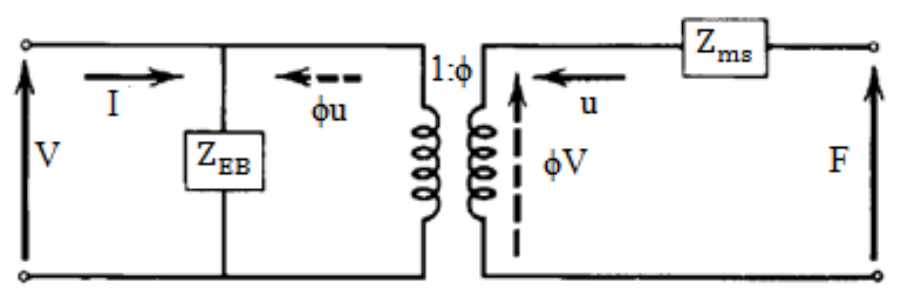

Figura 2.19 - Circuito elétrico equivalente de um transdutor recíproco. Fonte: Adaptado de Kynsler et al. (2000). 
Van Dyke (1928) propôs um circuito equivalente para representar o comportamento dielétrico e oscilador de cristais de quartzo nas proximidades da frequência fundamental de ressonância. O circuito é composto de dois ramos, sendo um composto por uma capacitância e outro por um circuito RLC série, como ilustrado na Figura 2.20.

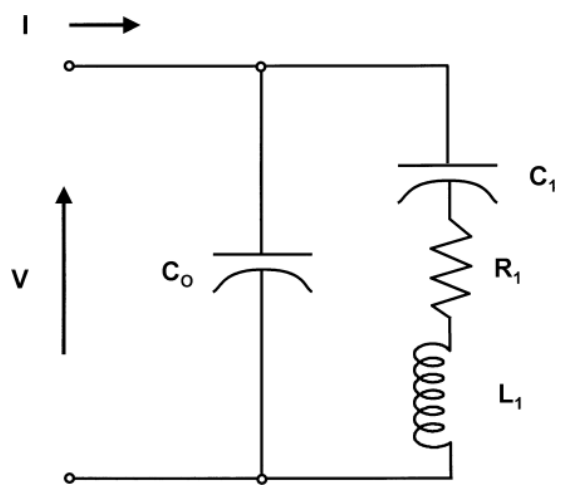

Figura 2.20 - Circuito elétrico equivalente proposto por Van Dyke para um cristal piezoelétrico nas proximidades de uma ressonância. Fonte: Adaptado de Van Dyke (1928).

Van Dyke (1928) relacionou parâmetros mecânicos do quartzo com os valores numéricos dos componentes do ramo oscilador. Para um cristal vibrando no modo longitudinal (direção da vibração paralela à polarização do transdutor), os parâmetros do ramo mecânico da figura são dados por:

$$
\begin{aligned}
\mathrm{L}_{1} & =\mathrm{e}^{2} \mathrm{M} / 4 \epsilon^{2} \mathrm{l}^{2} \mathrm{~b}^{2} \\
\mathrm{R}_{1} & =\mathrm{e}^{2} \mathrm{~N} / 4 \epsilon^{2} \mathrm{l}^{2} \mathrm{~b}^{2} \\
\mathrm{C}_{1} & =4 \epsilon^{2} \mathrm{l}^{2} \mathrm{~b}^{2} / \mathrm{e}^{2} \mathrm{~g}
\end{aligned}
$$

sendo "M" a metade da massa, "N" o fator de amortecimento e "g" a rigidez equivalente do cristal. " $\epsilon$ " se refere à constante piezoelétrica e "e", "l" e "b" são as dimensões do cristal, como indicado na Figura 2.21. 


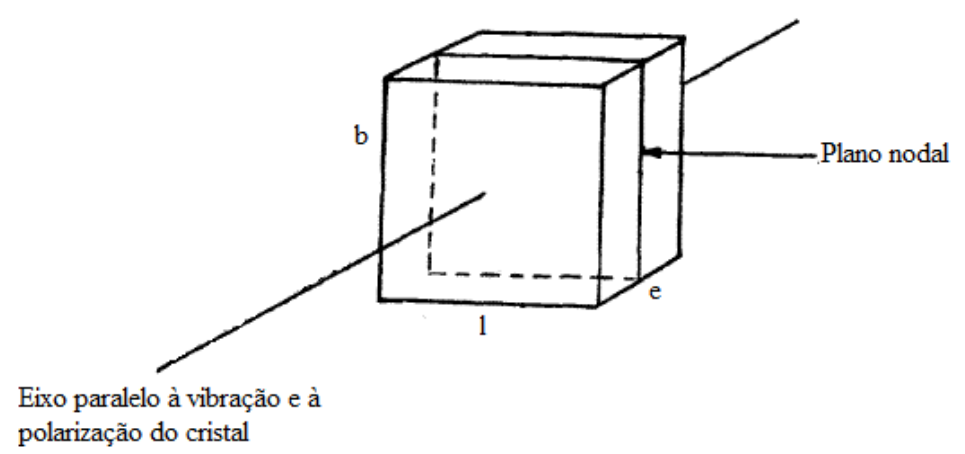

Figura 2.21 - Representação do cristal piezoelétrico e suas dimensões utilizadas nos cálculos dos parâmetros do circuito equivalente. Fonte: Adaptado de Van Dyke (1928).

O circuito da Figura 2.20 corresponde ao modo fundamental de ressonância do cristal. Entretanto, para se representar as demais ressonâncias de um transdutor, outros ramos osciladores devem ser acrescentados ao modelo (Figura 2.22), cada um representando uma frequência múltipla da ressonância fundamental (VAN DYKE, 1928).

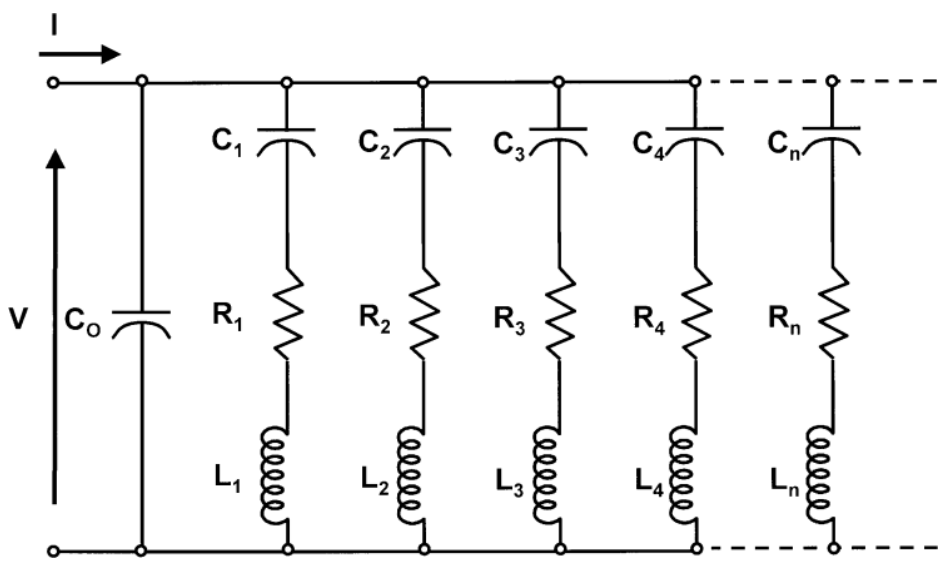

Figura 2.22 - Circuito equivalente de um cristal piezoelétrico para frequências múltiplas da ressonância fundamental. Fonte: Adaptado de Van Dyke (1928).

De acordo com Ballato (2001), o circuito equivalente proposto por Van Dyke é adequado para representação, nas proximidades da ressonância, da impedância de entrada do transdutor piezoelétrico. Entretanto, quando se deseja acoplar o movimento mecânico, terminais mecânicos devem ser adicionados ao circuito. Desta forma, Mason (1935) propôs um circuito equivalente que supre este problema. $\mathrm{O}$ circuito contem um terminal elétrico e dois terminais mecânicos, sendo que estes últimos têm o propósito de acoplar cada uma das faces do transdutor ao meio adjacente. 
Redwood e Lamb (1956) adaptaram o circuito de Mason adicionando ao modelo uma linha de transmissão. A modificação teve o objetivo principal de representar o tempo de propagação dos sinais mecânicos ao atravessar a estrutura do cristal, além de simular as reflexões que ocorrem nos seus terminais.

Krimholtz, Leedom e Matthaei (1970) propuseram outro circuito equivalente para transdutores piezoelétricos, chamado de modelo de KLM (Figura 2.23). O circuito é composto de um terminal elétrico, cujos componentes são variáveis com a frequência, conectado ao centro de uma linha de transmissão acústica. Assim como o modelo de Mason, o circuito de KLM apresenta dois terminais mecânicos, referentes aos terminais da linha de transmissão acústica, e um terminal elétrico. Para transdutores do tipo espessura, o comprimento da linha se refere à espessura do transdutor, enquanto que a impedância característica da linha de transmissão representa a impedância acústica do material.

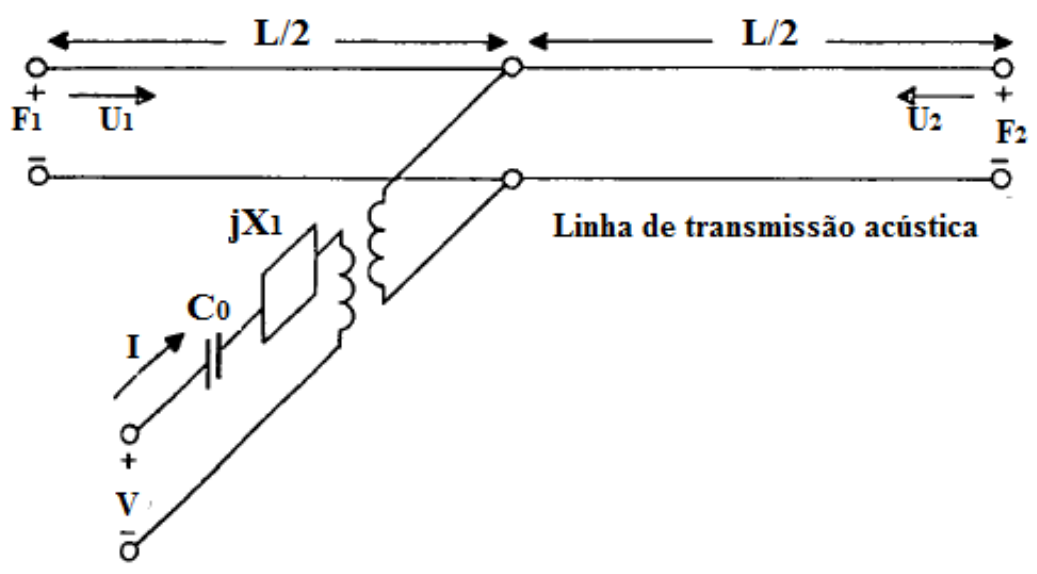

Figura 2.23 - Circuito equivalente de KLM para transdutores do tipo espessura. Fonte: Adaptado de Krimholtz, Leedom e Matthaei (1970).

Morris e Hutchens (1986) modificaram o circuito equivalente de Redwood e Lamb (adaptado do modelo de Mason) substituindo a capacitância negativa e o transformador ideal por arranjos com fontes controladas de corrente e de tensão. A mudança teve o objetivo de adaptar o modelo a softwares de análise de circuitos elétricos, tais como o SPICE.

Leach (1994) apresentou um modelo completo para transdutores sem perdas, combinando as equações que governam as ondas mecânicas em transdutores piezoelétricos com as equações do telegrafista, utilizadas no estudo de linhas de transmissão. O circuito obtido por Leach não apresenta a capacitância negativa e o transformador ideal utilizados no modelo de Mason, sendo que o acoplamento entre a parte mecânica e a parte elétrica é feita por meio do uso de fontes controladas. As equações utilizadas no modelo são: 


$$
\begin{gathered}
\frac{\mathrm{d}}{\mathrm{dz}}\left[\mathrm{F}-\frac{\mathrm{h}}{\mathrm{s}} \mathrm{I}\right]=-\rho A s \mathrm{U} \\
\frac{\mathrm{dU}}{\mathrm{dz}}=-\frac{\mathrm{s}}{\mathrm{Ac}}\left[\mathrm{F}-\frac{\mathrm{h}}{\mathrm{s}} \mathrm{I}\right] \\
\mathrm{V}=\frac{\mathrm{h}}{\mathrm{s}}[\mathrm{U} 1-\mathrm{U} 2]+\frac{1}{\mathrm{C}_{0} \mathrm{~S}} \mathrm{I}
\end{gathered}
$$

sendo $\mathrm{F}$ a força $(\mathrm{N}), \mathrm{h}$ a constante piezoelétrica $\left(\mathrm{N} \cdot \mathrm{m}^{4} / \mathrm{C}\right)$, s a constante complexa, $\rho$ a densidade $\left(\mathrm{kg} / \mathrm{m}^{3}\right)$, A a área da superfície do transdutor $\left(\mathrm{m}^{2}\right)$, $\mathrm{U}$ a velocidade de deslocamento das partículas $(\mathrm{m} / \mathrm{s}), \mathrm{c}$ a constante elástica $\left(\mathrm{N} / \mathrm{m}^{2}\right), \mathrm{V}$ a tensão elétrica $(\mathrm{V})$, I a corrente elétrica (A) e $C_{0}$ a capacitância da amostra presa $(\mathrm{F})$.

O modelo apresenta uma parte mecânica e outra elétrica. A parte mecânica é composta por uma linha de transmissão de comprimento $\mathbf{L}$ e dois terminais que representam as faces do transdutor em contato com o meio. Já a parte elétrica é composta pela capacitância do transdutor. A ligação entre as duas partes é feita por meio das fontes de tensão controladas por corrente, indicadas pelos losangos da Figura 2.24.
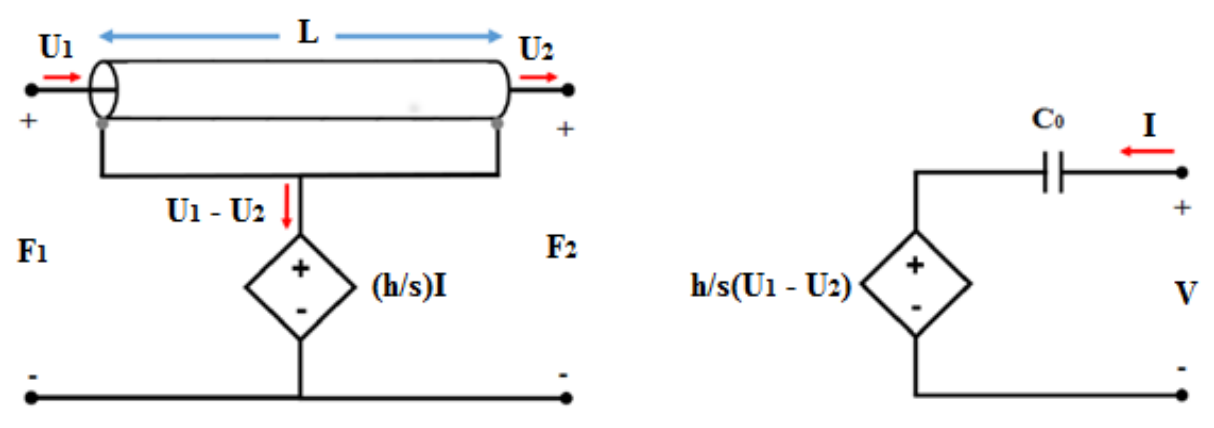

Figura 2.24 - Circuito equivalente proposto por Leach. Fonte: Adaptado de Leach (1994).

Os modelos elétricos citados são válidos apenas para transdutores com poucas perdas, tais como as cerâmicas e os cristais. Os polímeros piezoelétricos, entretanto, apresentam perdas dielétricas e mecânicas que não podem ser desprezadas, de modo que os tradicionais modelos não podem ser aplicados. Desta forma, diversos estudos foram realizados com o objetivo de adaptar os circuitos equivalentes existentes aos polímeros piezoelétricos.

Ohigashi et al. (1988) adaptaram as perdas dielétrica e mecânica de amostras de P(VDFTrFE) ao modelo de Mason, utilizando a permissividade dielétrica e a constante elástica dos 
copolímeros como grandezas complexas. Para representar as perdas dielétricas do PVDF e do P(VDF-TrFE), Brown e Carlson (1989) modelaram o ramo dielétrico do modelo de Van Dyke utilizando uma capacitância $\left(\mathrm{C}_{0}\right)$ em paralelo com uma resistência $\left(\mathrm{R}_{0}\right)$, ambos variáveis com a frequência. Para modelar estes parâmetros, foram utilizadas as expressões:

$$
\begin{gathered}
\mathrm{C}_{0}(\omega)=\frac{1}{\left|\mathrm{Z}_{\text {in }}\right| \omega \sqrt{1+\operatorname{tg}^{2} \delta_{\mathrm{e}}}} \\
\mathrm{R}_{0}(\omega)=\frac{1}{\omega \mathrm{C}_{0} \operatorname{tg} \delta_{\mathrm{e}}}
\end{gathered}
$$

sendo $\left|Z_{\text {in }}\right|$ o módulo da impedância de entrada da amostra para frequências distantes da ressonância, $\operatorname{tg} \delta_{\mathrm{e}}$ a tangente de perda dielétrica e $\omega$ a frequência angular em $\mathrm{rad} / \mathrm{s}$.

No estudo é afirmado que para frequências distantes da ressonância, a impedância de entrada de um transdutor é essencialmente representada pela capacitância e resistência dadas pelas expressões 2.34 e 2.35. Desta maneira, para calcular os parâmetros mecânicos do ramo RLC, os autores converteram a impedância medida em admitância e subtraíram desta os valores da função de interpolação para frequências distantes da ressonância, este último representado apenas pelo o ramo $\mathrm{C}_{0}-\mathrm{R}_{0}$. Analisando o resultado desta subtração, foi proposto um conjunto de passos para se determinar os valores da resistência, da indutância e da capacitância do ramo mecânico. O circuito completo está representado na Figura 2.25 (BROWN; CARLSON, 1989).

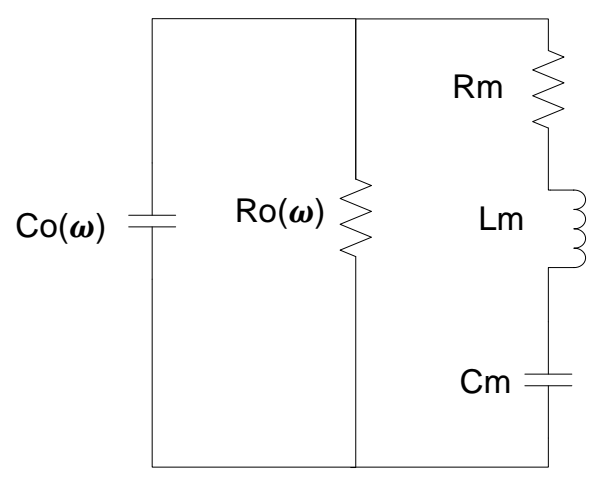

Figura 2.25 - Circuito equivalente com perdas adaptado do modelo de Van Dyke. Fonte: Adaptado de Brown e Carlson (1989). 
Sherrit et al. (1997) propuseram um circuito equivalente contendo apenas componentes complexos. As perdas dielétricas, mecânicas e piezoelétricas dos transdutores são consideradas por meio de componentes imaginários associados às constantes físicas destes materiais. Os componentes do circuito (Figura 2.26) foram calculados através destas constantes, que são tabeladas. Verificou-se que as simulações do circuito proposto apresentaram melhor conformidade com o espectro de frequência de materiais com perdas significativas, como o copolímero de PVDF-TrFE, quando comparadas com simulações obtidas com o modelo de Van Dyke.

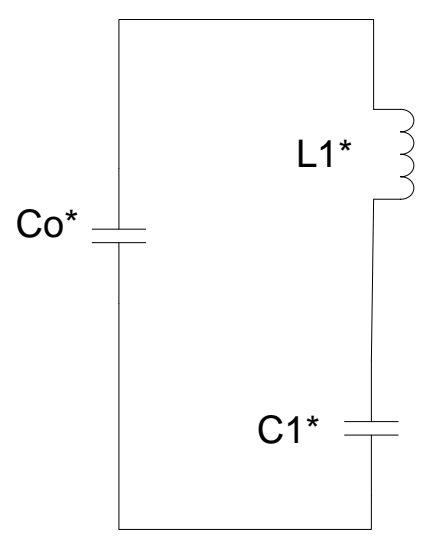

Figura 2.26 - Circuito equivalente contendo apenas componentes complexos. Fonte: Adaptado de Sherrit et al. (1997).

Püttmer et al. (1997) modificaram o circuito equivalente de Leach introduzindo uma resistência ao modelo de linha de transmissão do circuito, com o objetivo de representar cerâmicas piezoelétricas com perdas significativas. Comparando-se com o circuito equivalente original (sem perdas), observou-se que as simulações do circuito modificado apresentaram uma melhor correspondência tanto no espectro de frequência da cerâmica, como no seu ensaio transitório. Dahiya, Valle e Lorenzelli (2009) propuseram a utilização de constantes complexas para o cálculo das perdas dielétricas, mecânicas e piezoelétricas de polímeros piezoelétricos, criando um modelo baseado nas equações do telegrafista do circuito equivalente de Leach. Comparando com o circuito modificado por Püttmer et al. em 1997, os autores verificaram melhor correspondência das simulações do circuito proposto por eles com medidas dos espectros de frequência de amostras de PVDF e P(VDF-TrFE).

Outros autores utilizaram apenas componentes reais e constantes para simular as perdas de determinados materiais piezoelétricos. Fiorillo (2000) realizou um estudo sobre o ruído 
gerado em um transdutor curvo de PVDF para aplicações em frequências abaixo de $150 \mathrm{kHz}$, no qual adaptou um modelo elétrico equivalente contendo componentes reais (Figura 2.27). A modificação consistia da adaptação do modelo de Brown e Carlson (1989) por meio da adição de um ramo contendo um resistor em série com um capacitor.
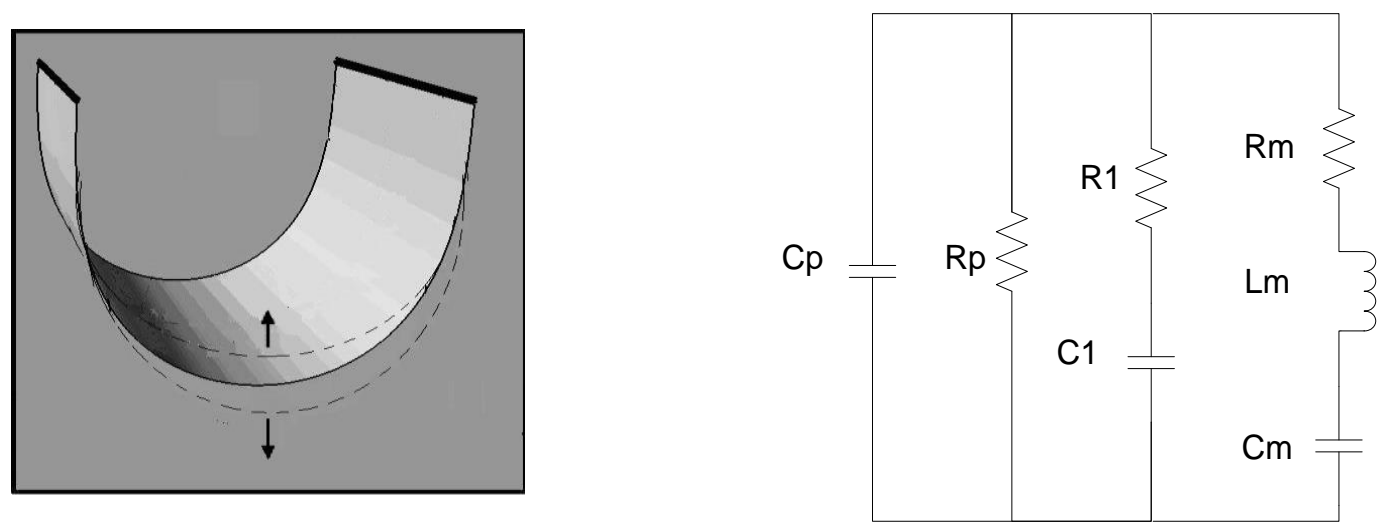

Figura 2.27 - Representação do transdutor curvo de PVDF e seu circuito equivalente para frequências entre 1 e 150 kHz. Fonte: Adaptado de Fiorillo (2000).

Já Guan e Liao (2004), simulando o comportamento de cerâmicas piezoelétricas, propuseram a utilização de resistores para representar a dissipação de energia do material. Os autores adaptaram o circuito para o transdutor vibrando livremente (sem carga) e para o transdutor com carga, esta última caracterizada pela existência de três frequências de ressonância no espectro de frequência. Kim et al. (2008) apresentam outro circuito equivalente para cerâmicas, adaptado do modelo de Van Dyke. No estudo é proposta uma metodologia para obtenção dos parâmetros do circuito equivalente por meio da análise das curvas de impedância pela frequência da cerâmica. Assim como no estudo de Guan e Liao (2004), é proposta a adição de ramos ressonantes para as situações em que o transdutor vibrava em contato com uma estrutura (com carga). Os circuitos propostos por Guan e Liao (2004) e Kim et al. (2008) estão representados na Figura 2.28. 


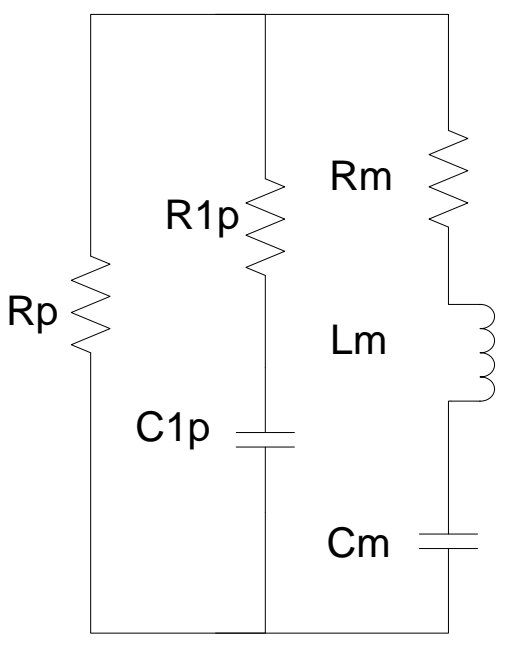

(a)

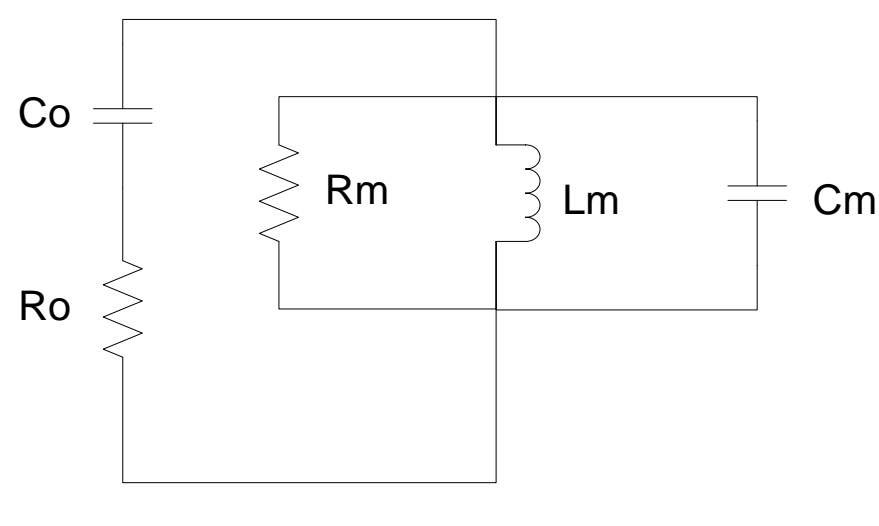

(b)

Figura 2.28 - Circuitos equivalentes contendo apenas componentes reais e constantes. Em: (a) Modelo proposto por Guan e Liao (2004); (b) Modelo proposto por Kim et al. (2008). Fonte: Adaptado de Guan e Liao (2004) e Kim et al. (2008), respectivamente.

Na tabela 2.1 consta um resumo dos estudos mais relevantes a cerca dos circuitos equivalentes de transdutores piezoelétricos. A tabela apresenta os autores, o ano da publicação, o material e as principais características dos circuitos. 
Tabela 2.1 - Resumo dos principais circuitos equivalentes utilizados na simulação de transutores piezoelétricos

\begin{tabular}{|c|c|c|}
\hline Autor / Ano & Material & Características \\
\hline Van Dyke (1928) & $\begin{array}{c}\text { Cristais e cerâmicas com poucas } \\
\text { perdas }\end{array}$ & $\begin{array}{l}\text { Circuito composto da capacitância } \\
\text { da amostra em paralelo com uma } \\
\text { ramo mecânico RLC. É válido nas } \\
\text { proximidades de uma ressonância. }\end{array}$ \\
\hline Mason (1935) & $\begin{array}{c}\text { Cristais e cerâmicas com poucas } \\
\text { perdas }\end{array}$ & $\begin{array}{l}\text { Circuito composto de um terminal } \\
\text { elétrico e dois terminais mecânicos, } \\
\text { que representam as faces do } \\
\text { transdutor. }\end{array}$ \\
\hline Redwood e Lamb (1956) & $\begin{array}{l}\text { Cristais e cerâmicas com poucas } \\
\text { perdas }\end{array}$ & $\begin{array}{l}\text { Adaptação do circuito de Mason, } \\
\text { com a adição de uma linha de } \\
\text { transmissão à parte mecânica. }\end{array}$ \\
\hline $\begin{array}{l}\text { Krimholtz, Leedom e Mathaei } \\
\text { (1970) }\end{array}$ & $\begin{array}{c}\text { Cristais e cerâmicas com poucas } \\
\text { perdas }\end{array}$ & $\begin{array}{l}\text { Circuito composto de uma parte } \\
\text { elétrica interligada a o centro de } \\
\text { uma linha de transmissão acústica } \\
\text { por meio de um transformador. }\end{array}$ \\
\hline Brown e Carlson (1989) & PVDF e PVDF-TrFE & $\begin{array}{l}\text { Adaptação do modelo de Van Dyke } \\
\text { que modela o ramo dielétrico por } \\
\text { meio de uma resistência em } \\
\text { paralelo com a capacitância da } \\
\text { amostra, ambos variáveis com a } \\
\text { frequência }\end{array}$ \\
\hline Leach (1994) & $\begin{array}{c}\text { Cristais e cerâmicas com poucas } \\
\text { perdas }\end{array}$ & $\begin{array}{l}\text { Circuito composto de uma linha de } \\
\text { transmissão mecânica e de um } \\
\text { terminal elétrico representado pela } \\
\text { capacitância da amostra. A } \\
\text { interligação entre as duas partes é } \\
\text { feita por meio de fontes controladas } \\
\text { de tensão. }\end{array}$ \\
\hline Sherrit et al. (1997) & $\begin{array}{c}\text { Cerâmicas com perdas e PVDF- } \\
\text { TrFE }\end{array}$ & $\begin{array}{l}\text { Circuito composto apenas de } \\
\text { componentes complexos que } \\
\text { simulam a dissipação de energia do } \\
\text { material. }\end{array}$ \\
\hline Fiorillo (2000) & PVDF & $\begin{array}{l}\text { Circuito modificado do circuito de } \\
\text { Brown e Carlson com a adição de } \\
\text { um ramo RC série. Todos os } \\
\text { compoentes têm valores reais e } \\
\text { fixos com a frequência. }\end{array}$ \\
\hline Guan e Liao (2004) & Cerâmica & $\begin{array}{l}\text { Baseado no modelo de Van Dyke, } \\
\text { com a adição de resistores ao ramo } \\
\text { dielétrico para representar a } \\
\text { dissipação de energia }\end{array}$ \\
\hline Kim et al. (2008) & Cerâmica & $\begin{array}{l}\text { Circuito modificado do modelo de } \\
\text { Van Dyke (circuito RLC paralelo), } \\
\text { com uma resistência no ramo } \\
\text { dielétrico. }\end{array}$ \\
\hline
\end{tabular}




\section{Capítulo 3}

\section{Metodologia}

A metodologia utilizada no trabalho dividiu-se em três partes: medição das grandezas elétricas por meio da espectroscopia dielétrica dos transdutores piezoelétricos, tratamento dos dados obtidos (transformação dos dados em componentes do circuito equivalente) e simulação dos circuitos elétricos. Na Figura 3.1, está resumido um diagrama de blocos da metodologia proposta para obtenção do circuito equivalente.

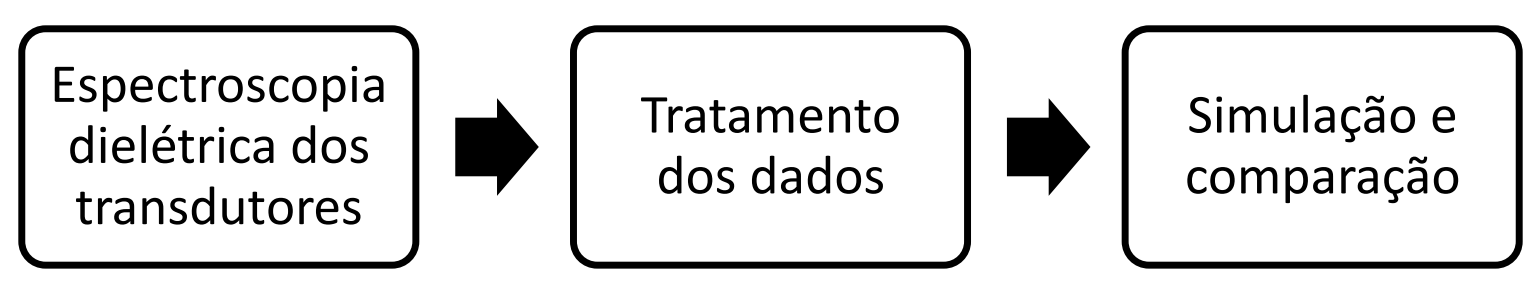

Figura 3.1- Diagrama de blocos da metodologia proposta.

\subsection{Medições}

A espectroscopia dielétrica foi realizada para transdutores poliméricos de três materiais distintos, sendo eles: piezoeletreto termo-formado de canaletas (teflon FEP), com cavidades de 25,50 e $70 \mu \mathrm{m}$ de altura, e outra amostra com canaletas de 2,0 e 2,5 mm de largura (duas ressonâncias); piezoeletreto poroso de polipropileno (PP) e um filme de PVDF, todos indicados na Figura 3.2. As amostras de piezoeletreto termo-formado foram produzidas pelo método desenvolvido por Altafim (2010). O processo consiste na laminação a $300{ }^{\circ} \mathrm{C}$ de dois filmes de FEP de $50 \mu \mathrm{m}$ de espessura com um molde de PTFE entre eles, processo descrito pela Figura 2.9. Após a remoção do molde, eletrodos de alumínio foram evaporados em ambos os lados da amostra. Por fim, as amostras foram carregadas com a aplicação de uma tensão DC de $3 \mathrm{kV}$ por aproximadamente 10 segundos. 


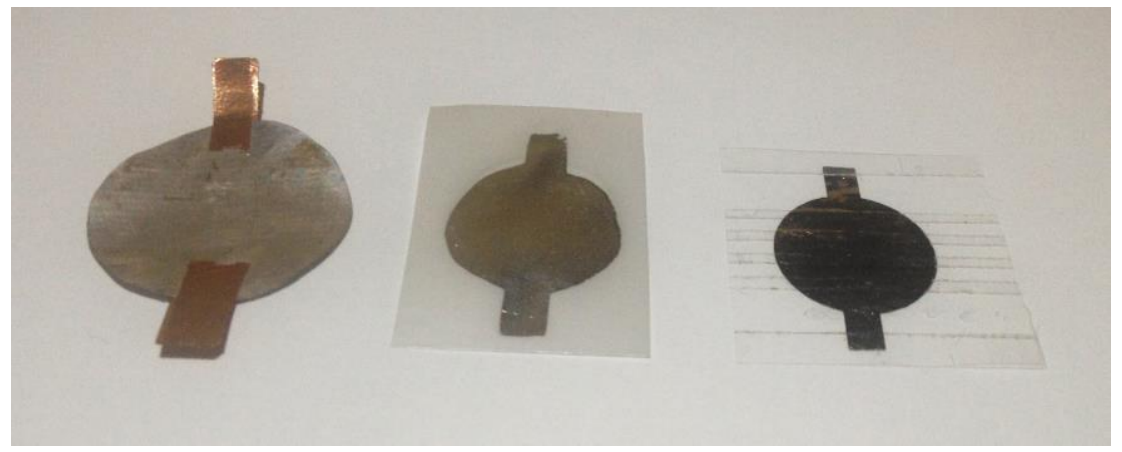

Figura 3.2 - Transdutores utilizados no experimento. Da esquerda para a direita: filme de PVDF, piezoeletreto poroso de PP e piezoeletreto de canaletas de teflon FEP.

A execução dos experimentos se deu em parceria com Grupo de Inovação em Instrumentação Médica e Ultrassom (GIIMUS) da Faculdade de Filosofia, Ciências e Letras de Ribeirão Preto (FFCLRP) da USP. Basicamente, o procedimento consistiu da espectroscopia dielétrica dos transdutores com a utilização de um analisador de impedância modelo Agilent 4294A conectado a uma interface de teste dielétrico modelo Agilent 16451B, equipamentos mostrados na Figura 3.3. Foram realizadas medidas da susceptância, da condutância, da magnitude da impedância e do ângulo de fase, com um nível de tensão de 500 $\mathrm{mV}$, e com faixas de frequência variando para cada transdutor, de acordo com seus picos ressonantes. Para a realização das medições foram adaptados dois eletrodos curvos de latão, de modo que as amostras pudessem vibrar livremente durante os experimentos. Como indicado na Figura 3.4, os eletrodos superior e inferior faziam o contato elétrico com a metalização das superfícies das amostras.

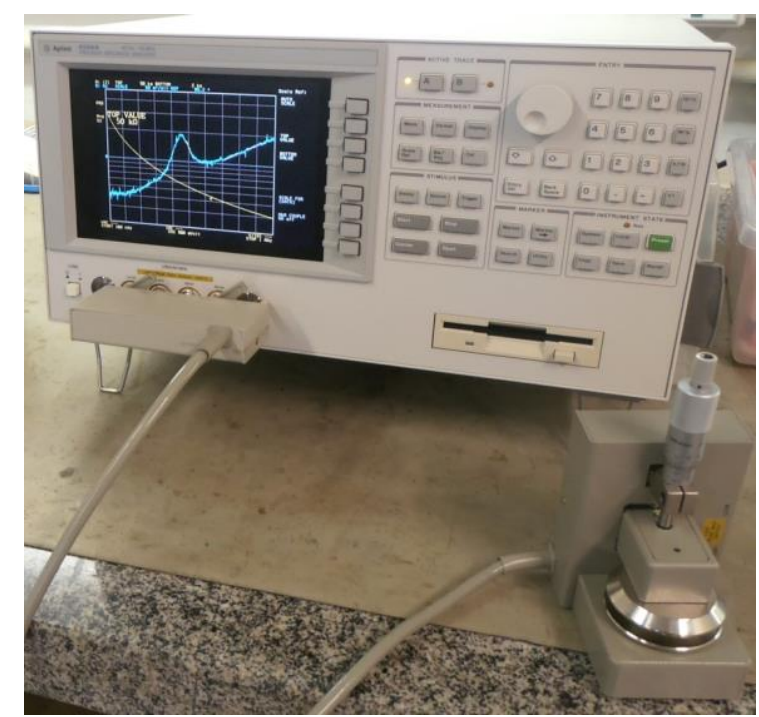

Figura 3.3 - Detalhe do analisador de impedância conectado à interface de teste dielétrico. 

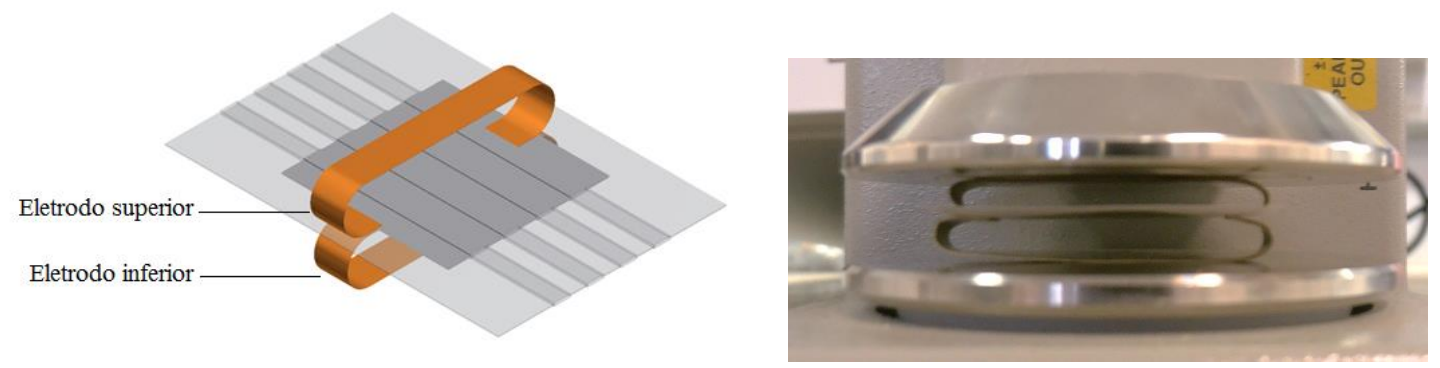

Figura 3.4 - Representação esquemática dos eletrodos utilizados nas medições e a foto lateral mostrando o contato com os eletrodos da interface de teste dielétrico.

\subsection{Tratamento dos dados}

Realizadas as medições, o procedimento seguinte foi adaptar um modelo existente na literatura aos resultados obtidos. Inicialmente, o circuito equivalente escolhido para simular o comportamento dos transdutores foi o circuito utilizado no trabalho de Fiorillo (2000) para a modelagem de um transdutor curvo de PVDF (Figura 3.5). Este, além de ser um material polimérico, é aplicado em frequências abaixo de $200 \mathrm{kHz}$, assim como os piezoeletretos de canaletas. $\mathrm{O}$ circuito pode ser dividido em duas partes, sendo uma mecânica e outra elétrica. Brown e Carlson (1989) afirmaram que para frequências distantes da ressonância, a impedância de entrada do transdutor pode ser representada essencialmente pelo ramo elétrico, enquanto que nas proximidades da frequência de ressonância a impedância do ramo RLC deve ser considerada. Por esta razão, o procedimento adotado neste trabalho foi dividido na determinação dos parâmetros do ramo elétrico e do ramo mecânico, separadamente.

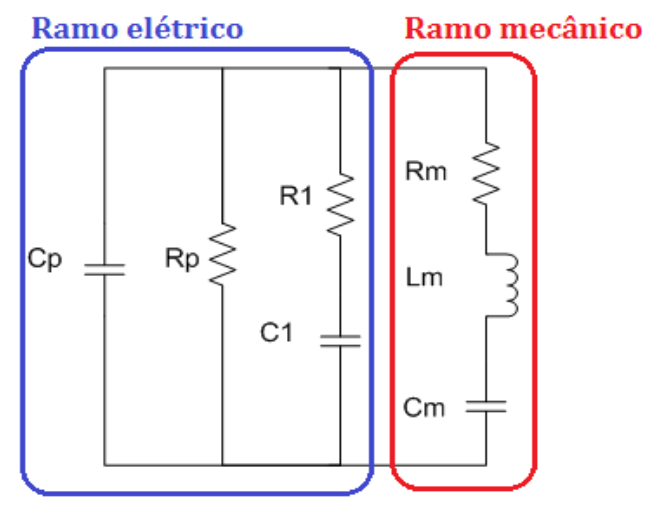

Figura 3.5 - Circuito equivalente para simulação dos transdutores piezoelétricos, dividido em ramo mecânico e elétrico. 
Para a divisão dos dados medidos em duas regiões distintas no espectro de frequência, sendo uma referente apenas ao ramo elétrico e a outra apresentando interferência do ramo mecânico RLC, foi desenvolvido um algoritmo para o cálculo da taxa de variação do valor da condutância pela frequência, baseado na expressão:

$$
\mathrm{G}^{\prime}(\mathrm{i})=\left|\frac{\mathrm{G}[\mathrm{i} \cdot \Delta \mathrm{i}]-\mathrm{G}[(\mathrm{i}-1) \cdot \Delta \mathrm{i}]}{\mathrm{f}[\mathrm{i} \cdot \Delta \mathrm{i}]-\mathrm{f}[(\mathrm{i}-1) \cdot \Delta \mathrm{i}]}\right|
$$

em que $G^{\prime}$ (i) é valor da taxa de variação da condutância na posição i, com i variando de 1 até $\mathrm{N} / \Delta \mathrm{i}$ (N: número de pontos medidos), G[] é o valor medido da condutância para a frequência f[] e $\Delta \mathrm{i}$ um número arbitrário.

Adotando-se um valor adequado para $\Delta \mathrm{i}$ verifica-se que próximo à frequência de ressonância, o valor de $G^{\prime}(i)$ tende a ser maior do que nas regiões distantes. Desta forma, estabelecendo-se um valor limite de $\mathrm{G}^{\prime}(\mathrm{i})$, chamado de limG, e realizando uma varredura por toda a faixa de frequência das medidas, é possível separar as duas regiões no espectro, de acordo com a seguinte condições:

- Se $G^{\prime}(i)$ for maior do que limG, então a região é próxima da ressonância;

- Se $G^{\prime}(i)$ for menor do que limG, então a região é distante da ressonância.

Com essas condições descritas, foram estabelecidos dois valores de frequência $\left(f_{1}\right.$ e $f_{2}$ ), sendo que a faixa de frequência entre $f_{1}$ e $f_{2}$ foi denominada de região próxima à ressonância (impedância de entrada com interferência do ramo RLC), enquanto que as regiões entre o primeiro valor de frequência medido e $f_{1}$, e entre $f_{2}$ e último valor de frequência, foram chamadas de regiões distantes da ressonância. Para facilitar os cálculos, todos os valores do vetor $G^{\prime}(i)$ foram divididos pelo seu valor máximo, limitando os valores do vetor de $G^{\prime}(i)$ entre 0 e 1 . $O$ valor $\operatorname{limG}$ foi definido para 0,4 .

Para automatização dos passos, todos os processos descritos foram implementados no Matlab, cujo fluxograma detalhado encontra-se na Figura 3.6. 


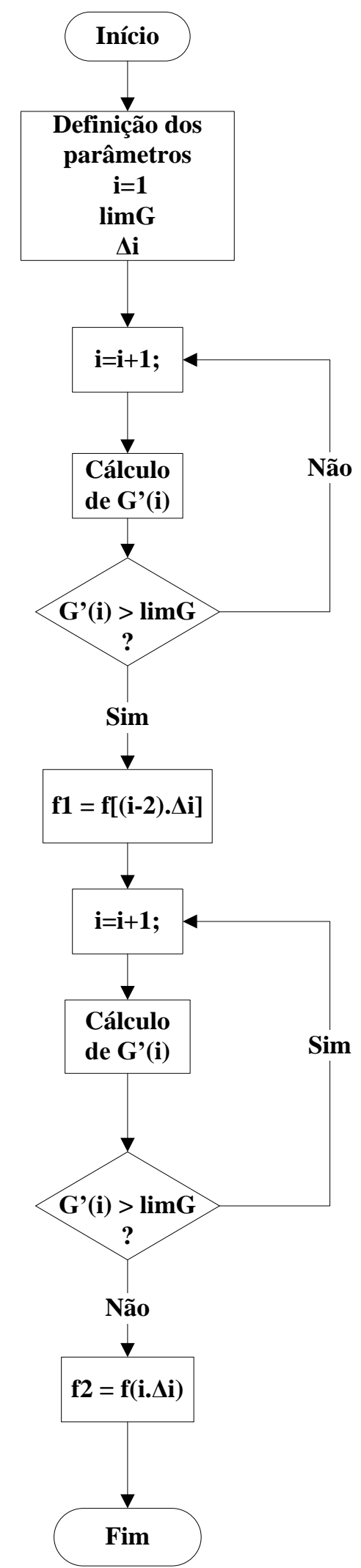

Figura 3.6 - Fluxograma para o cálculo da frequências $\mathrm{f}_{1}$ e $\mathrm{f}_{2}$. 


\section{Determinação dos parâmetros do ramo elétrico}

Nesta etapa, o primeiro passo foi aplicar o algoritmo da Figura 3.6 para todas as medidas de condutância, obtendo-se então os valores das frequências $f_{1}$ e $f_{2}$. A seguir, efetuou-se a subtração dos pontos experimentais da condutância compreendidos entre $\mathrm{f}_{1}$ e $\mathrm{f}_{2}$, para todas as medidas. Feito isso, a determinação dos parâmetros do ramo elétrico foi realizada com o ajuste das curvas dos pontos distantes da ressonância à expressão teórica da condutância a ser analisada a seguir.

O circuito da Figura 3.5 foi modificado com a adição de ramos RC à parte elétrica do modelo. Considerando que para frequências distantes da ressonância eletromecânica, os transdutores piezoelétricos sejam considerados como dielétricos, eles podem ser modelados pelo circuito equivalente da Figura 3.7, utilizado para simular qualquer dielétrico (ZAENGL, 2003).

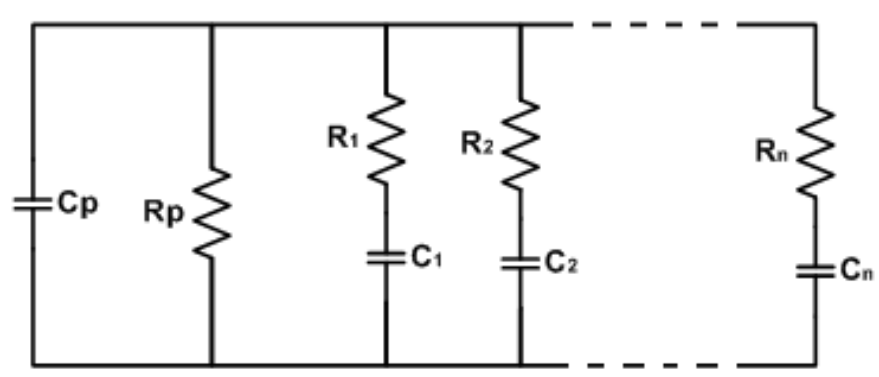

Figura 3.7 - Circuito equivalente para a modelagem dos dielétricos. Fonte: Adaptado de Zaengl (2003).

A admitância complexa do circuito da Figura 3.7 é dada por:

$$
Y(\omega)=\frac{1}{R_{p}}+\sum_{i=1}^{n} \frac{\omega^{2} C_{i}^{2} R_{i}}{\left(\omega C_{i} R_{i}\right)^{2}+1}+j \omega\left[C_{P}+\sum_{i=1}^{n} \frac{C_{i}}{\left(\omega C_{i} R_{i}\right)^{2}+1}\right]
$$

sendo $\omega=2 \pi f$, a frequência angular em $\mathrm{rad} / \mathrm{s}$ e $\mathbf{n}$ o número total de ramos $\mathrm{RC}$.

Da equação (3.2) obtém-se a condutância $(G(\omega))$ e a susceptância $(B(\omega))$ do circuito, que são:

$$
G(\omega)=\frac{1}{R_{p}}+\sum_{i=1}^{n} \frac{\omega^{2} C_{i}^{2} R_{i}}{\left(\omega C_{i} R_{i}\right)^{2}+1}
$$




$$
B(\omega)=\omega\left[C_{P}+\sum_{i=1}^{n} \frac{C_{i}}{\left(\omega C_{i} R_{i}\right)^{2}+1}\right]
$$

Analisando a expressão 3.3 observa-se que quando $\omega$ tende a zero, a expressão tende a $1 / R_{p}$. Desta forma, o valor de $R_{p}$ foi determinado como sendo o inverso da condutância para a frequência de $1 \mathrm{kHz}$ para todas as medidas realizadas.

Para o ajuste das curvas às expressões, foi utilizado o software OriginPro 8. Foram criadas funções idênticas às expressões 3.3 e 3.4, posteriormente adicionadas à biblioteca do software.

Para cada medida de condutância, foram determinados três circuitos diferentes, com um, dois e três ramos $\mathrm{RC}$, respectivamente. De maneira geral, fixado o valor de $\mathrm{R}_{\mathrm{p}}$, os valores de $R_{i}$ e $C_{i}$ foram obtidos com o ajuste da curva de condutância dos pontos distantes da ressonância à expressão 3.3. $\mathrm{O}$ valor de $C_{P}$ foi então calculado pelo ajuste da curva de susceptância à expressão 3.4, com os valores de $\mathrm{R}_{\mathrm{i}}$ e $\mathrm{C}_{\mathrm{i}}$ fixados.

\section{Determinação dos parâmetros do ramo mecânico}

Diferente do ramo elétrico, determinado pelo circuito da Figura 3.7, os componentes do circuito mecânico foram calculados nas proximidades da frequência de ressonância. O procedimento inicial foi subtrair ponto a ponto as medidas de condutância pela função polinomial de ajuste dos pontos distantes da ressonância (pontos contidos entre a frequência inicial e $f_{1}$, e entre $f_{2}$ e a frequência final). Tais funções polinomiais foram determinadas com o auxílio da ferramenta cftool do software Matlab. O resultado aproximado da subtração são os valores de condutância do ramo mecânico, apenas.

O procedimento seguinte assemelha-se ao adotado na determinação do ramo elétrico. Após a subtração, os pontos compreendidos entre $\mathrm{f}_{1}$ e $\mathrm{f}_{2}$ foram ajustados à expressão teórica do ramo mecânico também por meio do software OriginPro 8.

A admitância do circuito mecânico da Figura 3.5 é: 


$$
Y_{m}(\omega)=\frac{1}{R_{m}+j\left(\omega L_{m}-\frac{1}{\omega C_{m}}\right)}
$$

Separando a equação 3.5 em condutância (G) e susceptância (B), tem-se:

$$
Y_{m}(\omega)=G_{m}(\omega)+j B_{m}(\omega)=\frac{R_{m}}{R_{m}{ }^{2}+\left(\omega L_{m}-\frac{1}{\omega C_{m}}\right)^{2}}-\frac{j\left(\omega L_{m}-\frac{1}{\omega C_{m}}\right)}{R_{m}{ }^{2}+\left(\omega L_{m}-\frac{1}{\omega C_{m}}\right)^{2}}
$$

As equações 3.5 e 3.6 referem-se a apenas um ramo mecânico. Entretanto, quando há mais de uma ressonância presente no espectro de frequência, outros ramos RLC devem ser adicionados, como indicado na Figura 3.8. Para este circuito, com $\mathbf{n}$ ramos RLC dispostos em paralelo, a expressão 3.6 é alterada para:

$$
\mathrm{Y}_{\mathrm{m}}(\omega)=\sum_{\mathrm{i}=1}^{\mathrm{n}}\left[\frac{\mathrm{R}_{\mathrm{mi}}}{\mathrm{R}_{\mathrm{mi}}{ }^{2}+\left(\omega \mathrm{L}_{\mathrm{mi}}-\frac{1}{\omega \mathrm{C}_{\mathrm{mi}}}\right)^{2}}-\frac{j\left(\omega \mathrm{L}_{\mathrm{mi}}-\frac{1}{\omega \mathrm{C}_{\mathrm{mi}}}\right)}{\mathrm{R}_{\mathrm{mi}}^{2}+\left(\omega \mathrm{L}_{\mathrm{mi}}-\frac{1}{\omega \mathrm{C}_{\mathrm{mi}}}\right)^{2}}\right]
$$

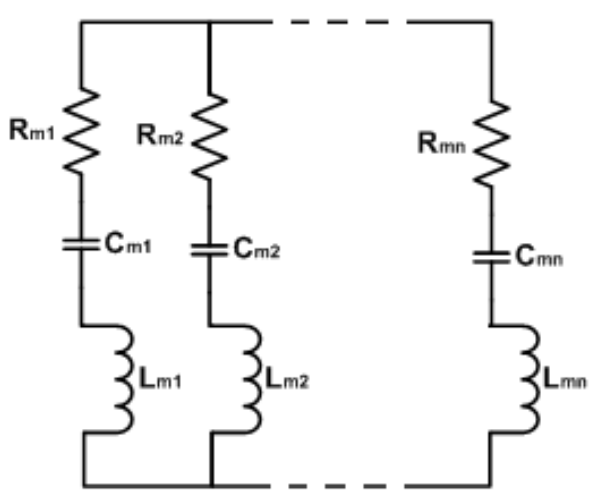

Figura 3.8 - Circuitos RLC paralelos para representação de n ressonâncias no espectro da frequência.

Desta forma, os ajustes referentes ao ramo mecânico dos transdutores foram feitos de acordo com o número de ressonâncias presentes na medida. 
Determinados os parâmetros tanto da parte elétrica quanto da mecânica, o modelo completo para a simulação da impedância de entrada dos transdutores pode ser exemplificado pelo circuito elétrico da Figura 3.9.

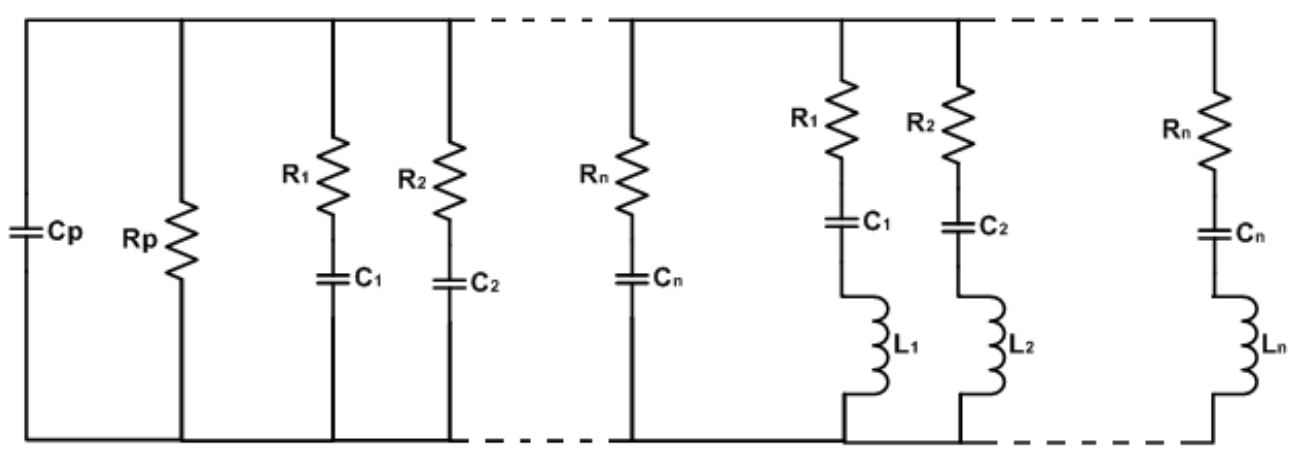

Figura 3.9 - Circuito equivalente para simulação dos transdutores, com $\mathbf{n}$ ramos RC na parte elétrica e $\mathbf{n}$ ramos RLC na parte mecânica.

\section{Simulações e erros numéricos}

A etapa seguinte à determinação dos parâmetros do circuito compreendeu a simulação destes via software Pspice 9.1 Schematics. Primeiramente, os componentes dos circuitos foram conectados como indicado na Figura 3.10, seguindo-se então com as simulações das curvas de condutância, susceptância, módulo da impedância e ângulo de fase, através dos terminais da fonte VSIM do circuito e nas mesmas faixas de frequência em que as medidas experimentais foram realizadas.

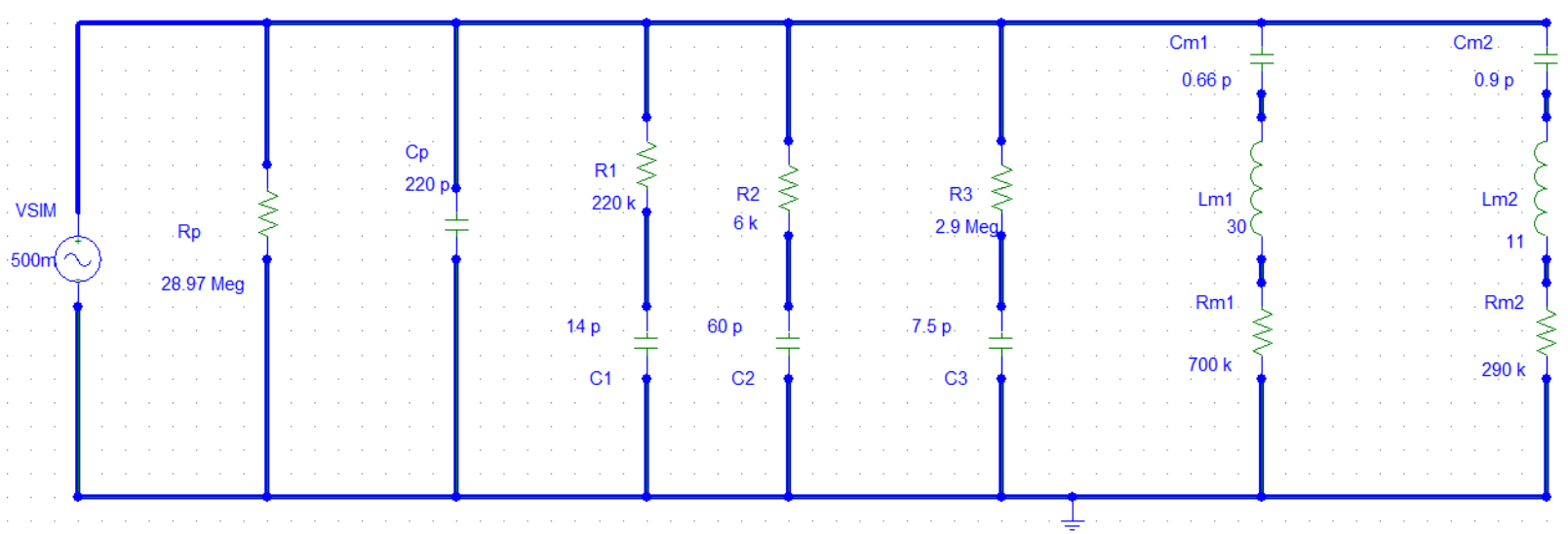

Figura 3.10 - Exemplo de circuito simulado no software Pspice, contendo três ramos RC na parte elétrica e dois ramos RLC na mecânica. 
Com o objetivo de determinar a equivalência entre os sinais medidos e os simulados, foi aplicada a expressão de erro relativo percentual médio. Os valores da condutância, susceptância, módulo da impedância e do ângulo de fase simulados, foram amostradas em vetores com o mesmo número de pontos das medidas, compreendidos também na mesma faixa de frequência. Comparou-se então, ponto a ponto, por meio de uma rotina em Matlab, cada valor medido com o simulado por meio da expressão:

$$
E_{\text {rel }}=\frac{100}{N} \sum_{i=1}^{N}\left|\frac{Y_{\text {med }}(i)-Y_{\text {sim }}(i)}{Y_{\text {med }}(i)}\right|
$$

em que $\mathrm{N}$ é o número de pontos do vetor, $\mathrm{Y}_{\text {med }}(\mathrm{i})$ é o valor do parâmetro medido pelo analisador na i-ésima posição do vetor de medição e $\mathrm{Y}_{\text {sim }}(\mathrm{i})$ é o valor do parâmetro simulado na i-ésima posição do vetor de simulação. 


\section{Capítulo 4}

\section{Resultados e discussões}

O objetivo deste capítulo é apresentar os resultados obtidos a partir da metodologia proposta. Na seção 4.1 serão mostrados os resultados da espectroscopia das amostras, na seção 4.2 serão discutidos os resultados da aplicação do algoritmo para determinação das frequências $\mathrm{f}_{1}$ e $\mathrm{f}_{2}$ descritas na metodologia, a seção 4.3 abordará a obtenção dos circuitos equivalentes dos ramos mecânico e elétrico, e por fim, na seção 4.4, será feita uma análise comparativa entre as simulações dos circuitos e as medidas.

\subsection{Medições}

Nas Figuras 4.1 a 4.16 estão presentes os resultados das medições de todos os transdutores. As medições compreenderam a faixa de 1 a $100 \mathrm{kHz}$ para o filme de PVDF, de 1 a $1000 \mathrm{kHz}$ para o filme de PP, e de 1 a $150 \mathrm{kHz}$ para as amostras de piezoeletretos de canaletas, sendo que cada faixa foi escolhida de modo a destacar as ressonâncias presentes nos espectros das amostras. 


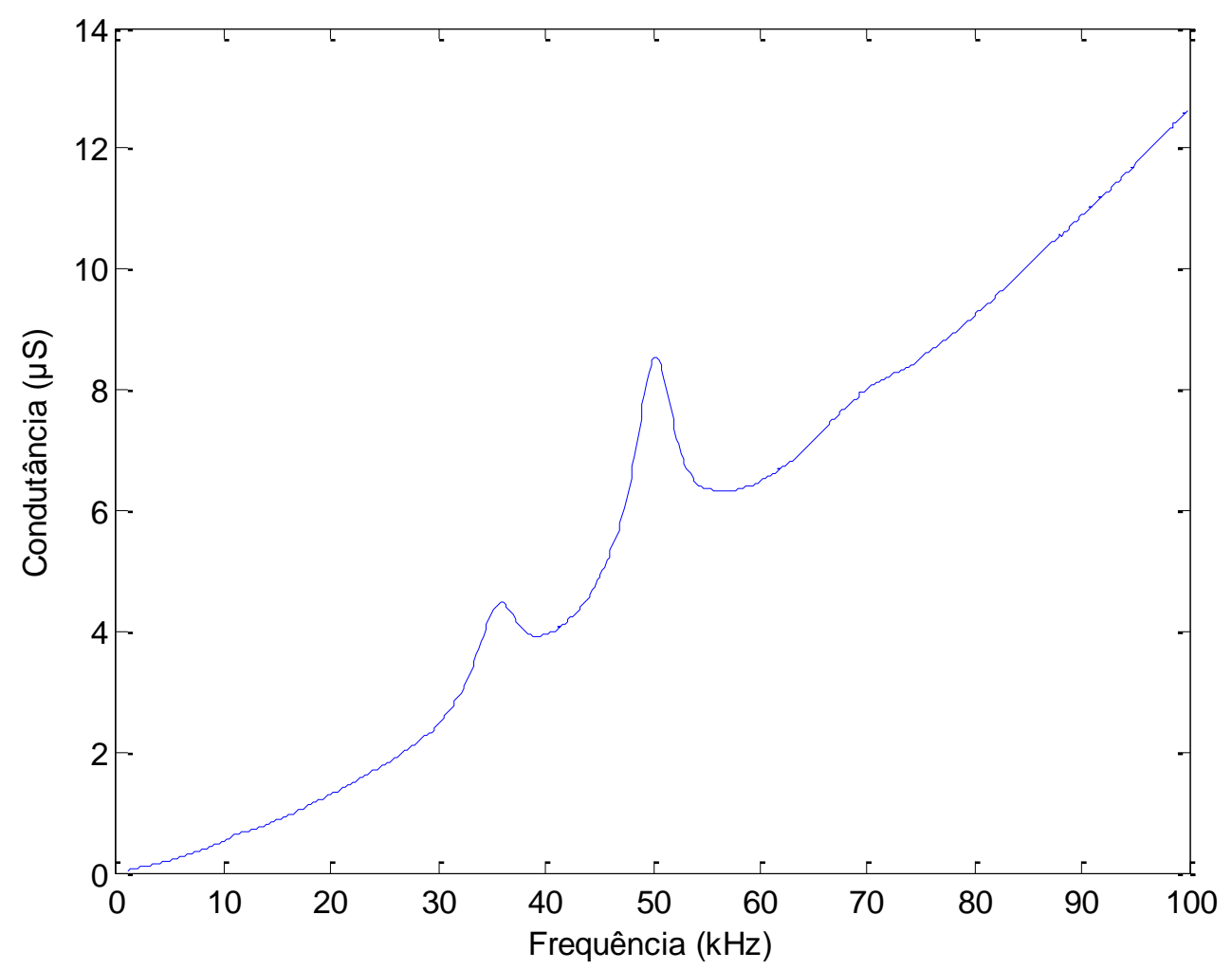

Figura 4.1 - Gráfico da condutância pela frequência do filme de PVDF.

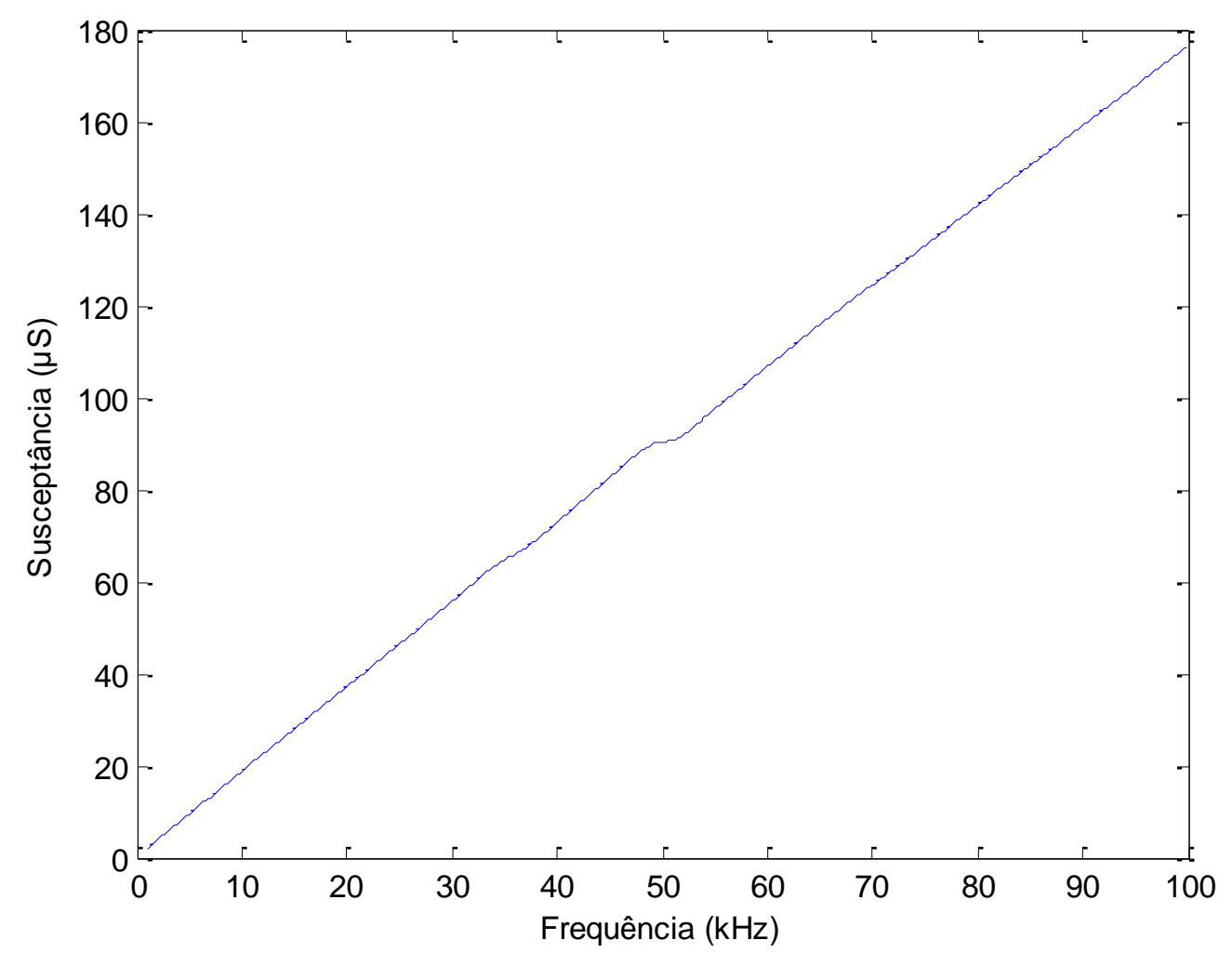

Figura 4.2 - Gráfico da susceptância pela frequência do filme de PVDF. 


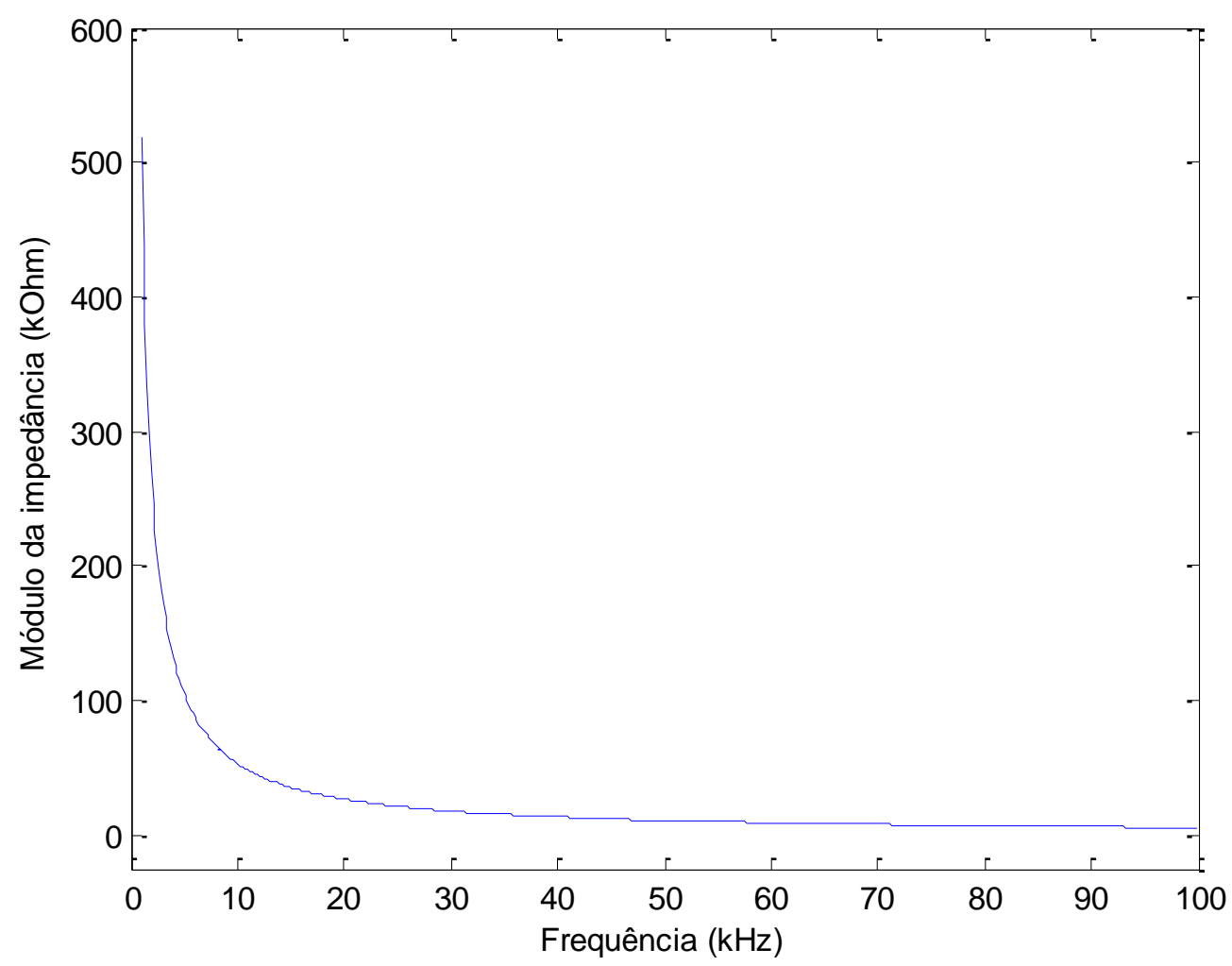

Figura 4.3 - Gráfico do módulo da impedância pela frequência do filme de PVDF.

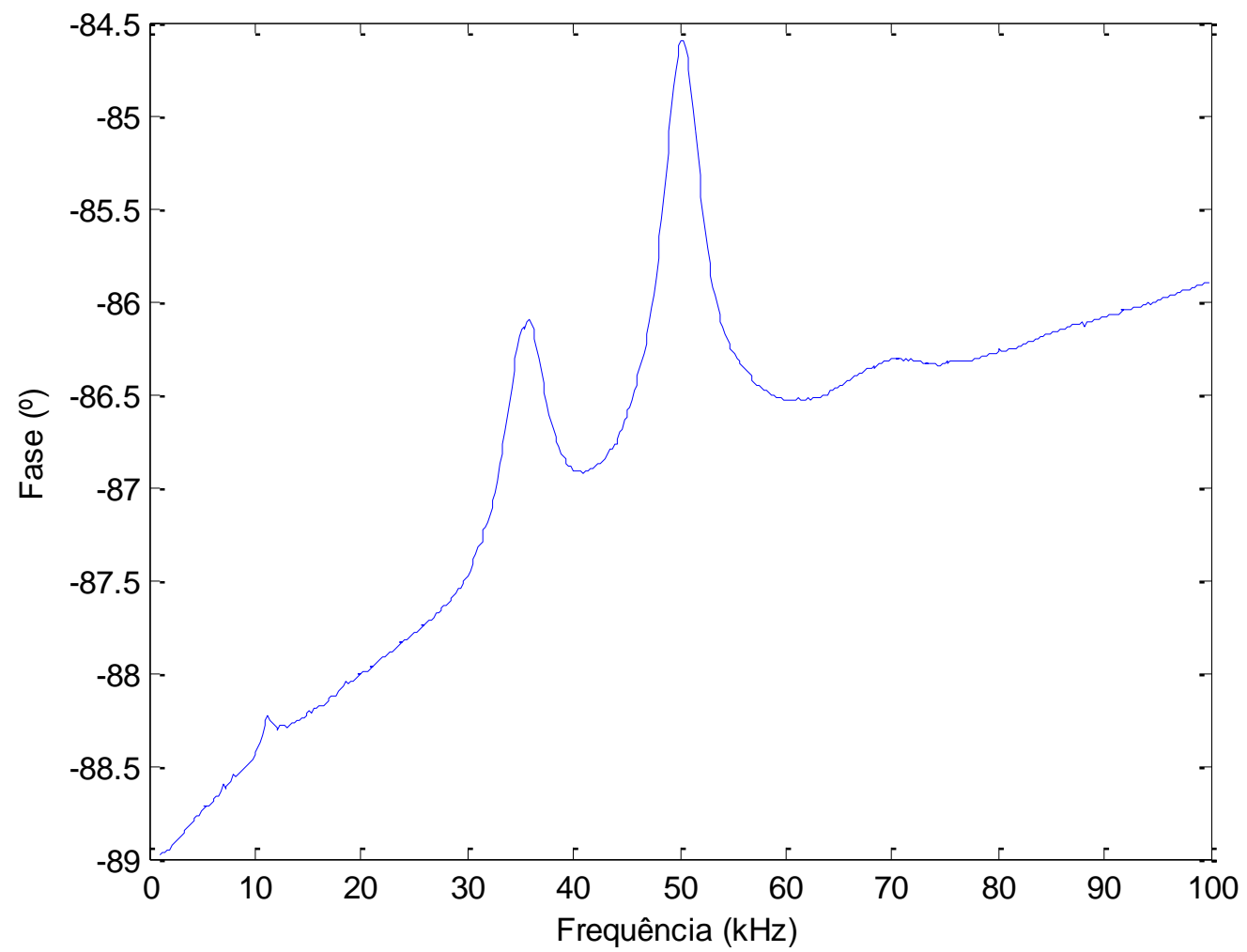

Figura 4.4 - Gráfico da fase pela frequência do filme de PVDF. 


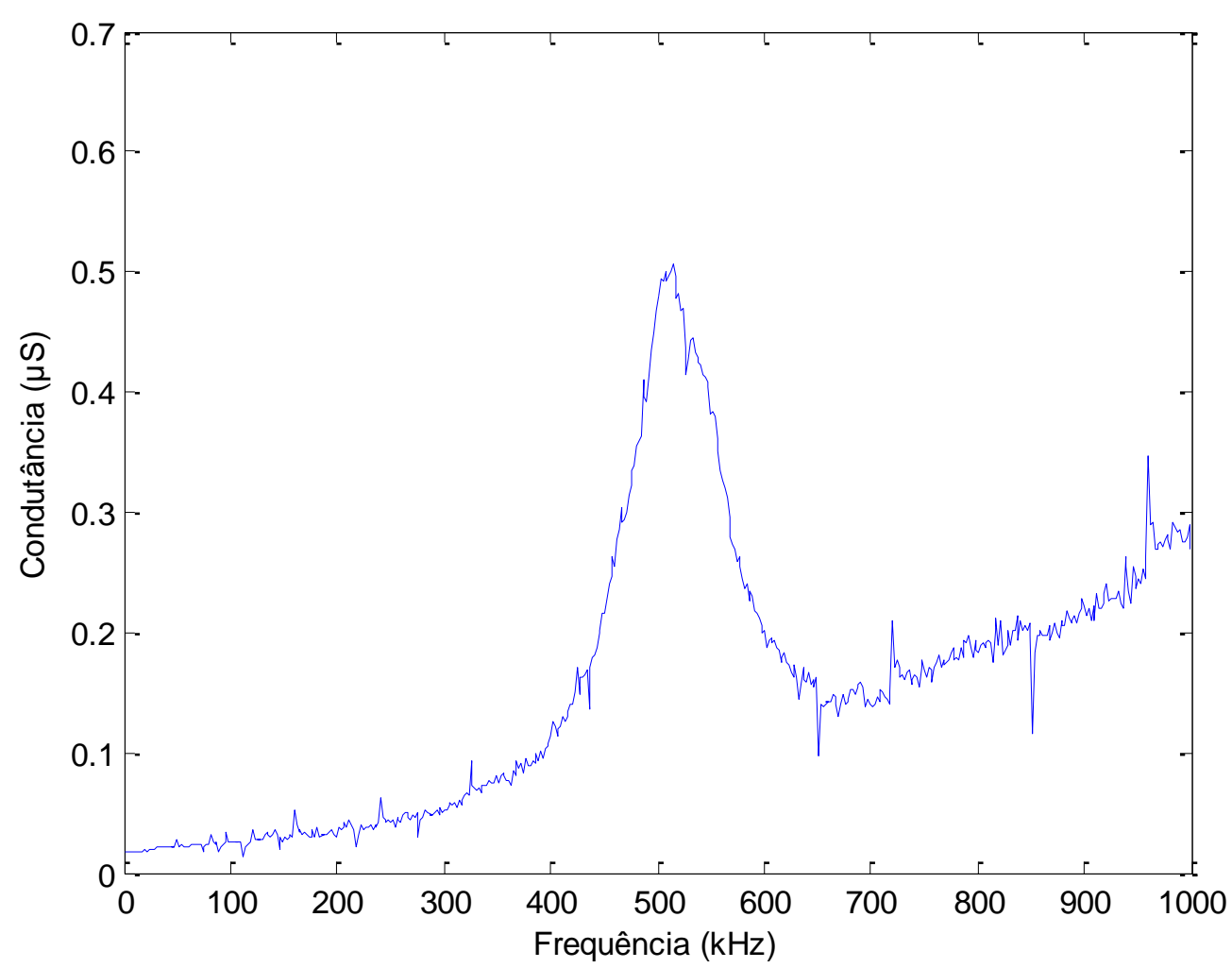

Figura 4.5 - Gráfico da condutância pela frequência do filme de PP.



Figura 4.6 - Gráfico da susceptância pela frequência do filme de PP. 


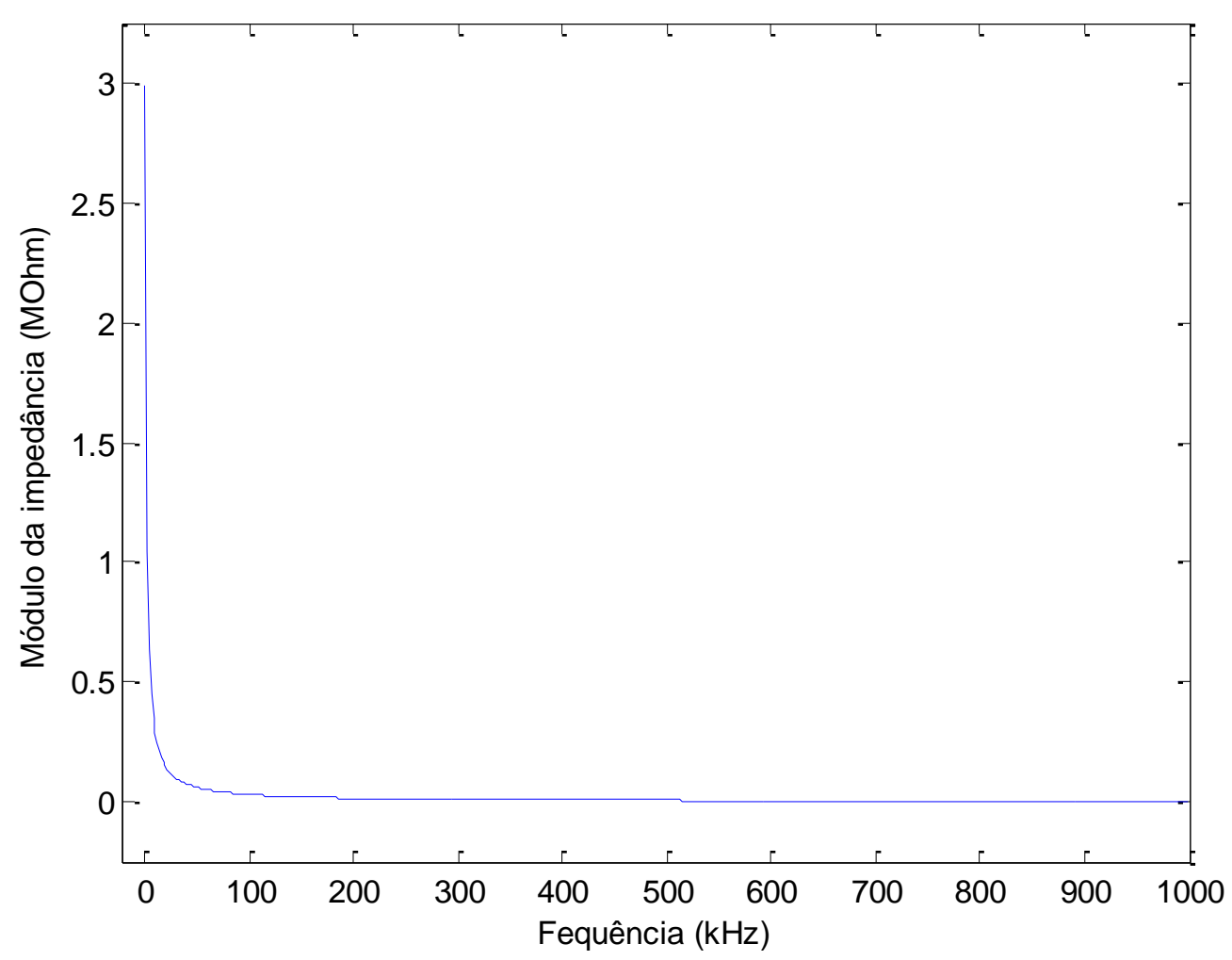

Figura 4.7 - Gráfico do módulo da impedância pela frequência do filme de PP.

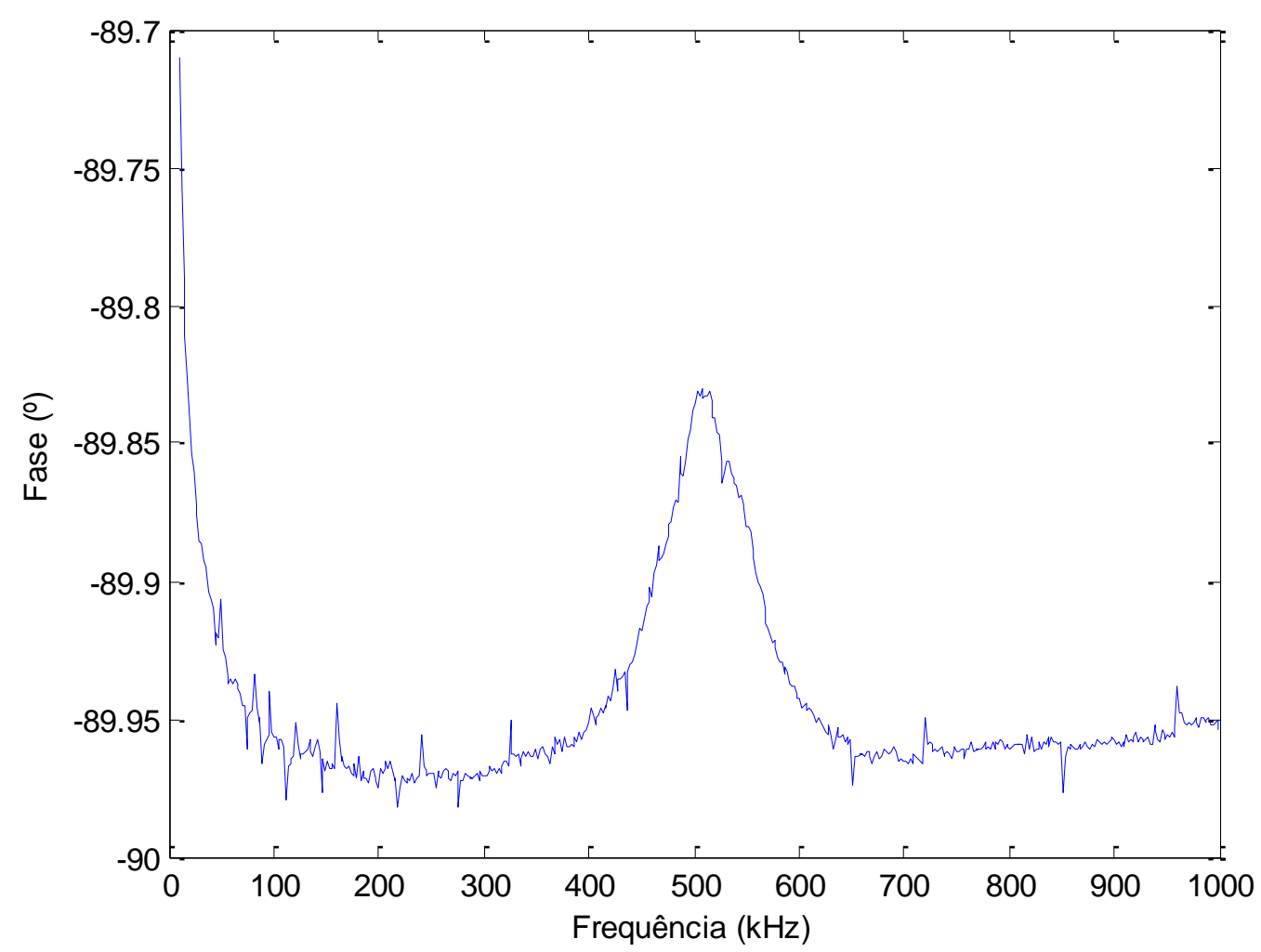

Figura 4.8 - Gráfico da fase pela frequência do filme de PP. 


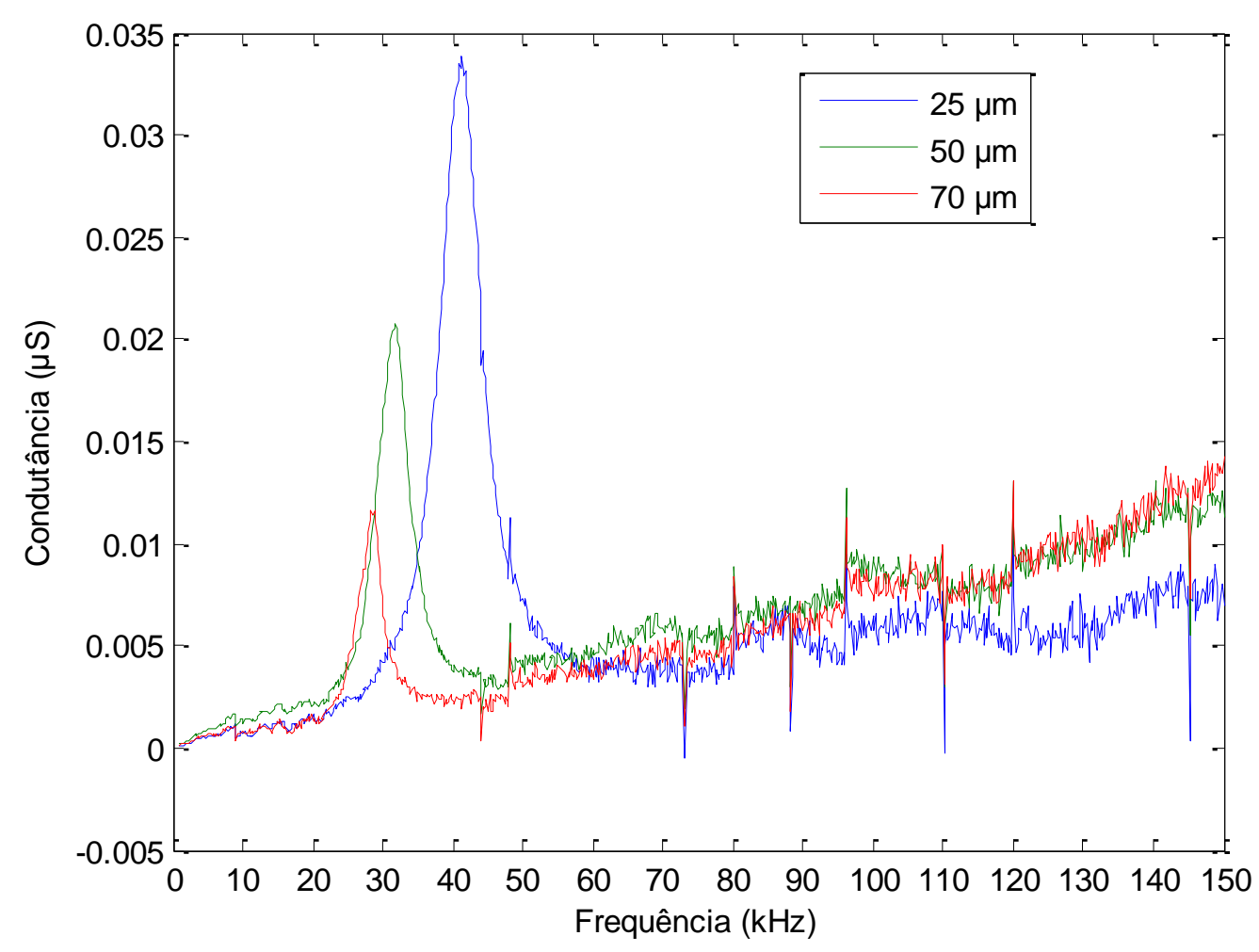

Figura 4.9 - Gráfico da condutância pela frequência dos piezoeletretos de canaletas.

Observando-se Figura 4.9, nota-se a relação entre a frequência de ressonância das amostras de piezoeletretos e a altura das canaletas. Com o aumento da altura da canaleta, há uma diminuição da frequência ressonante, bem como a diminuição do valor de pico da condutância. 


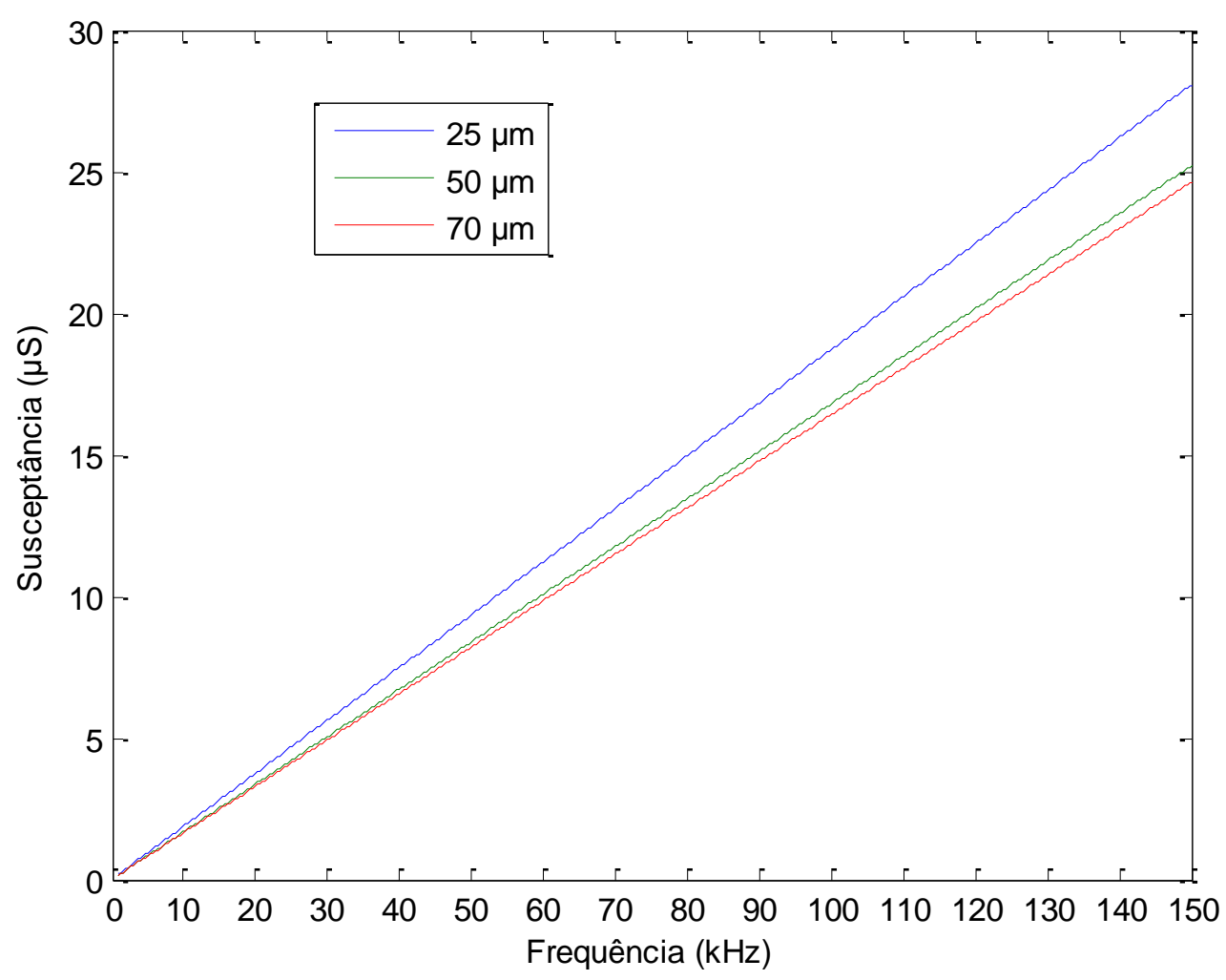

Figura 4.10 - Gráfico da susceptância pela frequência dos piezoeletretos de canaletas.

Outra relação que se observa na Figura 4.10 é o aumento da inclinação da curva de susceptância com a diminuição da cavidade entre as canaletas. Tal fato é relacionado com capacitância geométrica de cada amostra, a qual também aumenta de valor com a diminuição da altura das canaletas. 


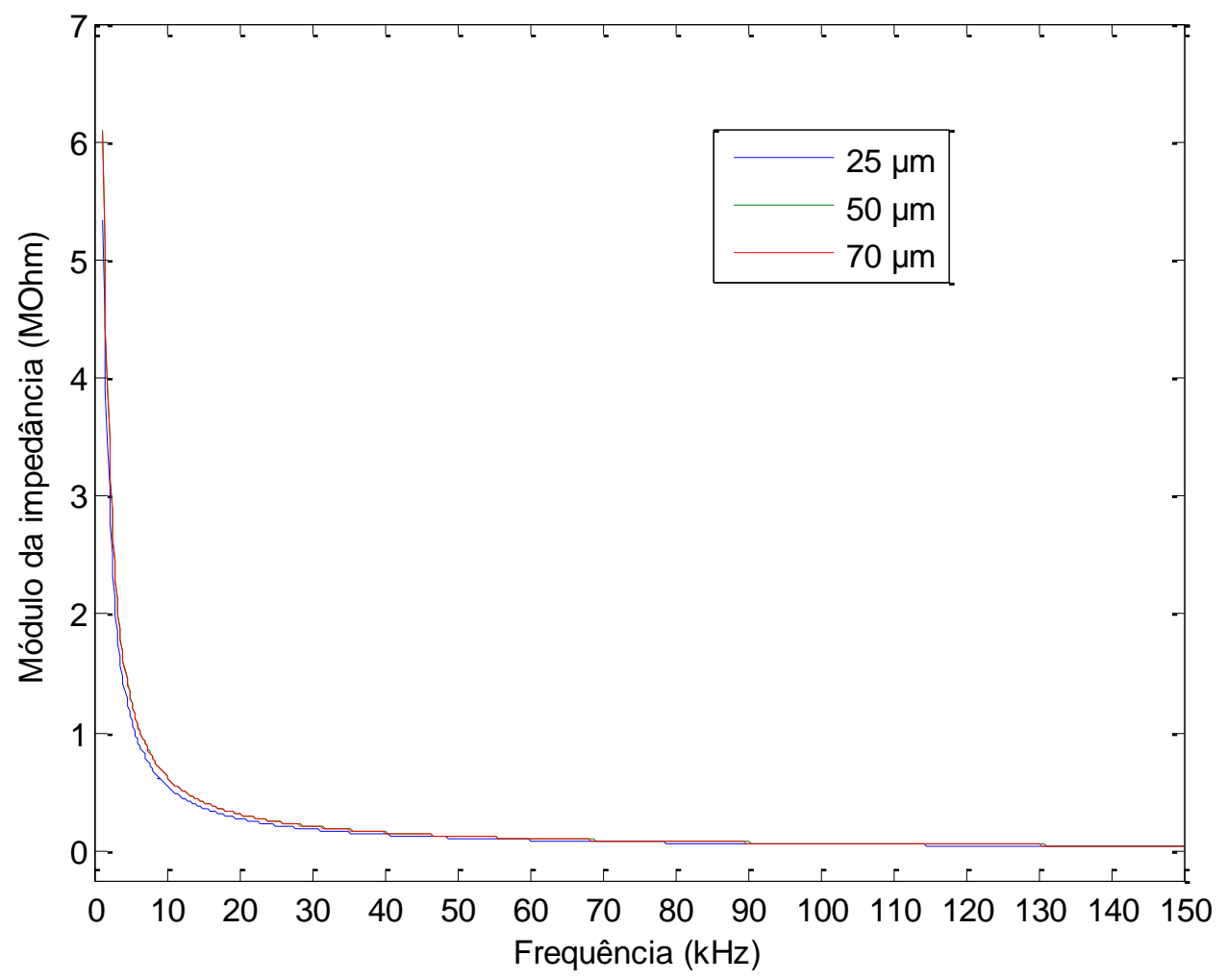

Figura 4.11 - Gráfico do módulo de impedância pela frequência dos piezoeletretos de canaletas.

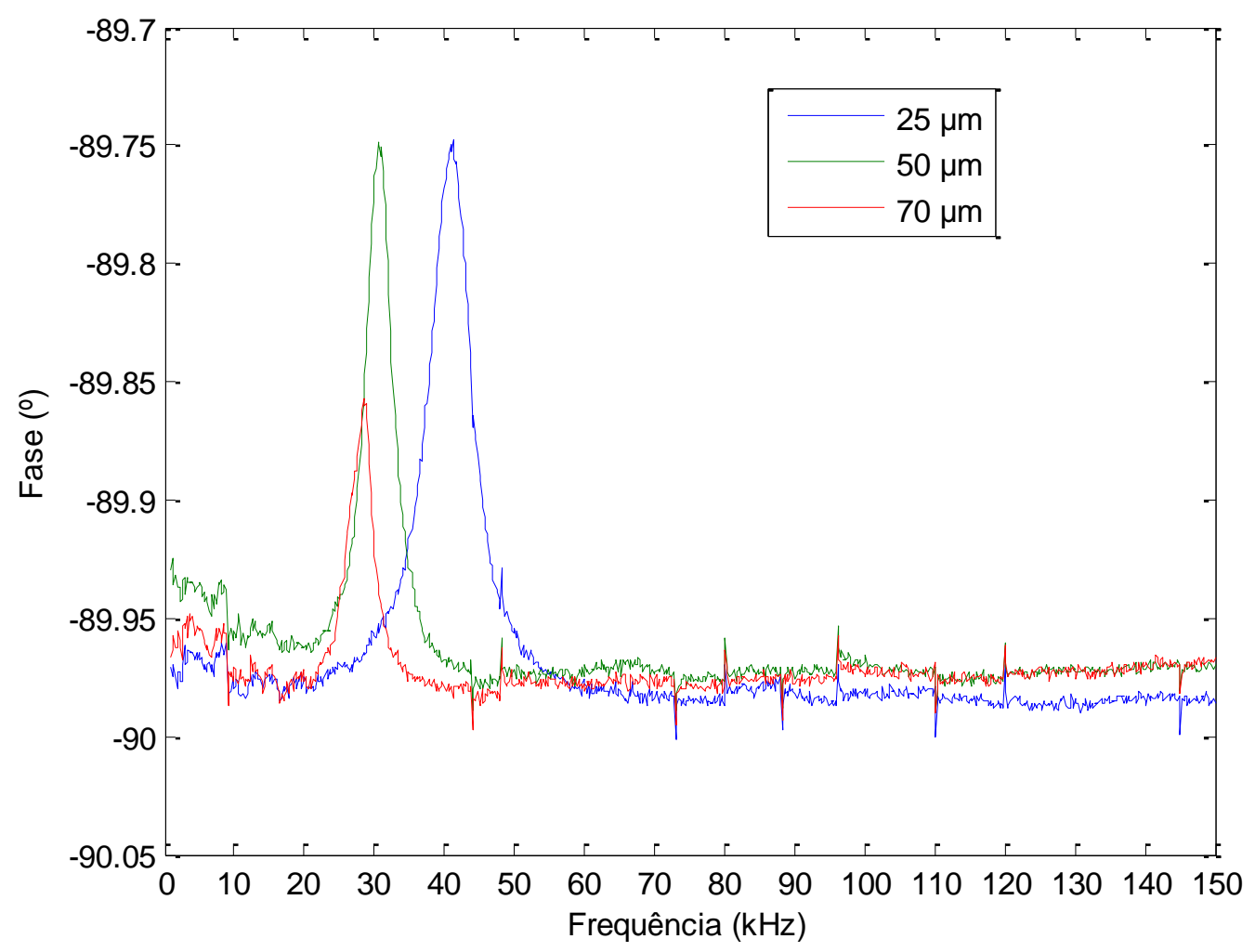

Figura 4.12 - Gráfico da fase pela frequência dos piezoeletreto de canaletas. 


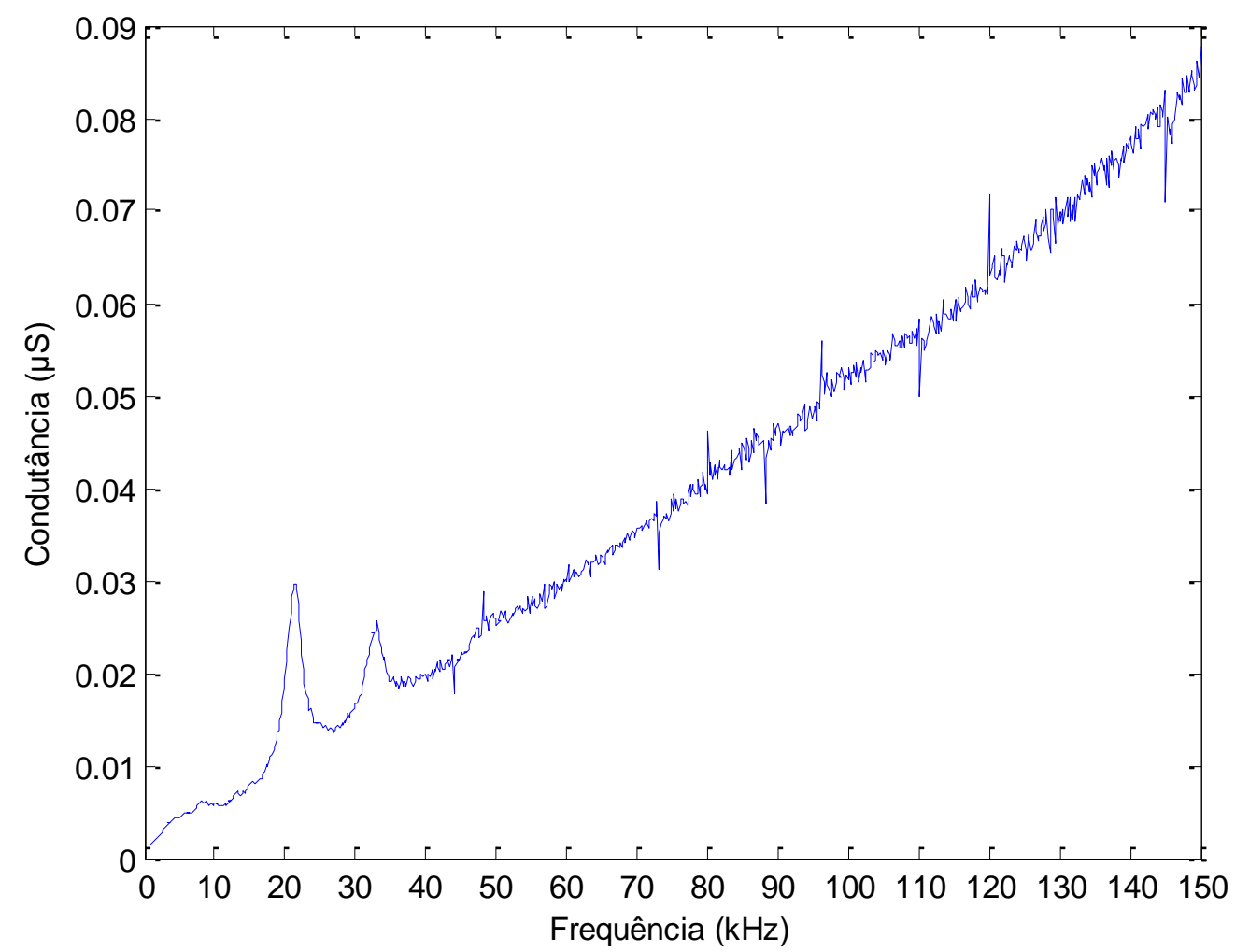

Figura 4.13 - Gráfico da condutância pela frequência do piezoeletreto de canaletas com duas ressonâncias.

As duas ressonâncias presentes na curva de condutância da Figura 4.13 é uma característica das amostras de piezoeletretos com canaletas de larguras diferentes. Uma frequência de ressonância refere-se às canaletas de 2,0 $\mathrm{mm}$ de largura, enquanto que o outro valor é relacionado às canaletas de $2,5 \mathrm{~mm}$. 


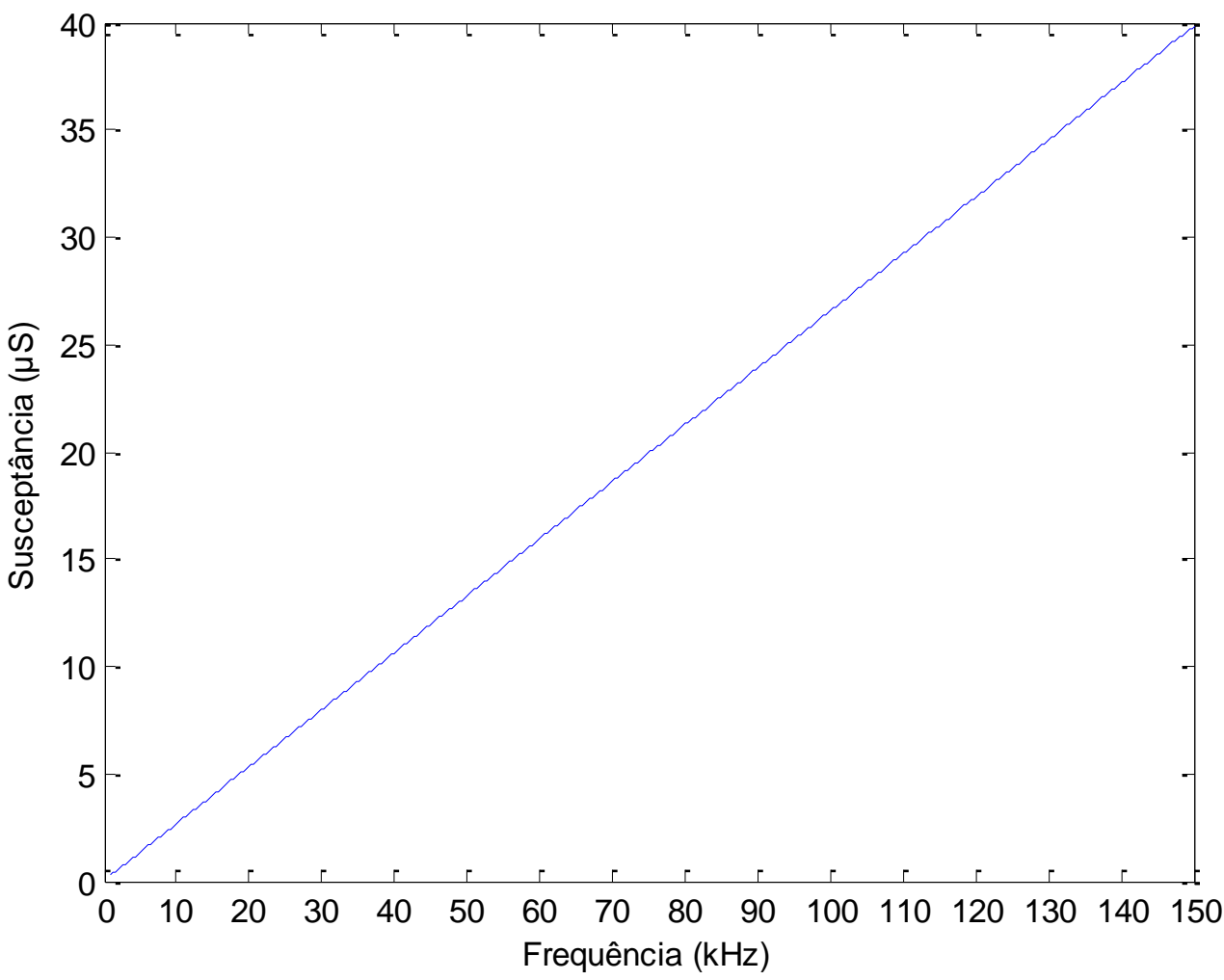

Figura 4.14 - Gráfico da susceptância pela frequência do piezoeletreto de canaletas com duas ressonâncias.

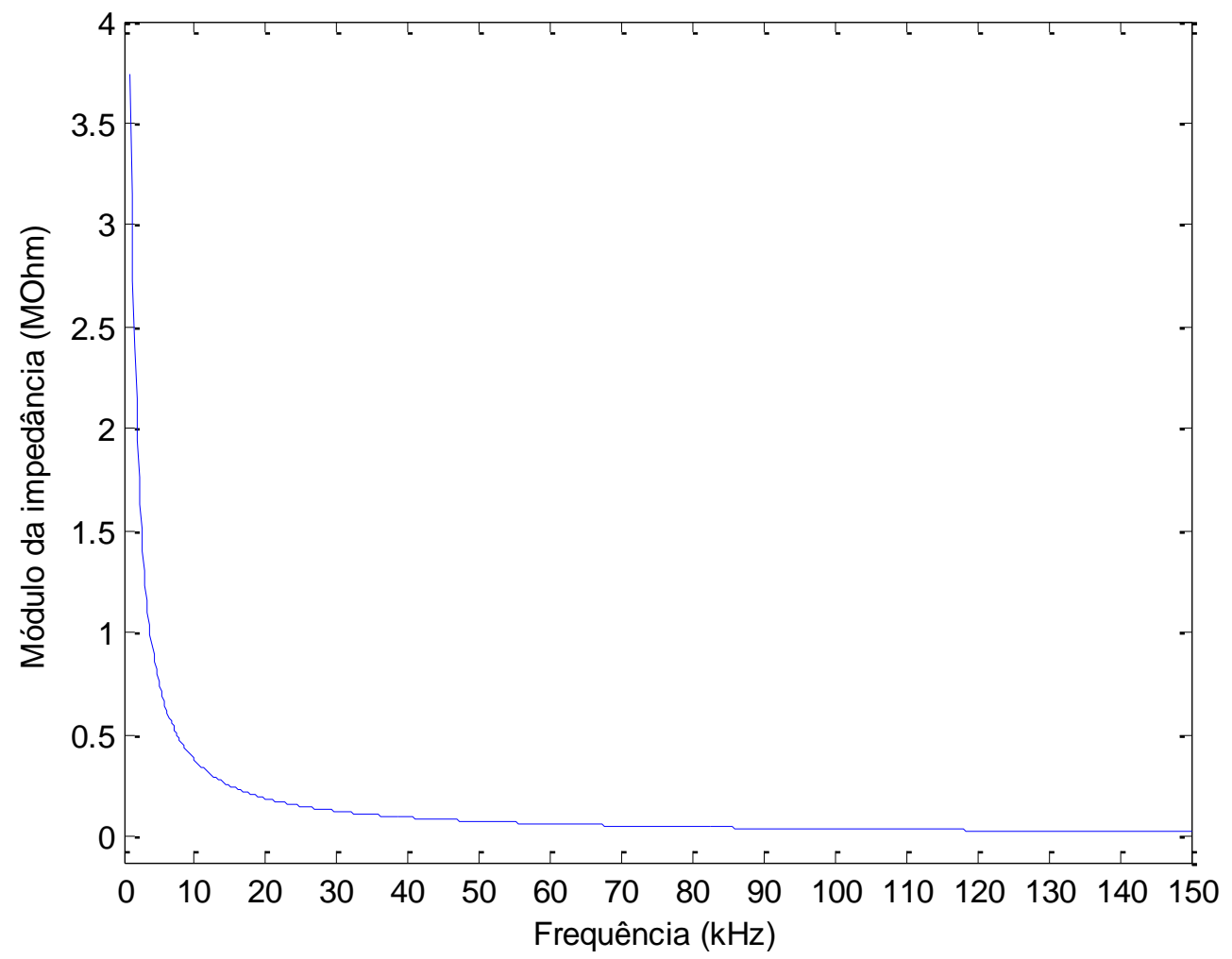

Figura 4.15 - Gráfico do módulo da impedância pela frequência do piezoeletreto de canaletas com duas ressonâncias. 
Analisando as Figuras 4.3, 4.7, 4.11 e 4.15, percebe-se que os piezoeletretos de canaletas e o filme de PP apresentam valores mais elevados do módulo da impedância do que o filme de PVDF, para baixas frequências. Tal fato sugere que o filme de PVDF tenha uma capacitância geométrica maior do que as demais amostras.

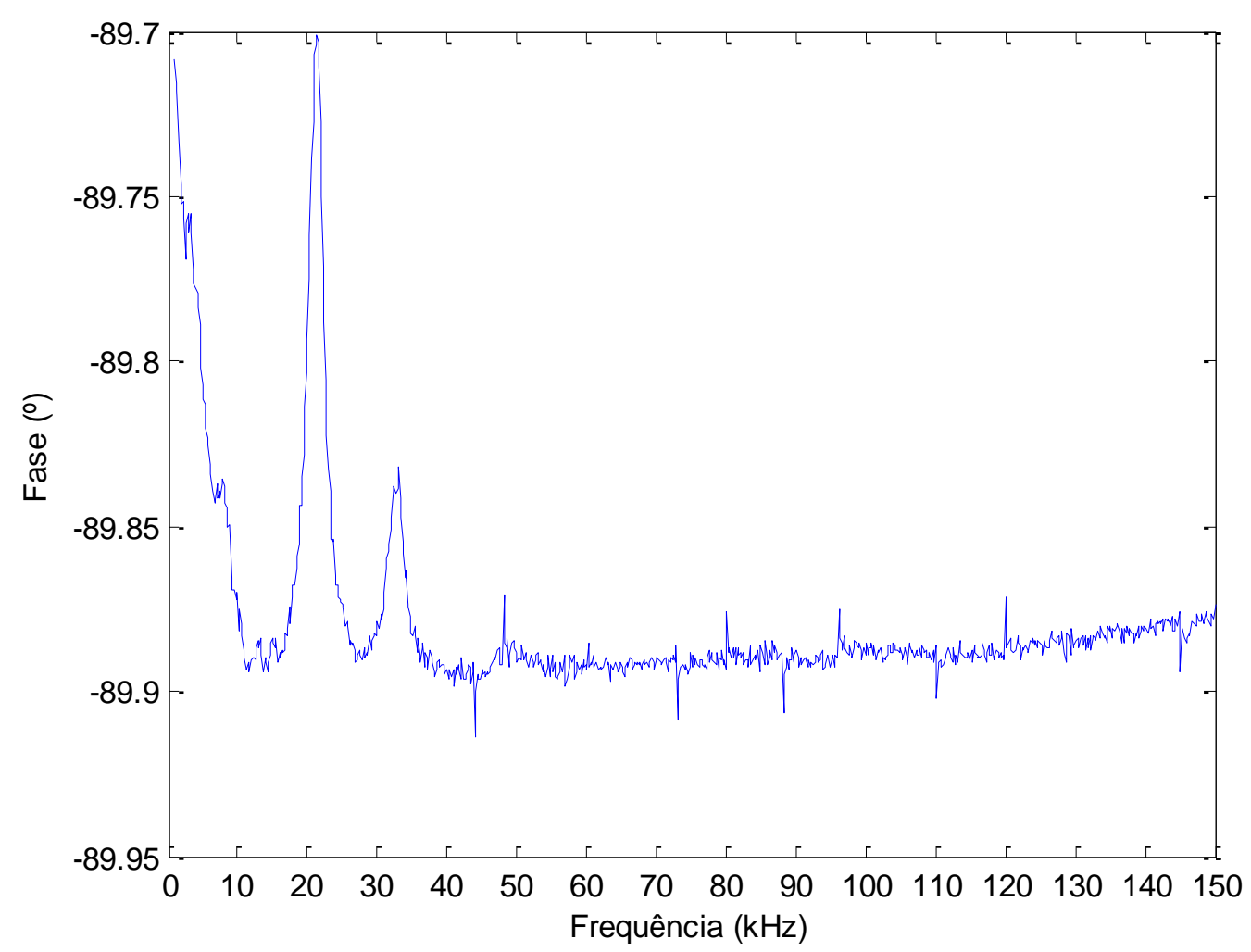

Figura 4.16 - Gráfico da fase pela frequência do piezoeletreto de canaletas com duas ressonâncias.

As figuras referentes à fase das amostras revelaram uma menor variação angular para as amostras de piezoeletretos de canaletas e para filme de PP do que para o filme de PVDF. Enquanto que para as primeiras o pico ressonante não ultrapassou o valor de $-89,7^{\circ}$, para o filme de PVDF o valor máximo do ângulo de fase foi de $-84,5^{\circ}$, aproximadamente. Com essa análise, pode-se concluir que os piezoeletretos apresentam ramos ressonantes cujos valores têm menor interferência na impedância de entrada quando comparados com o filme de PVDF.

Pela análise das medições, observa-se que a frequências de ressonância dos transdutores puderam ser verificadas através das curvas de condutância e de fase. $O$ filme de PVDF apresentou ressonâncias em 35 e 50 kHz, o filme de PP em 513 kHz, enquanto que os piezoeletretos de canaletas com cavidades de 25,50 e $70 \mu \mathrm{m}$ exibiram picos ressonantes em 41, 31 e $28 \mathrm{kHz}$, respectivamente. Por fim, a amostra de piezoeletreto de canaletas com larguras de 2,0 e 2,5 mm, apresentou ressonâncias em 21 e 33 kHz. 


\subsection{Algoritmo para separação das regiões no espectro de frequência}

Apresentadas as medidas, nesta etapa serão detalhados os resultados referentes à aplicação do algoritmo para a separação das regiões próximas e distantes da frequência de ressonância para as medidas de condutância.

Como detalhado no item 3.2, a aplicação do algoritmo tem como resultado a obtenção de duas frequências, chamadas de $\mathrm{f}_{1}$ e $\mathrm{f}_{2}$, as quais são determinadas a partir dos valores calculados da taxa de variação da condutância pela frequência, de acordo com a expressão 3.1. Para cada curva de condutância, determinou-se um valor de $\Delta \mathrm{i}$ que melhor destacasse a região de ressonância nos gráficos das taxas de variação, como observado nas Figuras 4.17 a 4.22 .

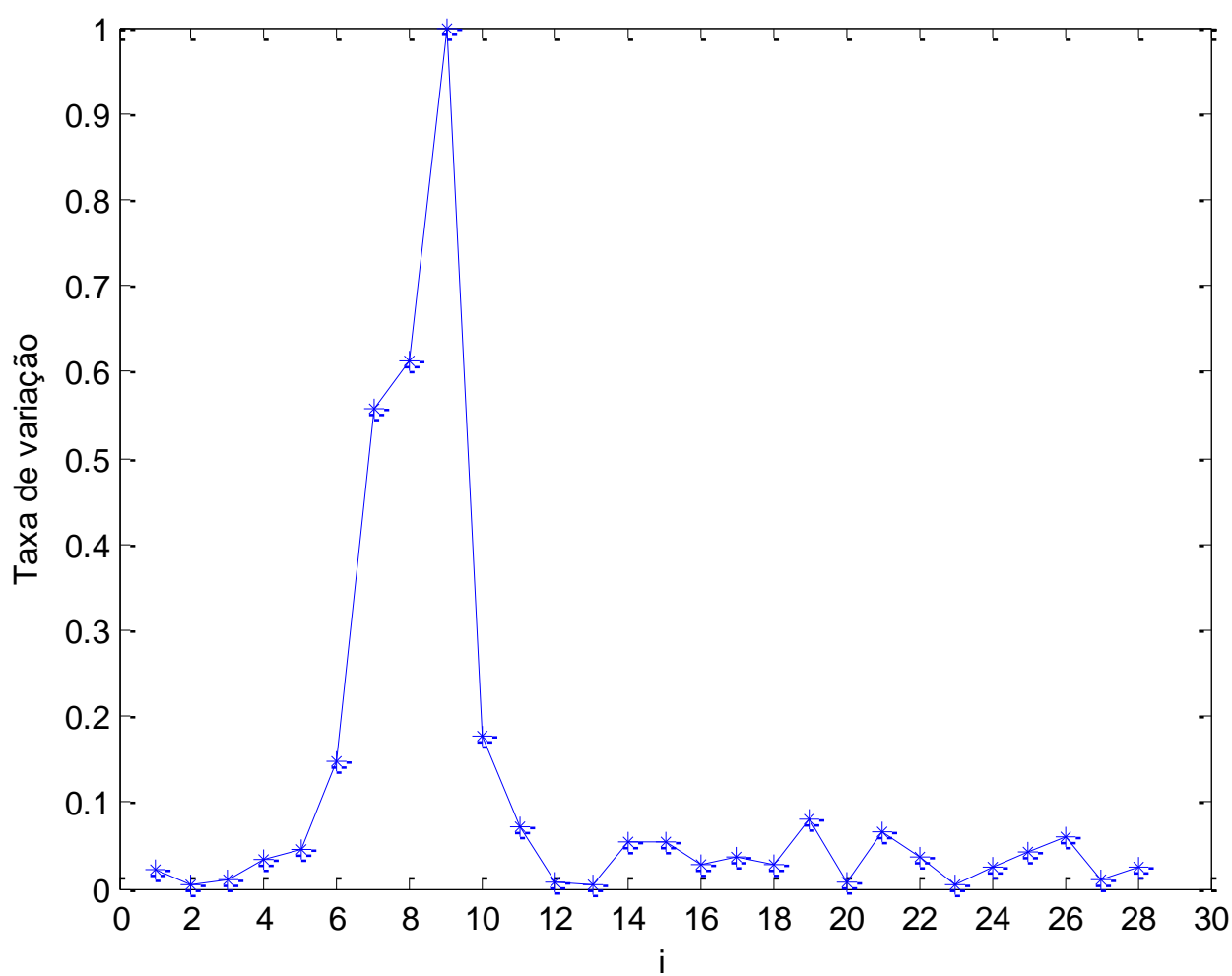

Figura 4.17 - Gráfico da taxa de variação da condutância pela sua posição no vetor medido, com $\Delta \mathrm{i}=28$, para o piezoeletreto de canaletas com cavidades de $25 \mu \mathrm{m}$ de altura. 


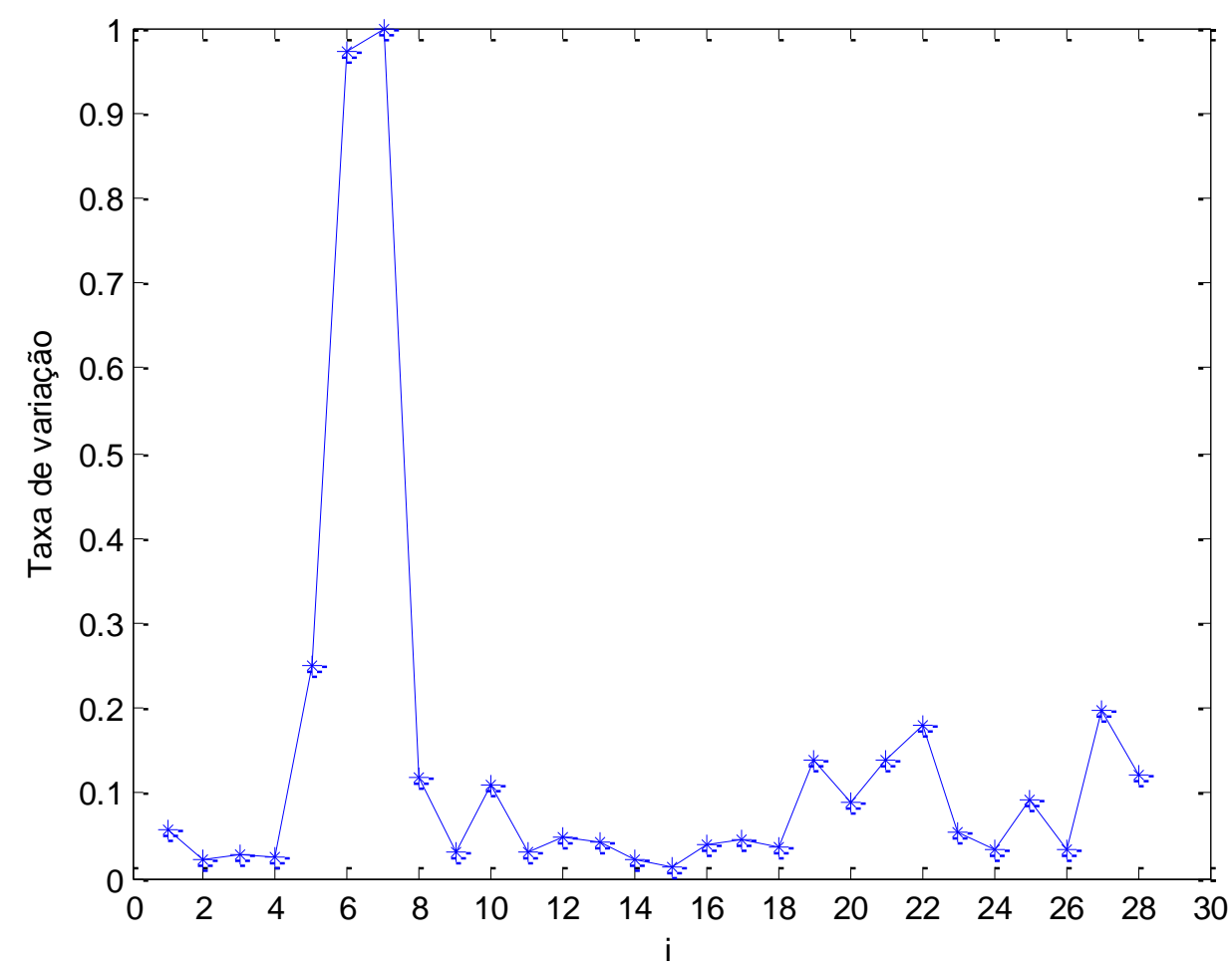

Figura 4.18 - Gráfico da taxa de variação da condutância pela sua posição no vetor medido, $\operatorname{com} \Delta \mathrm{i}=28$, para o piezoeletreto de canaletas com cavidades de $50 \mu \mathrm{m}$ de altura.

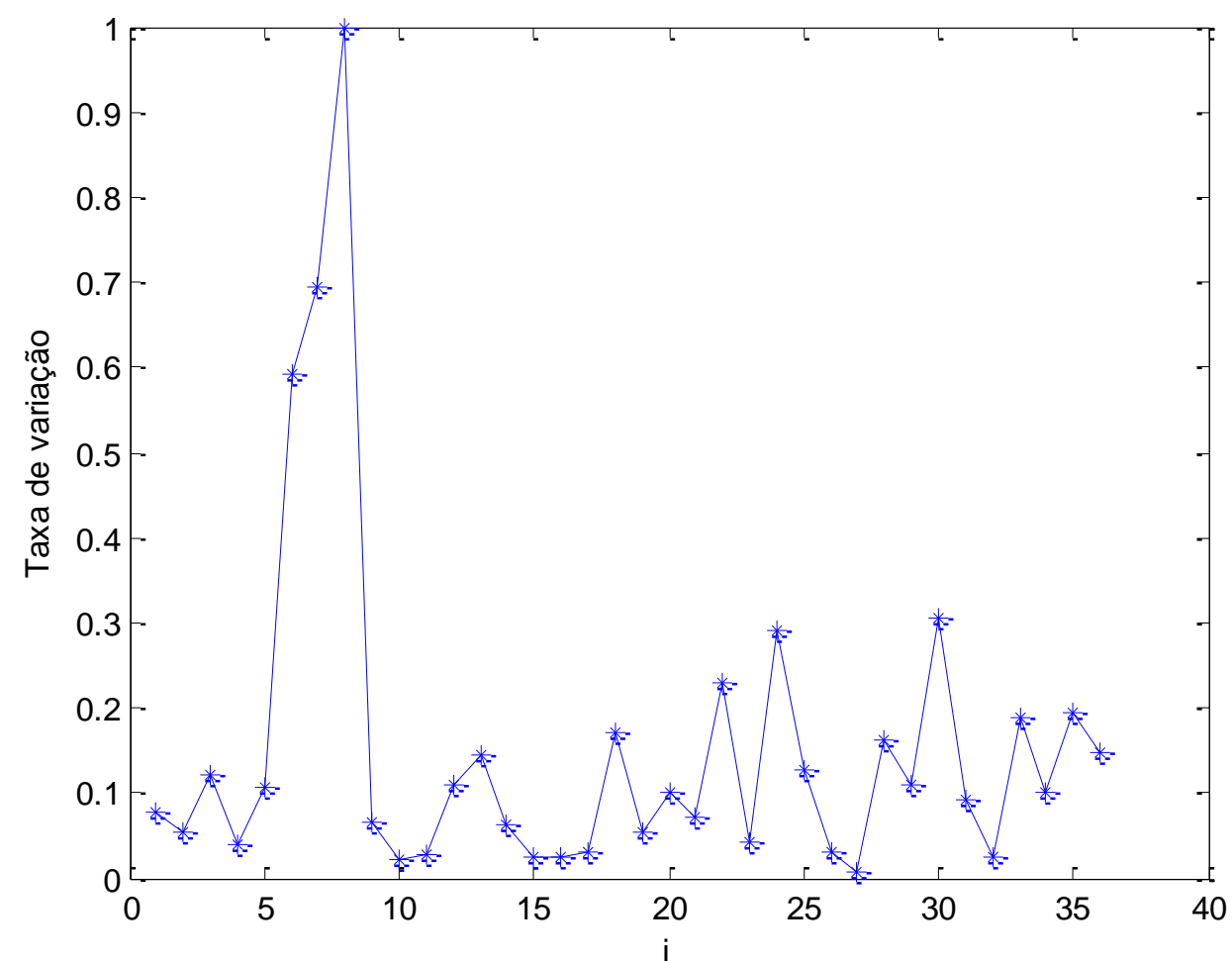

Figura 4.19 - Gráfico da taxa de variação da condutância pela sua posição no vetor medido, $\operatorname{com} \Delta \mathrm{i}=22$, para o piezoeletreto de canaletas com cavidades de $70 \mu \mathrm{m}$ de altura. 


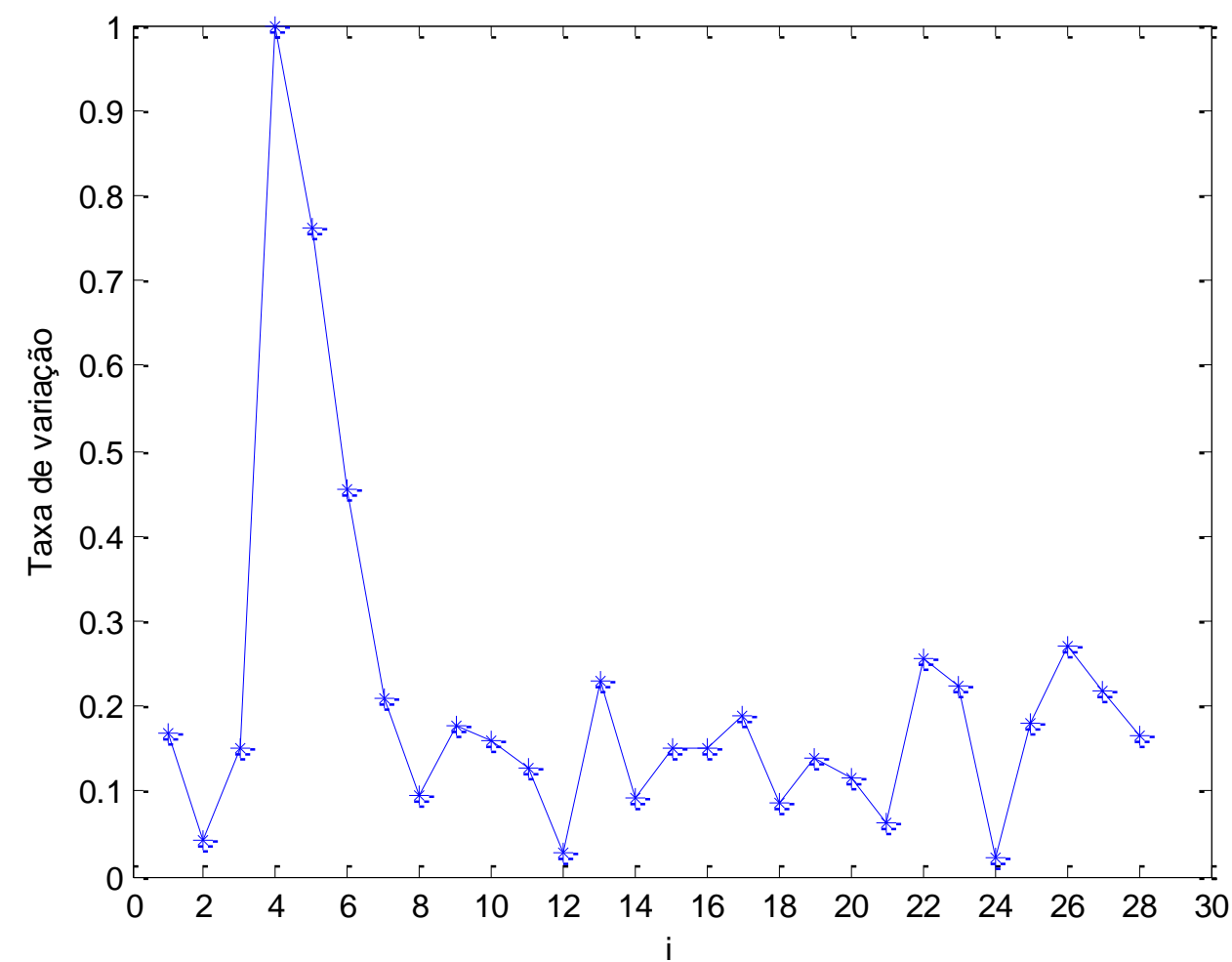

Figura 4.20 - Gráfico da taxa de variação da condutância pela sua posição no vetor medido, $\operatorname{com} \Delta \mathrm{i}=28$, para o piezoeletreto de canaletas com larguras de 2,0 e 2,5 mm.

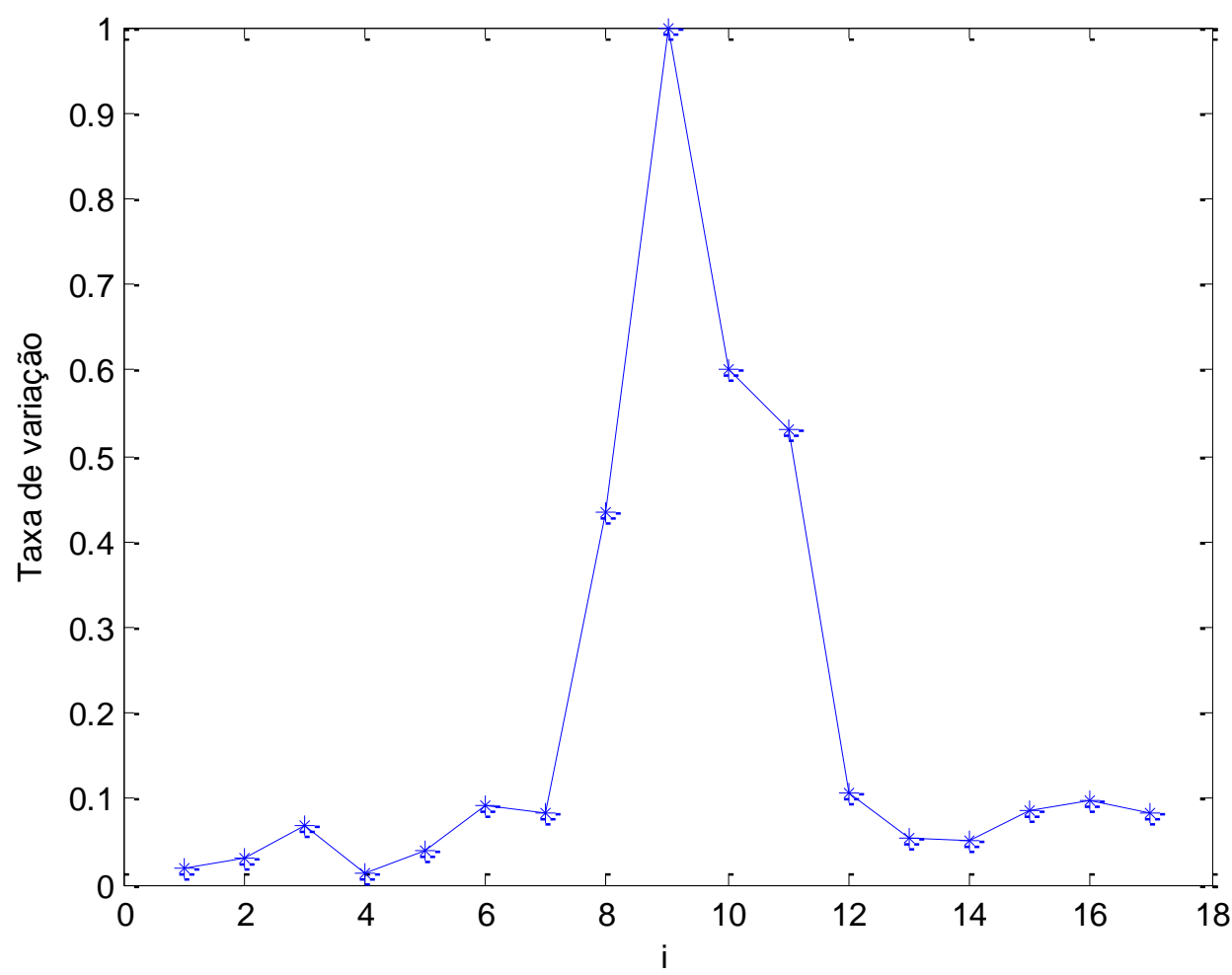

Figura 4.21 - Gráfico da taxa de variação da condutância pela sua posição no vetor medido, $\operatorname{com} \Delta \mathrm{i}=30$, para o filme de PP. 


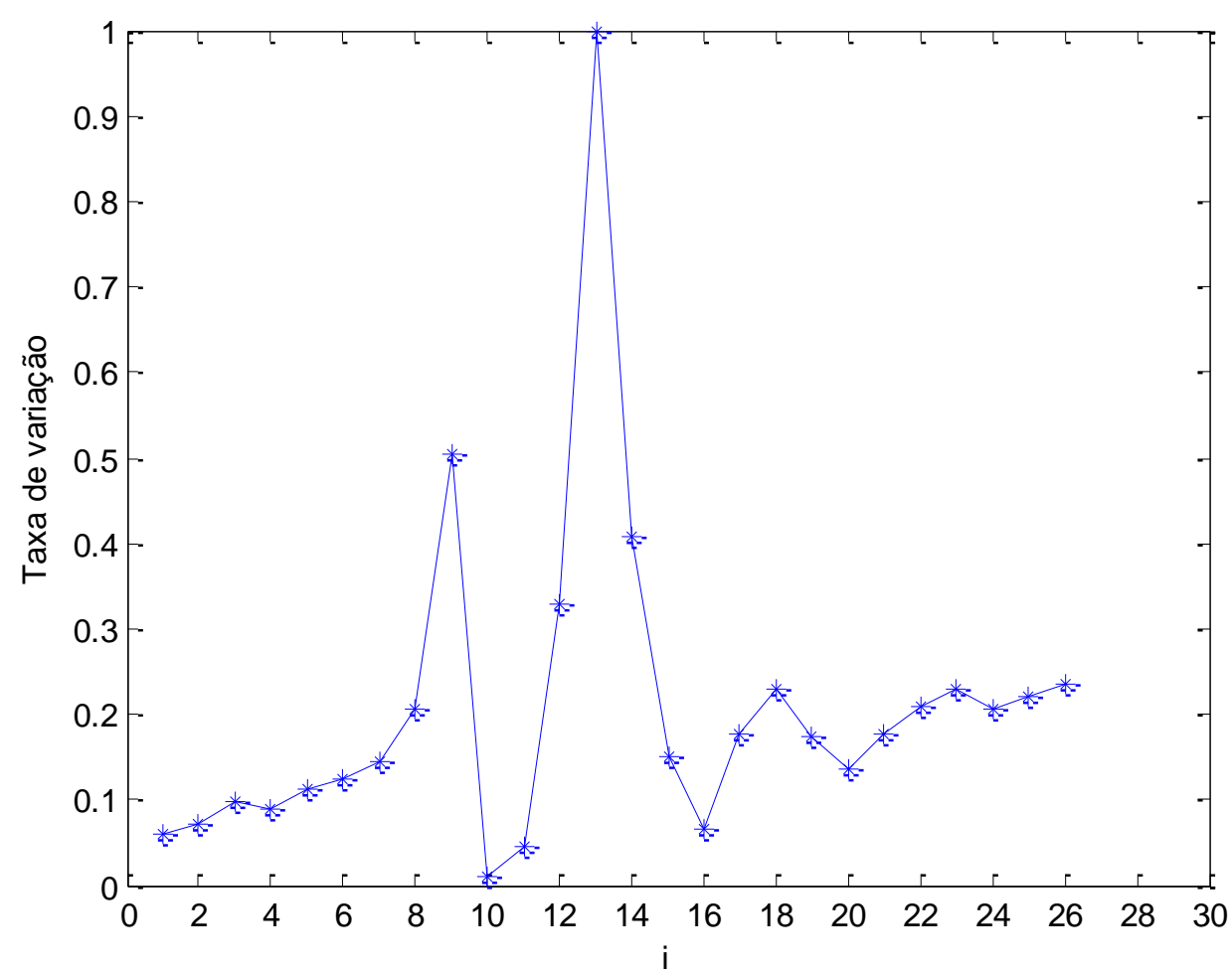

Figura 4.22 - Gráfico da taxa de variação da condutância pela sua posição no vetor medido, com $\Delta \mathrm{i}=20$, para o filme de PVDF.

Pelo fluxograma da Figura 3.6, quando o valor de G'(i) ultrapassa o valor limG (neste caso sendo de 0,4$)$, o valor de $\mathrm{f}_{1}$ é calculado. Continuando com a varredura, o valor de $\mathrm{f}_{2}$ é calculado quando $G^{\prime}(i)$ for novamente menor do que 0,4. A título de exemplo, pela Figura 4.17, o valor de $f_{1}$ foi calculado quando $G^{\prime}(i)$ se encontra na posição $i=7$, enquanto que $f_{2}$ foi calculado para $\mathrm{i}=10$.

Ao se aplicar o algoritmo para as amostras que exibiram duas ressonâncias, escolhendo-se o valor de $\Delta \mathrm{i}=28$ para o piezoeletreto de canaletas, foi possível isolar as duas frequências de ressonância aplicando-se o mesmo procedimento feito com as amostras de única ressonância. Entretanto, para a medida de condutância do PVDF, não houve um valor adequado de $\Delta \mathrm{i}$ que separasse de uma vez a duas ressonâncias. Desta maneira, determinou-se um valor de $\Delta \mathrm{i}=20$ que destacou o gráfico de $\mathrm{G}^{\prime}(\mathrm{i})$ em dois picos distintos, cada um referente a uma ressonância. Assim, pela Figura 4.22, os valores de $f_{1}$ e $f_{2}$ foram determinados para $i=8$ e $\mathrm{i}=15$, respectivamente, separando, assim, a região próxima às duas ressonâncias.

$\mathrm{Na}$ tabela 4.1 constam os valores das frequências $\mathrm{f}_{1}$ e $\mathrm{f}_{2}$ calculados para todos os transdutores. 
Tabela 4.1 - Valores de $\mathrm{f}_{1}$ e $\mathrm{f}_{2}$ determinados a partir das medidas de condutância dos transdutores

\begin{tabular}{ccccccc}
\hline & \multicolumn{7}{c}{ Transdutor } \\
Frequências & FEP & FEP & FEP & FEP & PP & PVDF \\
& $\mathbf{2 5} \boldsymbol{\mu m}$ & $\mathbf{5 0} \boldsymbol{\mu m}$ & $\mathbf{7 0} \boldsymbol{\mu m}$ & $\mathbf{2 , 0 - 2 , 5 ~} \mathbf{~ m m}$ & & \\
\hline $\mathbf{f}_{\mathbf{1}}(\mathbf{k H z})$ & 26,89 & 21,67 & 16,46 & 11,24 & 336,40 & 26,89 \\
$\mathbf{f}_{\mathbf{2}}(\mathbf{k H z})$ & 56,96 & 42,53 & 37,32 & 37,32 & 673,68 & 52,96 \\
\hline \hline
\end{tabular}

Determinados os valores de $\mathrm{f}_{1}$ e $\mathrm{f}_{2}$, o procedimento seguinte compreendeu a remoção dos pontos das curvas de condutância e de susceptância compreendidos entre estes valores.

\subsection{Determinação dos parâmetros dos circuitos elétrico e mecânico}

Neste item, serão apresentados os resultados referentes à determinação dos componentes dos circuitos equivalentes das amostras. Primeiramente, foram determinados os componentes do ramo elétrico do circuito mostrado na Figura 3.7. Após a subtração dos pontos próximos à ressonância das curvas de condutância e de susceptância, os dados foram obtidos pelo ajuste não linear das curvas às expressões 3.3 e 3.4. Nas Figuras 4.23 a 4.28 encontram-se os resultados dos ajustes das curvas de condutância para n=1, n=2 e n=3, sendo $\mathrm{n}$ o número de ramos $\mathrm{RC}$ presente no circuito da parte elétrica, em que foram determinados os parâmetros $\mathrm{R}_{\mathrm{i}}$ e $\mathrm{C}_{\mathrm{i}}$ da expressão 3.3. 


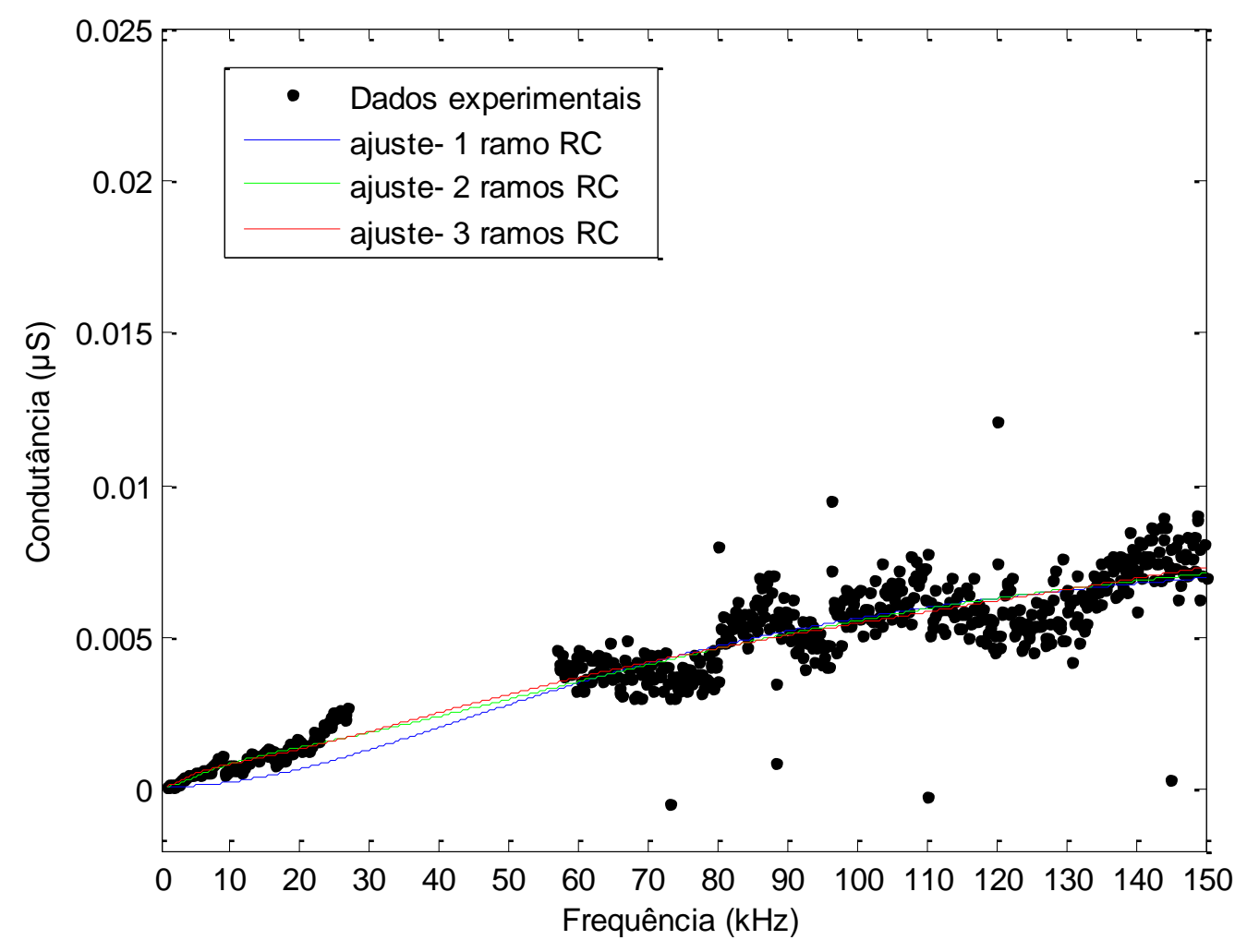

Figura 4.23 - Ajustes da curva de condutância para a amostra de piezoeletreto com canaletas de $25 \mu \mathrm{m}$ de altura.

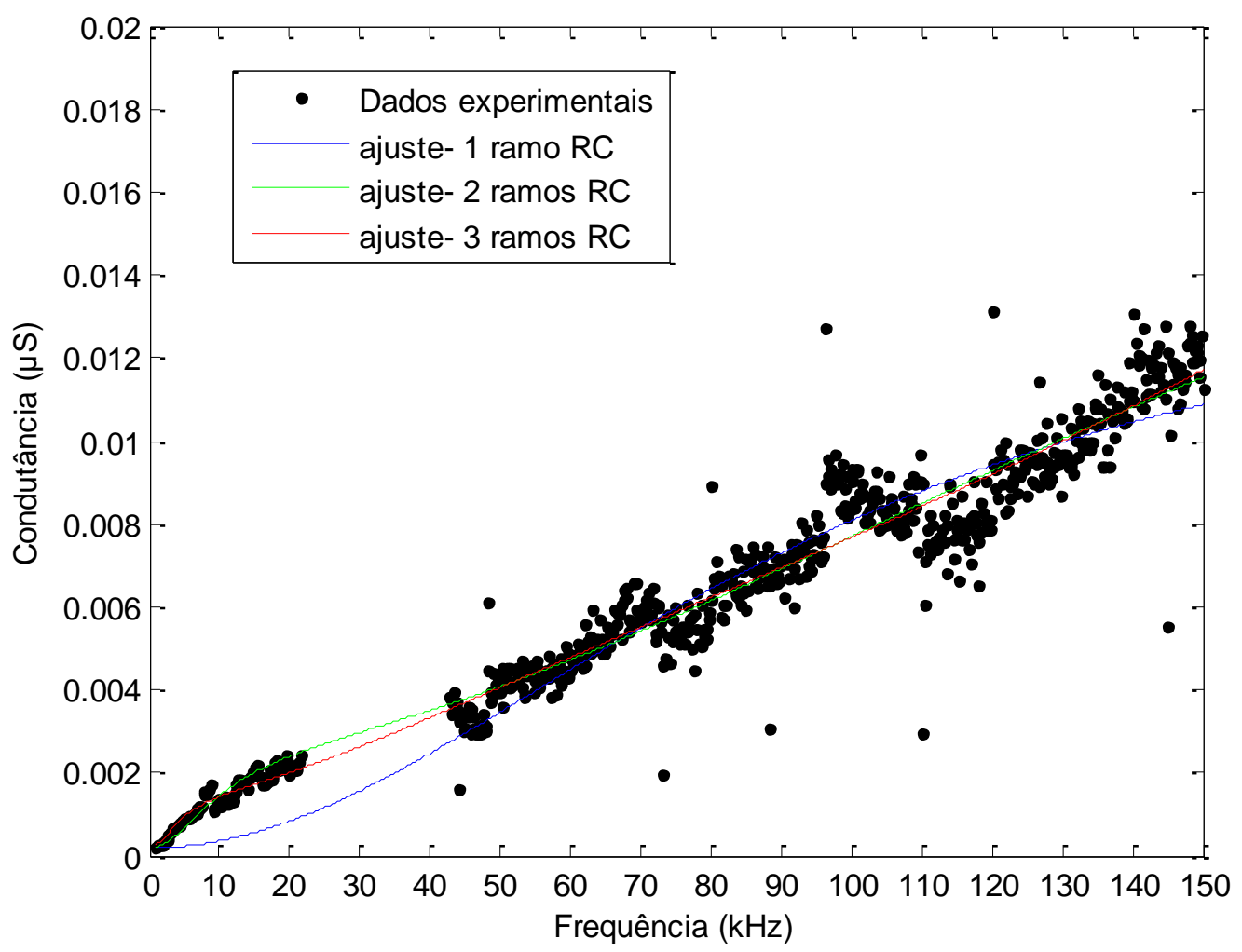

Figura 4.24 - Ajustes da curva de condutância para a amostra de piezoeletreto com canaletas de $50 \mu \mathrm{m}$ de altura. 


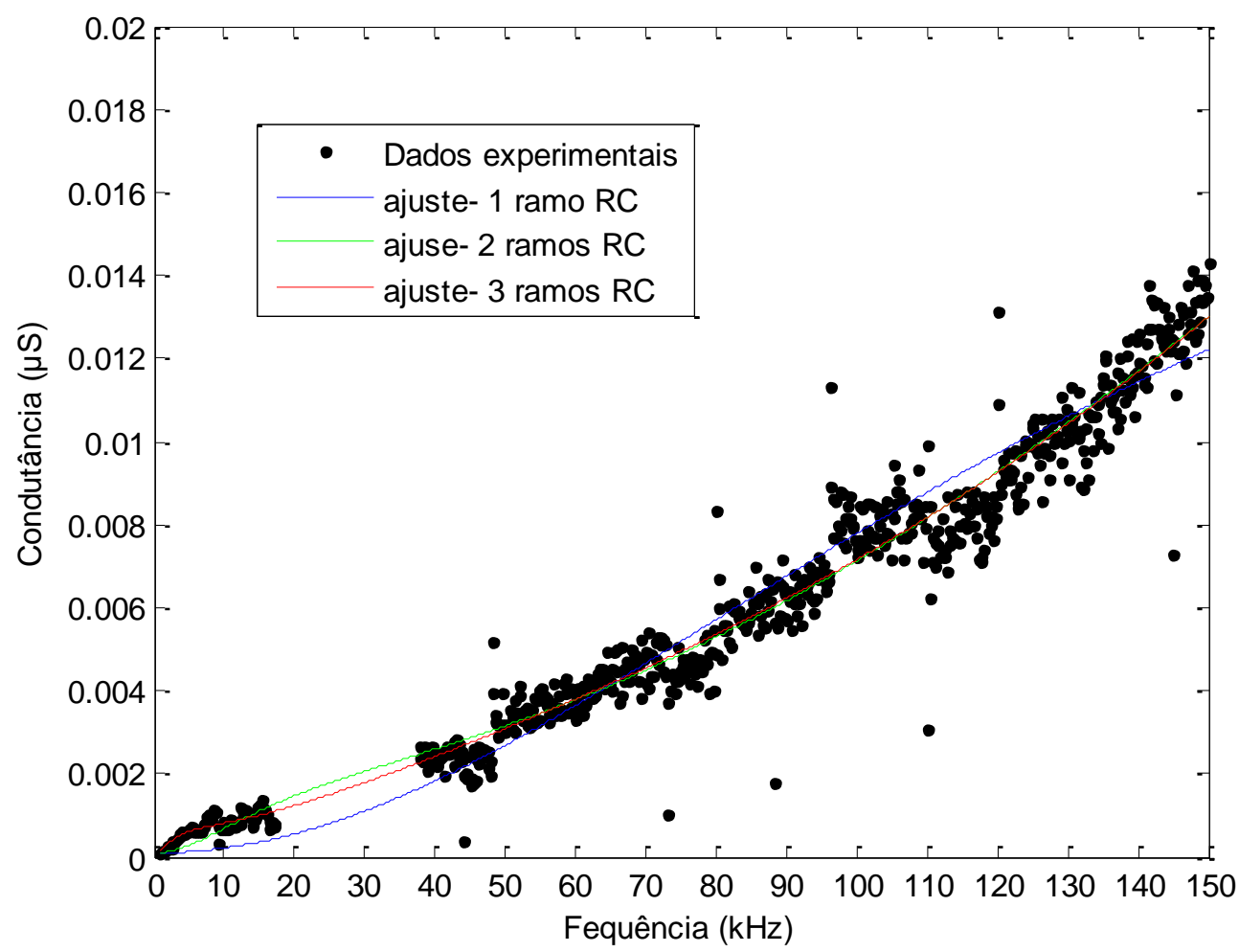

Figura 4.25 - Ajustes da curva de condutância para a amostra de piezoeletreto com canaletas de $70 \mu \mathrm{m}$ de altura.

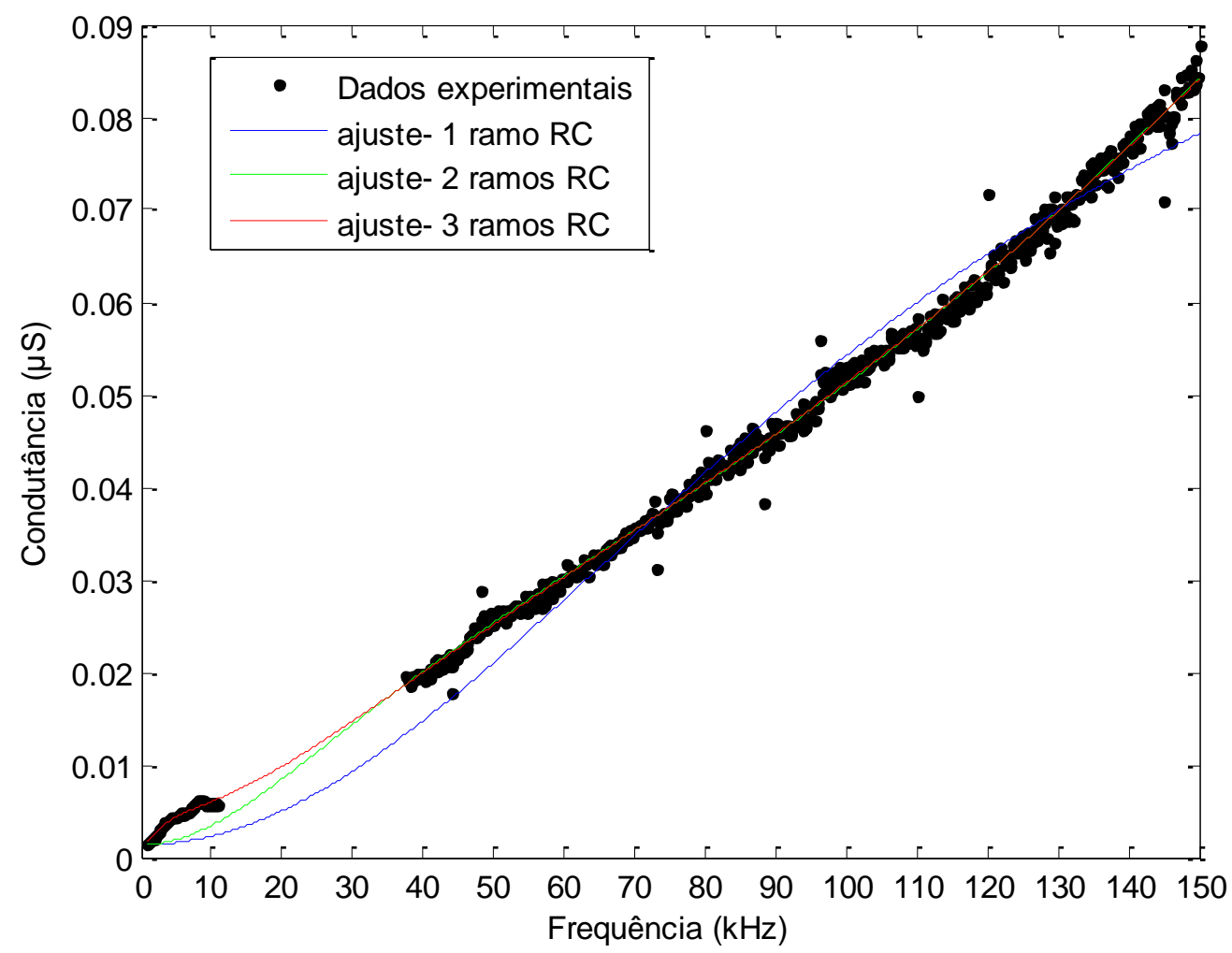

Figura 4.26 - Ajustes da curva de condutância para a amostra de piezoeletreto com canaletas de 2,0-2,5 mm de largura. 


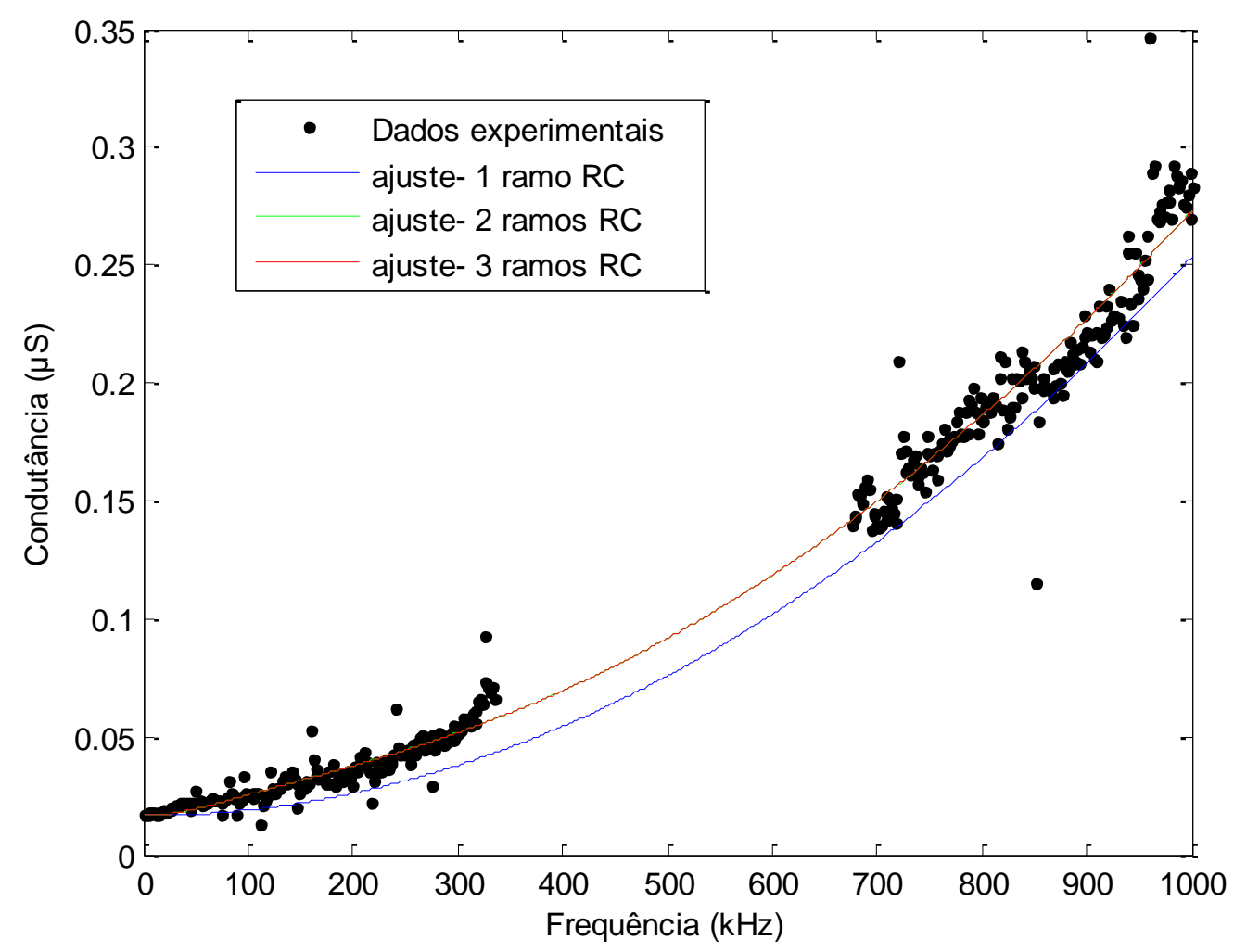

Figura 4.27 - Ajustes da curva de condutância para o filme de PP.

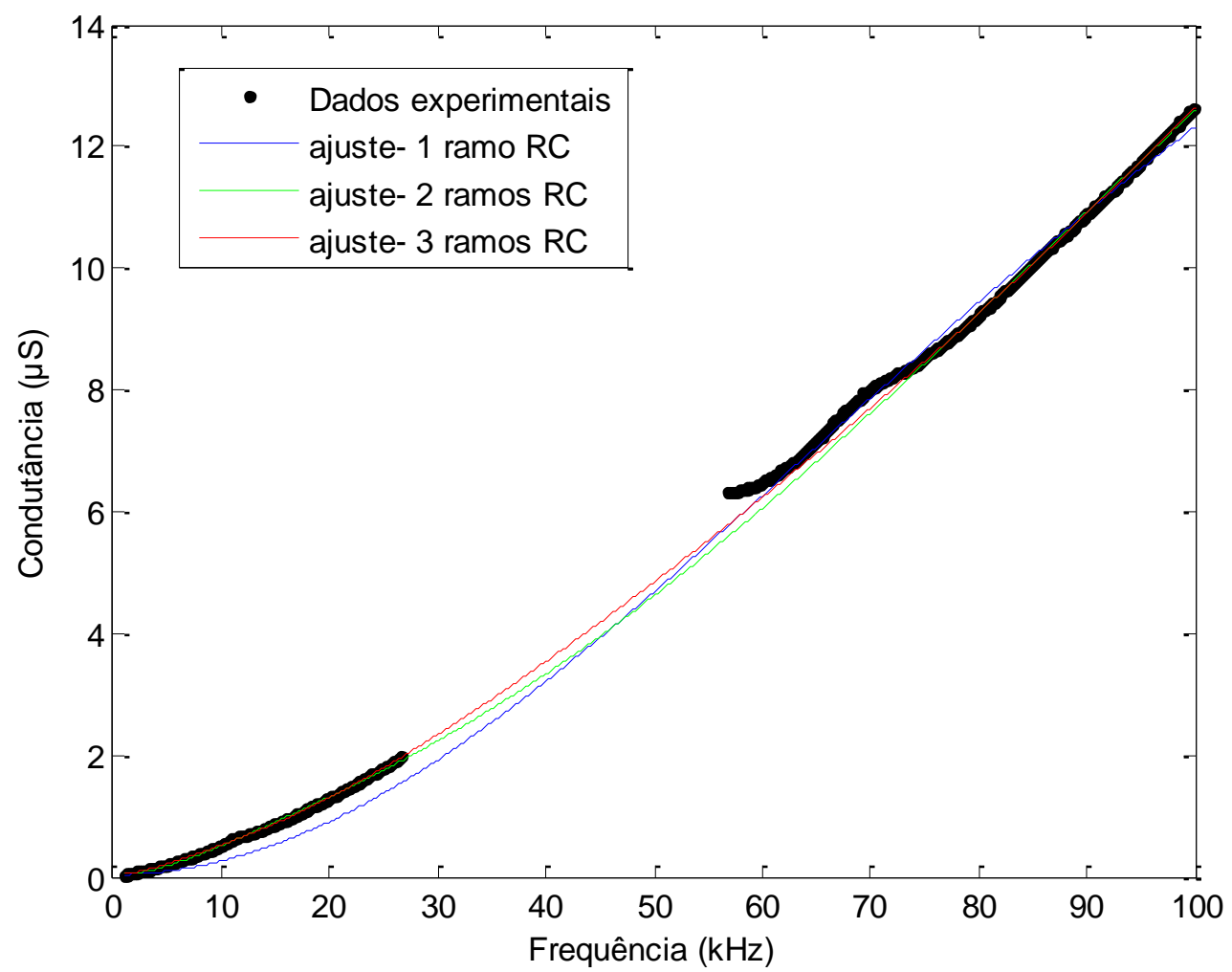

Figura 4.28 - Ajustes da curva de condutância para o filme de PVDF. 
O mesmo procedimento foi repetido para as curvas de susceptância, a partir das quais foram determinados os valores de $\mathrm{C}_{\mathrm{p}}$. Nas tabelas 4.2 , 4.3 e 4.4 estão presentes os valores dos componentes obtidos com os ajustes do circuito da parte elétrica com um, dois e três ramos RC paralelos.

Tabela 4.2 - Parâmetros do circuito elétrico com 1 ramo RC paralelo

\begin{tabular}{ccccc}
\hline \hline Transdutor & $\begin{array}{c}\mathbf{R}_{\mathbf{p}} \\
\left(\mathbf{x 1 0}^{\mathbf{9}} \mathbf{\Omega}\right)\end{array}$ & $\begin{array}{c}\mathbf{C}_{\mathbf{p}} \\
\left(\mathbf{x 1 0}^{-12} \mathbf{F}\right)\end{array}$ & $\begin{array}{c}\mathbf{R}_{\mathbf{1}} \\
\left(\mathbf{x 1 0}^{\mathbf{9}} \mathbf{\Omega}\right)\end{array}$ & $\begin{array}{c}\mathbf{C}_{\mathbf{1}} \\
\left(\mathbf{x 1 0}^{-\mathbf{1 2}} \mathbf{F}\right)\end{array}$ \\
\hline FEP 25 $\boldsymbol{\mu m}$ & 10,77 & 29,76 & 0,12 & 0,018 \\
FEP 50 $\boldsymbol{\mu m}$ & 5,32 & 26,71 & 0,067 & 0,025 \\
FEP 70 $\boldsymbol{\mu m}$ & 10,57 & 26,09 & 0,044 & 0,026 \\
FEP 2,0-2,5 $\mathbf{~ m m}$ & 0,73 & 42,17 & 0,0082 & 0,17 \\
PP & 0,061 & 50,20 & 0,00000073 & 2,87 \\
PVDF & 0,029 & 257,79 & 0,000037 & 0,39 \\
\hline \hline
\end{tabular}

Tabela 4.3 - Parâmetros do circuito elétrico com 2 ramos RC paralelos

\begin{tabular}{ccccccc}
\hline \hline Transdutor & $\begin{array}{c}\mathbf{R}_{\mathbf{p}} \\
\left(\mathbf{x 1 0}^{\mathbf{9}} \mathbf{\Omega}\right)\end{array}$ & $\begin{array}{c}\mathbf{C}_{\mathbf{p}} \\
\left(\mathbf{x 1 0}^{\mathbf{- 1 2}} \mathbf{F}\right)\end{array}$ & $\begin{array}{c}\mathbf{R}_{\mathbf{1}} \\
\left(\mathbf{x 1 0}^{\mathbf{9}} \mathbf{\Omega}\right)\end{array}$ & $\begin{array}{c}\mathbf{C}_{\mathbf{1}} \\
\left(\mathbf{x 1 0}^{-12} \mathbf{F}\right)\end{array}$ & $\begin{array}{c}\mathbf{R}_{\mathbf{2}} \\
\left(\mathbf{x 1 0}^{\mathbf{9}} \mathbf{\Omega}\right)\end{array}$ & $\begin{array}{c}\mathbf{C}_{\mathbf{2}} \\
\left(\mathbf{x 1 0}^{-12} \mathbf{F}\right)\end{array}$ \\
\hline FEP 25 $\boldsymbol{\mu m}$ & 10,77 & 29,76 & 0,91 & 0,022 & 0,12 & 0,014 \\
FEP 50 $\boldsymbol{\mu m}$ & 5,32 & 26,71 & 0,40 & 0,038 & 0,045 & 0,019 \\
FEP 70 $\boldsymbol{\mu m}$ & 10,57 & 26,07 & 0,53 & 0,019 & 0,0088 & 0,040 \\
FEP 2,0-2,5 $\mathbf{~ m m}$ & 0,73 & 41,91 & 0,00057 & 0,34 & 0,037 & 0,12 \\
$\mathbf{P P}$ & 0,061 & 50,81 & 0,063 & 0,021 & 0,0000019 & 2,26 \\
PVDF & 0,029 & 250,05 & 0,0010 & 10,66 & 0,000024 & 41,03 \\
\hline \hline
\end{tabular}

Tabela 4.4 - Parâmetros do circuito elétrico com 3 ramos RC paralelos

\begin{tabular}{ccccccccc}
\hline \hline Transdutor & $\begin{array}{c}\mathbf{R}_{\mathbf{p}} \\
\left(\mathbf{x 1 0}^{\mathbf{9}} \mathbf{\Omega}\right)\end{array}$ & $\begin{array}{c}\mathbf{C}_{\mathbf{p}} \\
\left(\mathbf{x 1 0}^{-\mathbf{1 2}} \mathbf{F}\right)\end{array}$ & $\begin{array}{c}\mathbf{R}_{\mathbf{1}} \\
\left(\mathbf{x 1 0}^{\mathbf{9}} \mathbf{\Omega}\right)\end{array}$ & $\begin{array}{c}\mathbf{C}_{\mathbf{1}} \\
\left(\mathbf{x 1 0}^{-12} \mathbf{F}\right)\end{array}$ & $\begin{array}{c}\mathbf{R}_{\mathbf{2}} \\
\left(\mathbf{x 1 0}^{\mathbf{9}} \mathbf{\Omega}\right)\end{array}$ & $\begin{array}{c}\mathbf{C}_{2} \\
\left(\mathbf{x 1 0}^{-12} \mathbf{F}\right)\end{array}$ & $\begin{array}{c}\mathbf{R}_{\mathbf{3}} \\
\left(\mathbf{x 1 0}^{\mathbf{3}} \mathbf{\Omega}\right)\end{array}$ & $\begin{array}{c}\mathbf{C}_{\mathbf{3}} \\
\left(\mathbf{x 1 0}^{-\mathbf{1 2}} \mathbf{F}\right)\end{array}$ \\
\hline FEP 25 $\boldsymbol{\mu m}$ & 10,77 & 29,62 & 1,38 & 0,036 & 0,020 & 0,013 & 120,65 & 0,14 \\
FEP 50 $\boldsymbol{\mu m}$ & 5,32 & 26,32 & 0,76 & 0,045 & 0,21 & 0,012 & 43,04 & 0,40 \\
FEP 70 $\boldsymbol{\mu m}$ & 10,57 & 25,61 & 1,64 & 0,025 & 0,41 & 0,0081 & 46,40 & 0,49 \\
FEP 2,0-2,5 $\mathbf{~ m m}$ & 0,73 & 40,42 & 0,28 & 0,20 & 0,036 & 0,09 & 18,60 & 1,81 \\
$\quad$ PP & 0,061 & 52,25 & 0,064 & 0,021 & 0,000018 & 0,41 & 17,83 & 0,42 \\
PVDF & 0,029 & 220,13 & 0,00022 & 14,05 & 0,0029 & 7,49 & 6,33 & 60,59 \\
\hline \hline
\end{tabular}


Verificando-se os resultados dos ajustes das Figuras 4.23 a 4.28, percebe-se que, de maneira geral, a adição dos ramos RC resultou em um melhor ajuste da expressão teórica de condutância aos dados experimentais, principalmente para as frequências menores.

Obtidos os parâmetros da parte elétrica do modelo, a etapa seguinte consistiu da determinação dos parâmetros do ramo mecânico. Para isso, foram obtidas, primeiramente, funções polinomiais de ajuste das curvas de condutância para as frequências distantes da ressonância, como indicado na Figura 4.29. A seguir, foi feita a subtração ponto a ponto dos dados experimentais pela função polinomial. Na Figura 4.30 é mostrado o resultado desta subtração para a amostra de piezoeletreto de canaletas com cavidades de $70 \mu \mathrm{m}$ de altura.

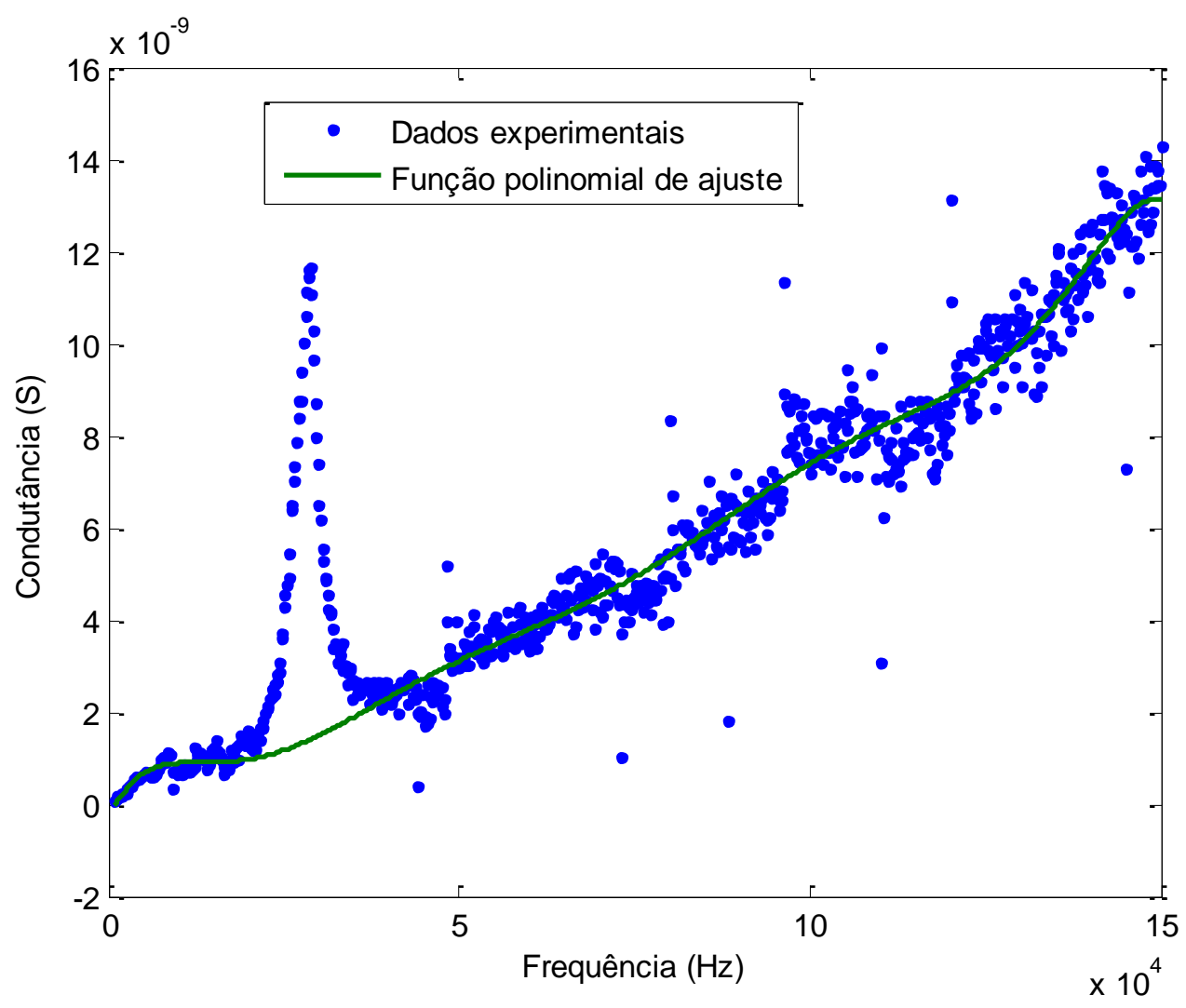

Figura 4.29 - Gráficos da condutância do piezoeletreto de canaletas (70 $\mu \mathrm{m})$ e da função polinomial de ajuste para frequências distantes da ressonância. 


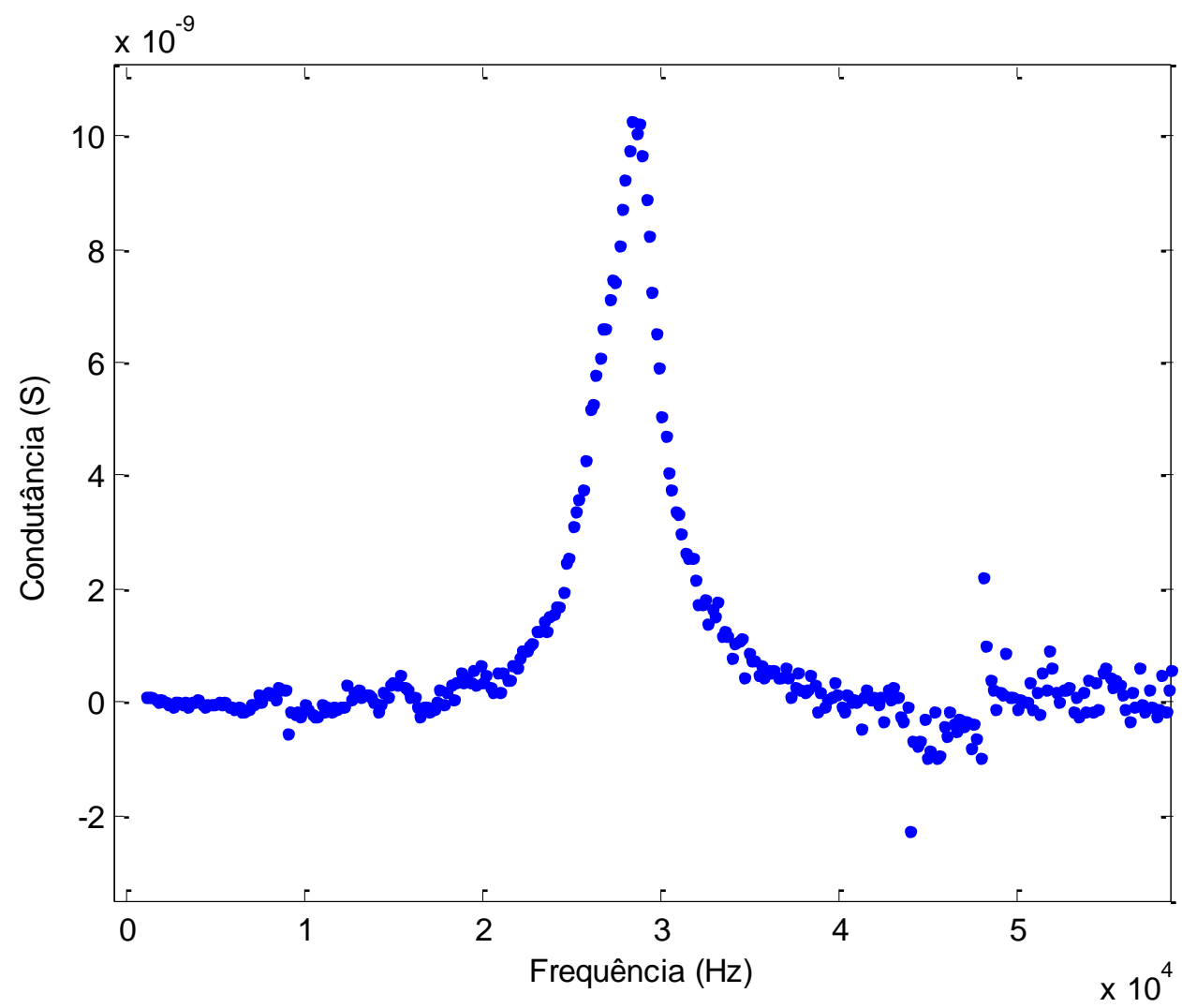

Figura 4.30 - Resultado da subtração ponto a ponto dos dados experimentais pela função polinomial de ajuste dos pontos distantes da ressonância para o piezoeletreto de canaletas de $70 \mu \mathrm{m}$ de altura.

O objetivo destas subtrações foi isolar, de maneira aproximada, o comportamento da parte mecânica do modelo. Assim, para se determinar os componentes dos circuitos RLC mecânicos, aplicou-se o ajuste não linear dos resultados das subtrações à expressão de condutância, obtida em 3.7. Os resultados gráficos destes ajustes estão nas Figuras 4.31 a 4.36 . 


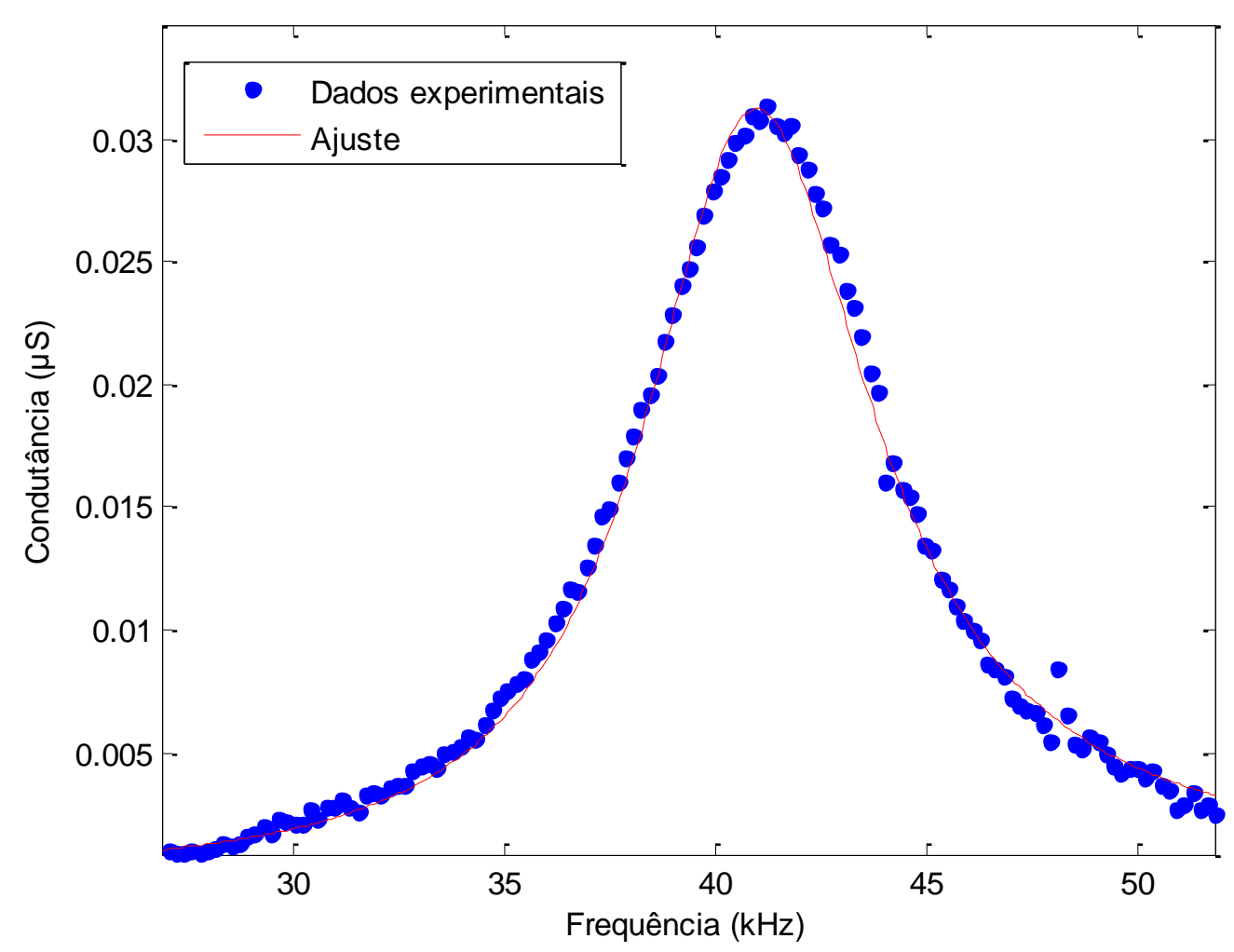

Figura 4.31 - Ajuste do ramo mecânico do piezoeletreto de canaletas $25 \mu \mathrm{m}$ de altura.

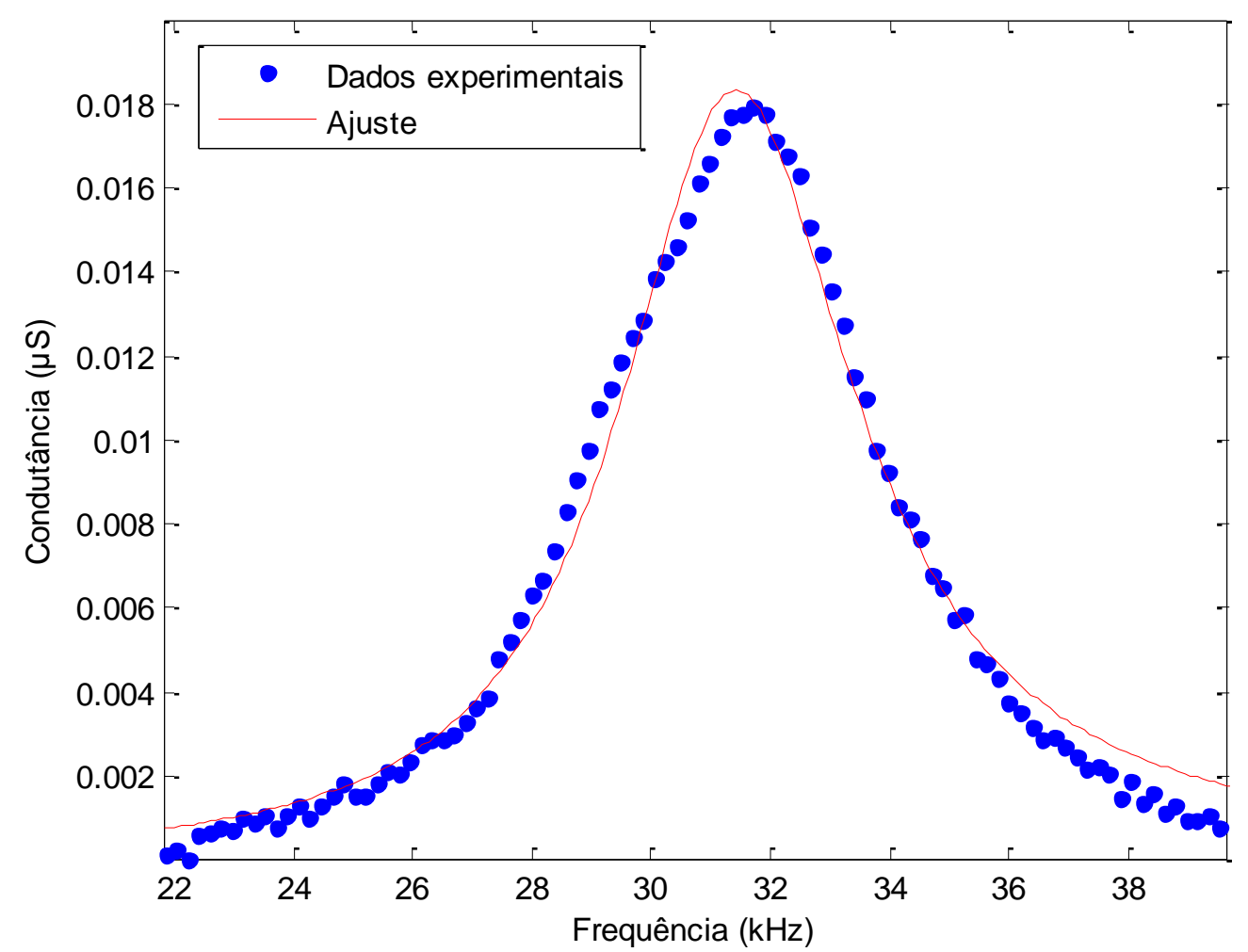

Figura 4.32 - Ajuste do ramo mecânico do piezoeletreto de canaletas $50 \mu \mathrm{m}$ de altura. 


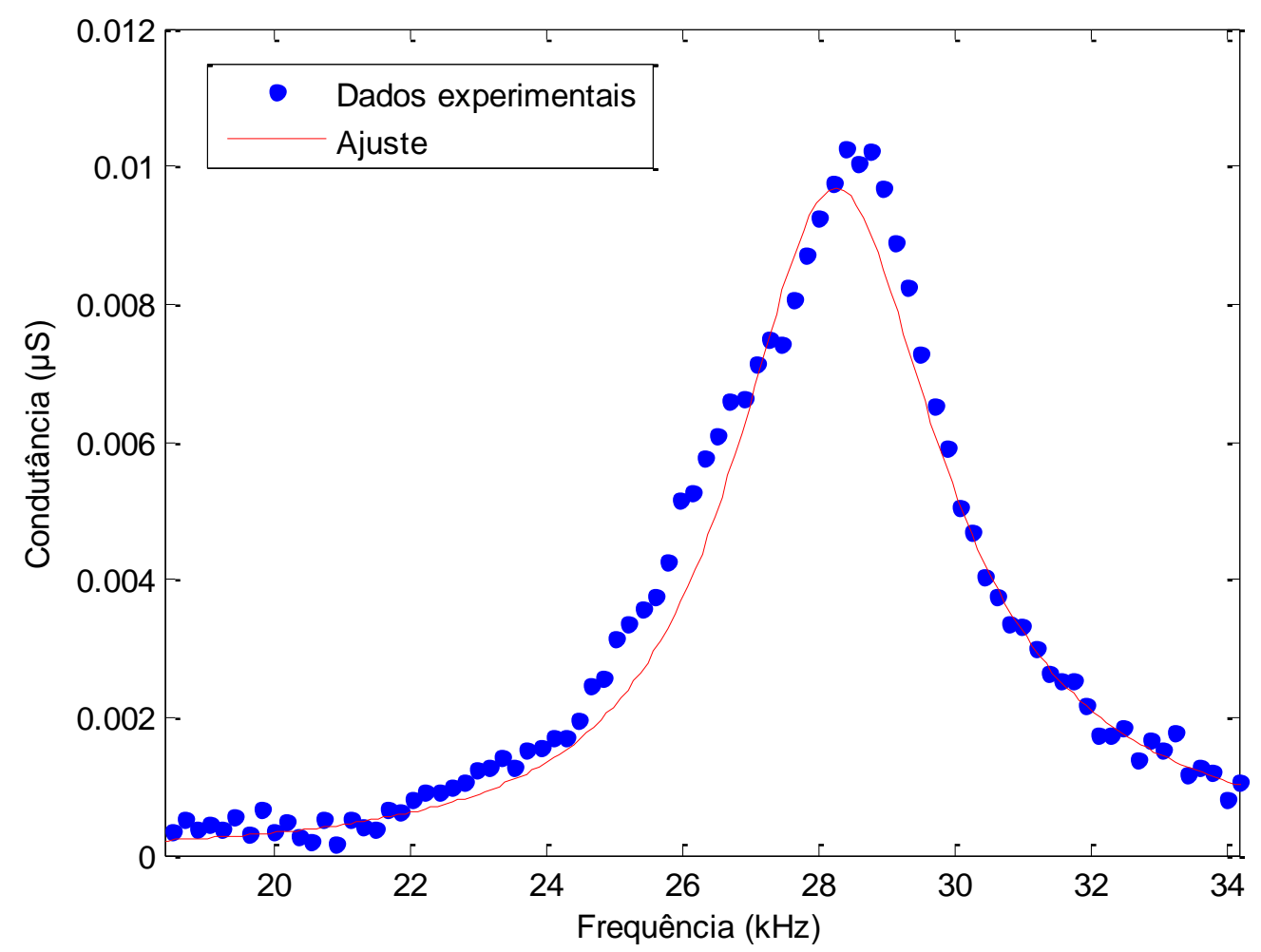

Figura 4.33 - Ajuste do ramo mecânico do piezoeletreto de canaletas $70 \mu \mathrm{m}$ de altura.

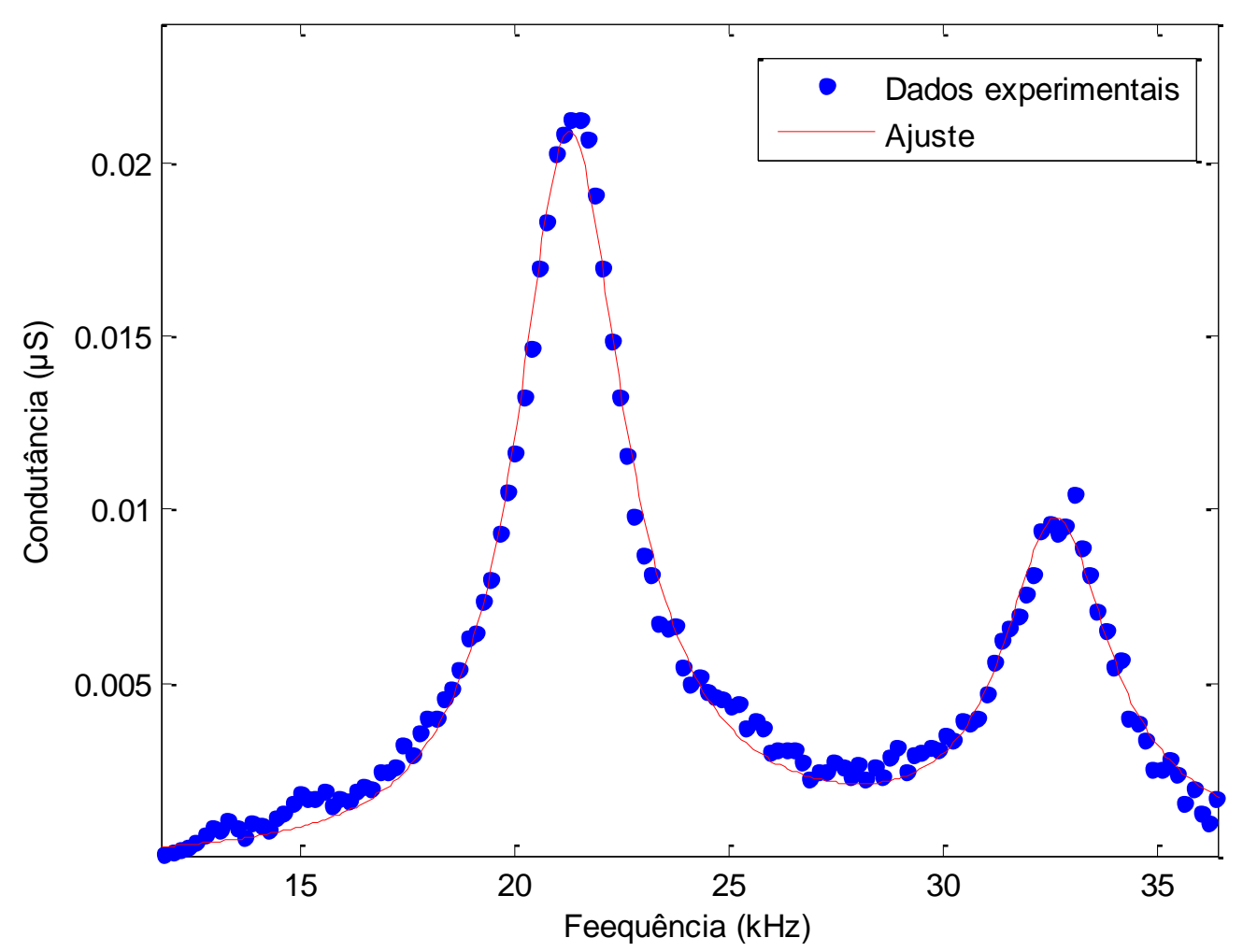

Figura 4.34 - Ajuste do ramo mecânico do piezoeletreto de canaletas com 2,0-2,5 mm de largura. 


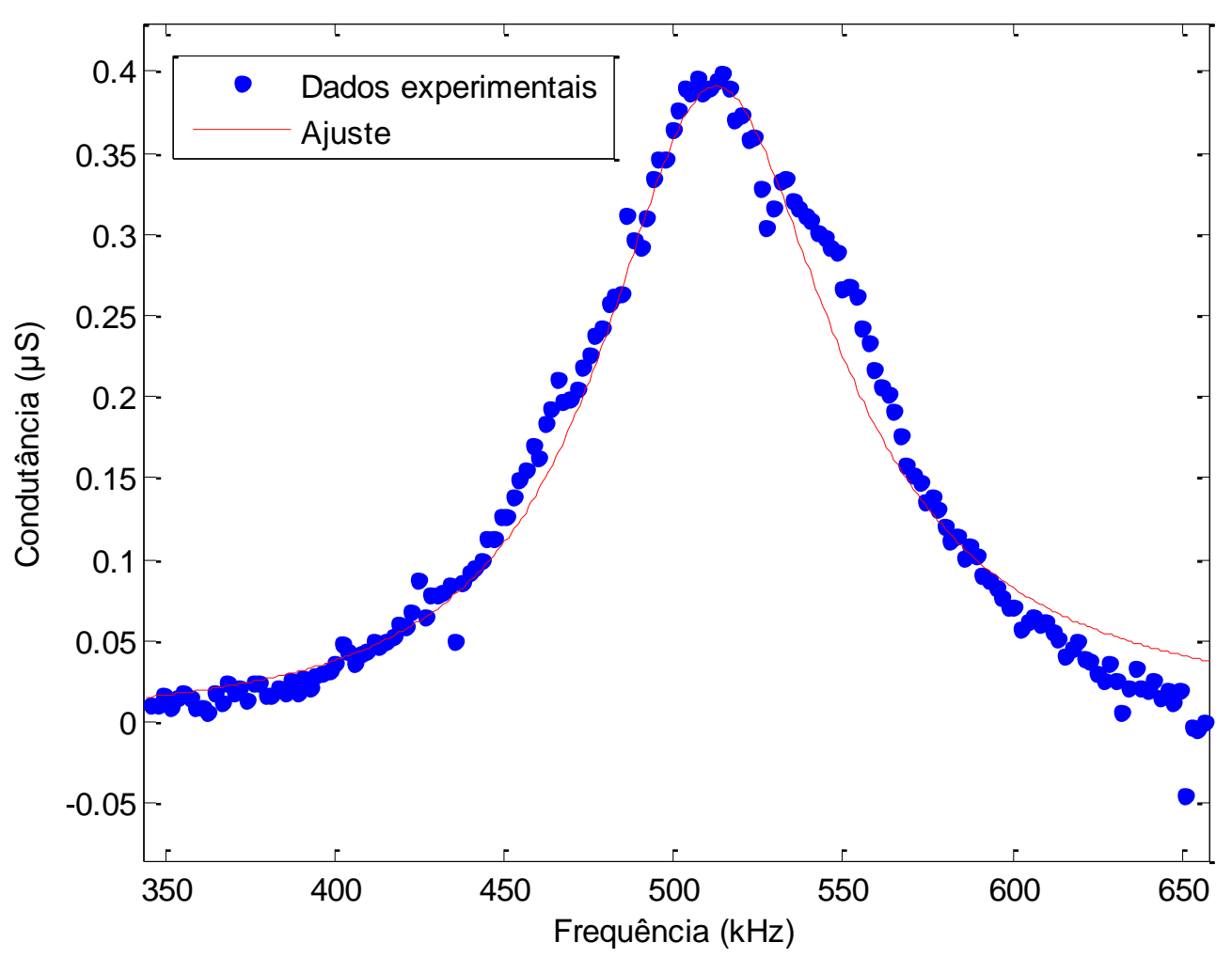

Figura 4.35 - Ajuste do ramo mecânico do filme de PP.

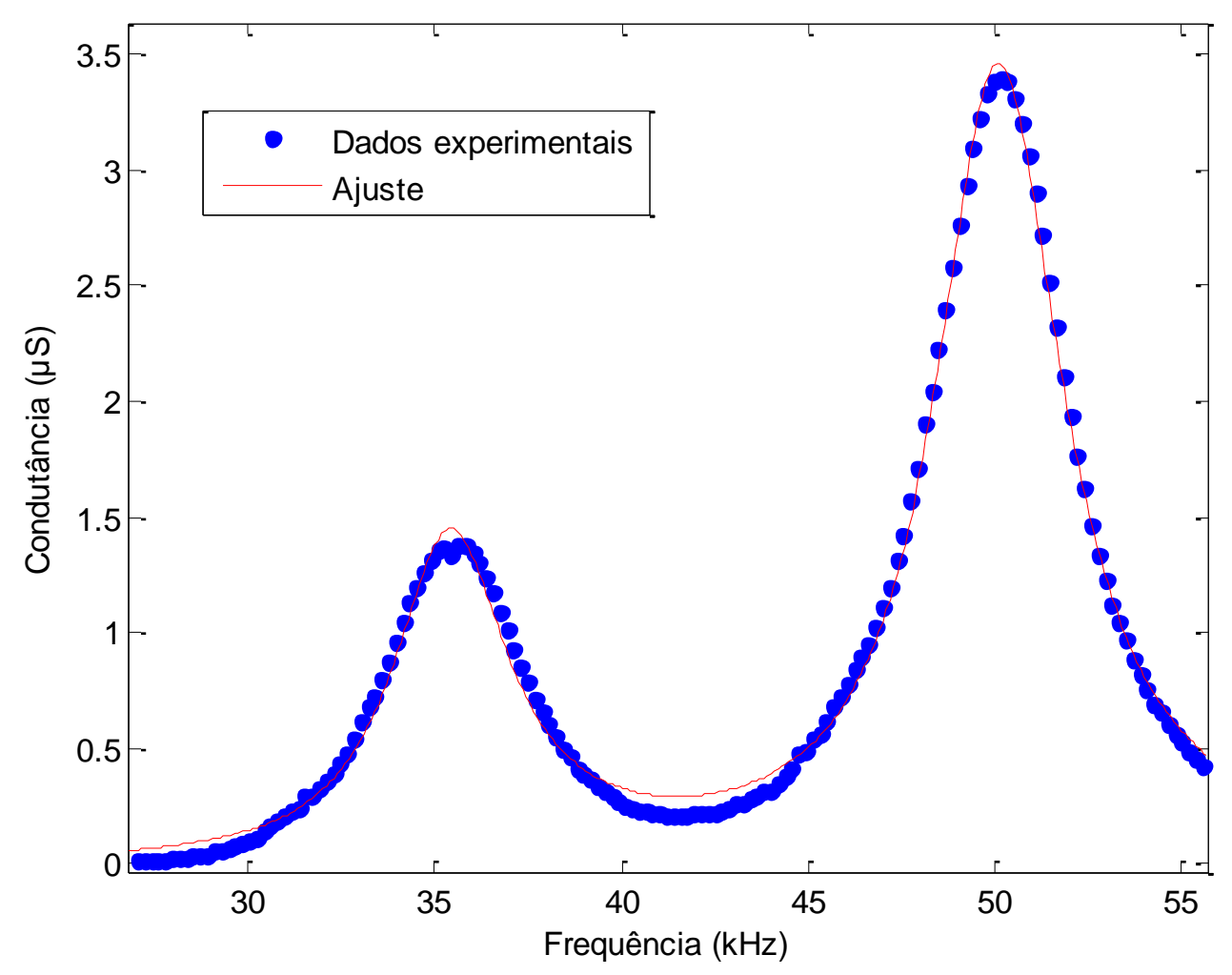

Figura 4.36 - Ajuste do ramo mecânico do filme de PVDF. 
Como se observa nas Figuras 4.34 e 4.36, devido à presença de dois picos ressonantes, foram determinados dois circuitos RLC para estas medidas. Os parâmetros mecânicos das amostras obtidos pelos ajustes, além do fator de qualidade $\left(Q_{m}\right.$, dado pela expressão 2.22) e da frequência de ressonância $\left(\mathrm{f}_{\mathrm{r}}\right)$ estão presentes na tabela 4.5 .

Tabela 4.5 - Componentes referentes à parte mecânica dos circuitos equivalentes

\begin{tabular}{|c|c|c|c|c|c|c|c|c|c|c|}
\hline Transdutor & $\begin{array}{c}\mathbf{R}_{\mathrm{m} 1} \\
\left(\mathbf{x} 10^{6} \Omega\right)\end{array}$ & $\begin{array}{c}\mathrm{C}_{\mathrm{m} 1} \\
\left(\mathrm{x10}^{-12} \mathrm{~F}\right)\end{array}$ & $\begin{array}{l}\mathbf{L}_{\mathbf{m} 1} \\
(\mathbf{H})\end{array}$ & $\begin{array}{c}\mathbf{f}_{\mathrm{r} 1} \\
(\mathrm{kHz})\end{array}$ & $\mathbf{Q}_{\mathrm{m} 1}$ & $\begin{array}{c}\mathbf{R}_{\mathrm{m} 2} \\
\left(\mathbf{x 1 0 ^ { 6 }} \mathbf{\Omega}\right)\end{array}$ & $\begin{array}{c}\mathrm{C}_{\mathrm{m} 2} \\
\left(\mathrm{x} 10^{12}\right)\end{array}$ & $\begin{array}{l}\mathbf{L}_{\mathbf{m} 2} \\
(\mathbf{H})\end{array}$ & $\begin{array}{c}\mathbf{f}_{\mathrm{r} 2} \\
(\mathrm{kHz})\end{array}$ & $\mathbf{Q}_{\mathrm{m} 2}$ \\
\hline FEP $25 \mu \mathrm{m}$ & 32,04 & 0,020 & 768,39 & 40,94 & 6,1 & - & - & - & - & - \\
\hline FEP $50 \mu \mathrm{m}$ & 54,55 & 0,014 & 1797,20 & 31,42 & 6,6 & - & - & - & - & - \\
\hline FEP $70 \mu \mathrm{m}$ & 103,27 & 0,0072 & 4428,27 & 28,25 & 7,6 & - & - & - & - & - \\
\hline PP & 2,56 & 0,020 & 4,84 & 513 & 6,1 & - & - & - & - & - \\
\hline FEP 2,0-2,5 mm & 48,00 & 0,023 & 2465,64 & 21,22 & 6,8 & 108,52 & 0,0042 & 5715,89 & 32,61 & 10,7 \\
\hline PVDF & 0,713 & 0,66 & 30,47 & 35,39 & 9,6 & 0,291 & 0,90 & 11,21 & 50,05 & 12,1 \\
\hline
\end{tabular}

\subsection{Comparação: simulação e medição}

Após a determinação de todos os parâmetros do circuito equivalente, o passo final foi desenhar os circuitos através do software Pspice (como indicado na Figura 3.10) e simular os parâmetros destes. Foram simuladas a condutância, a susceptância, o módulo da impedância e a fase de todos os circuitos, compreendendo as mesmas faixas de frequência das medidas. Nas Figuras 4.37 a 4.60 encontram-se as comparações gráficas das simulações dos circuitos equivalentes (para 3 ramos RC na parte elétrica do modelo) e das medições realizadas. 


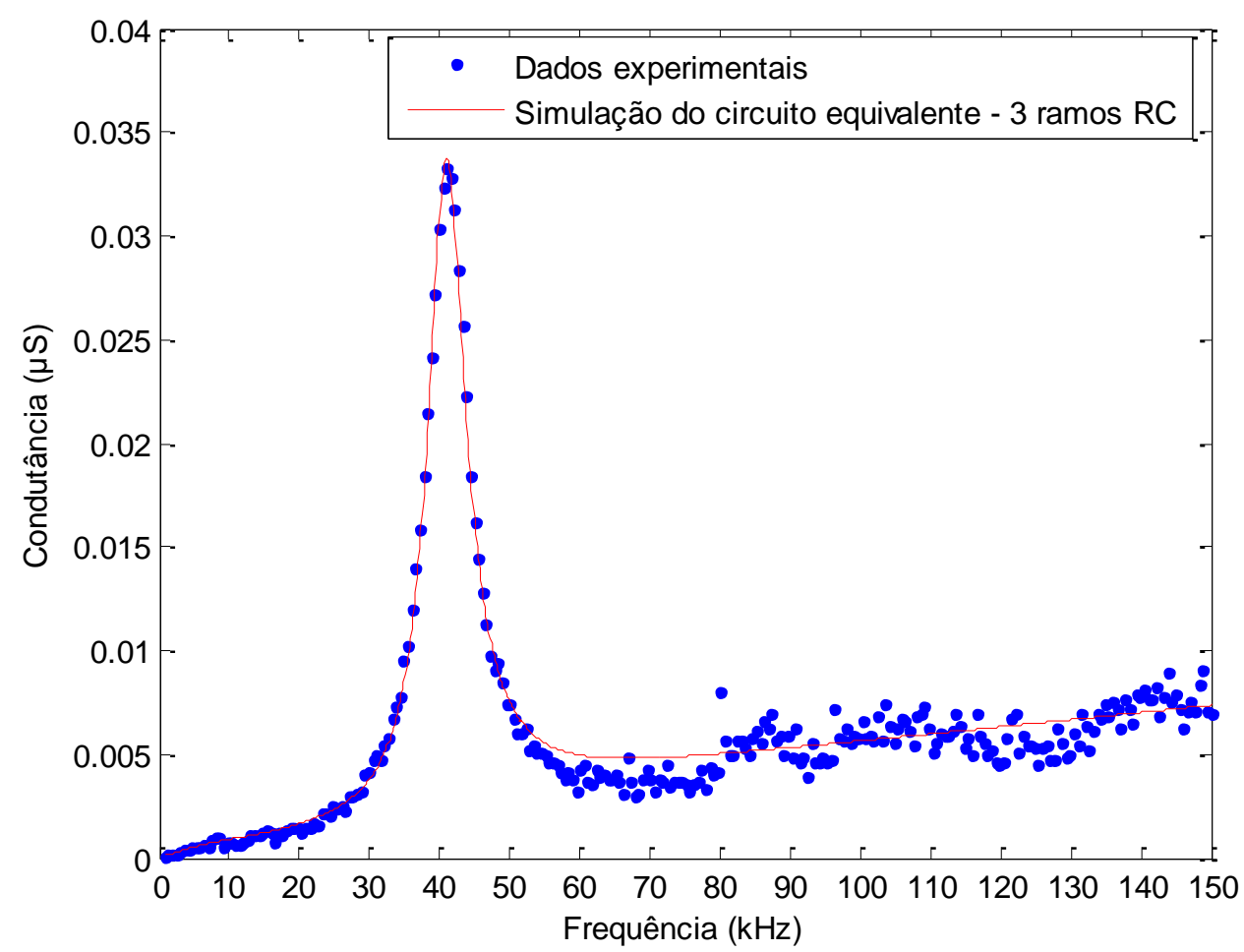

Figura 4.37 - Simulação do circuito equivalente e medição do piezoeletreto de canaletas ( $25 \mu \mathrm{m}$ de altura): condutância.

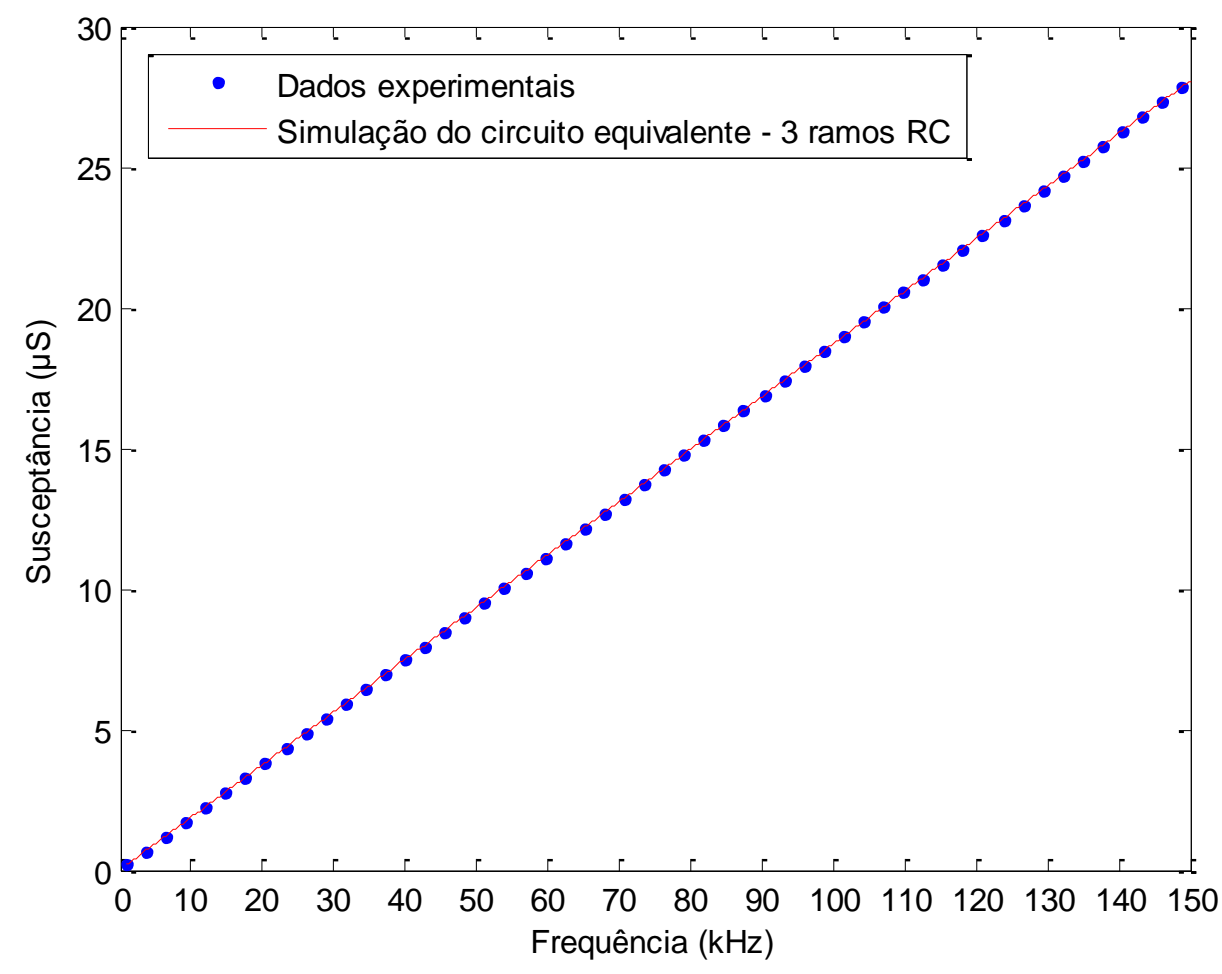

Figura 4.38 - Simulação do circuito equivalente e medição do piezoeletreto de canaletas ( $25 \mu \mathrm{m}$ de altura): susceptância. 




Figura 4.39 - Simulação do circuito equivalente e medição do piezoeletreto de canaletas ( $25 \mu \mathrm{m}$ de altura): módulo da impedância.

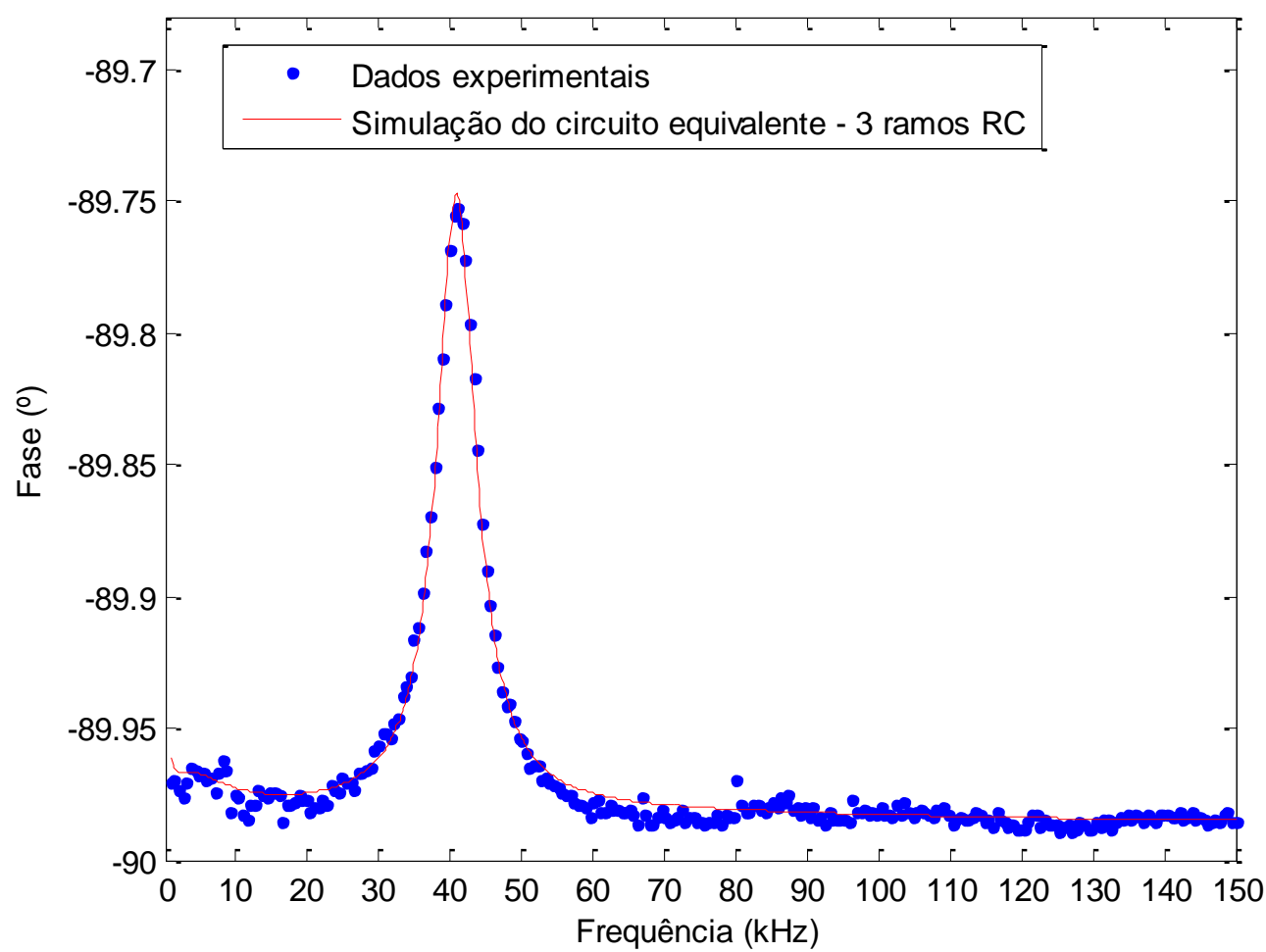

Figura 4.40 - Simulação do circuito equivalente e medição do piezoeletreto de canaletas ( $25 \mu \mathrm{m}$ de altura): fase. 


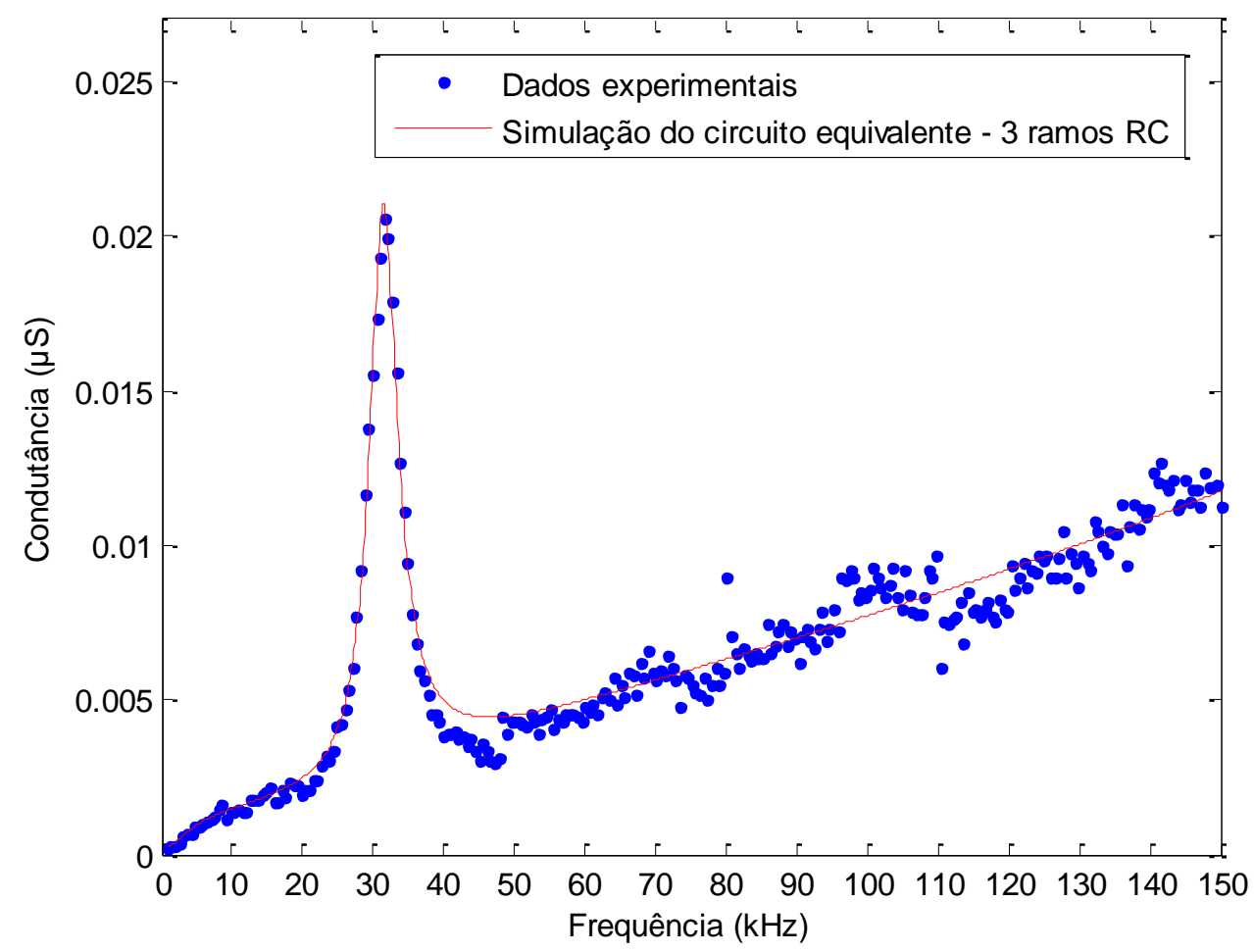

Figura 4.41 - Simulação do circuito equivalente e medição do piezoeletreto de canaletas (50 $\mu \mathrm{m}$ de altura): condutância.

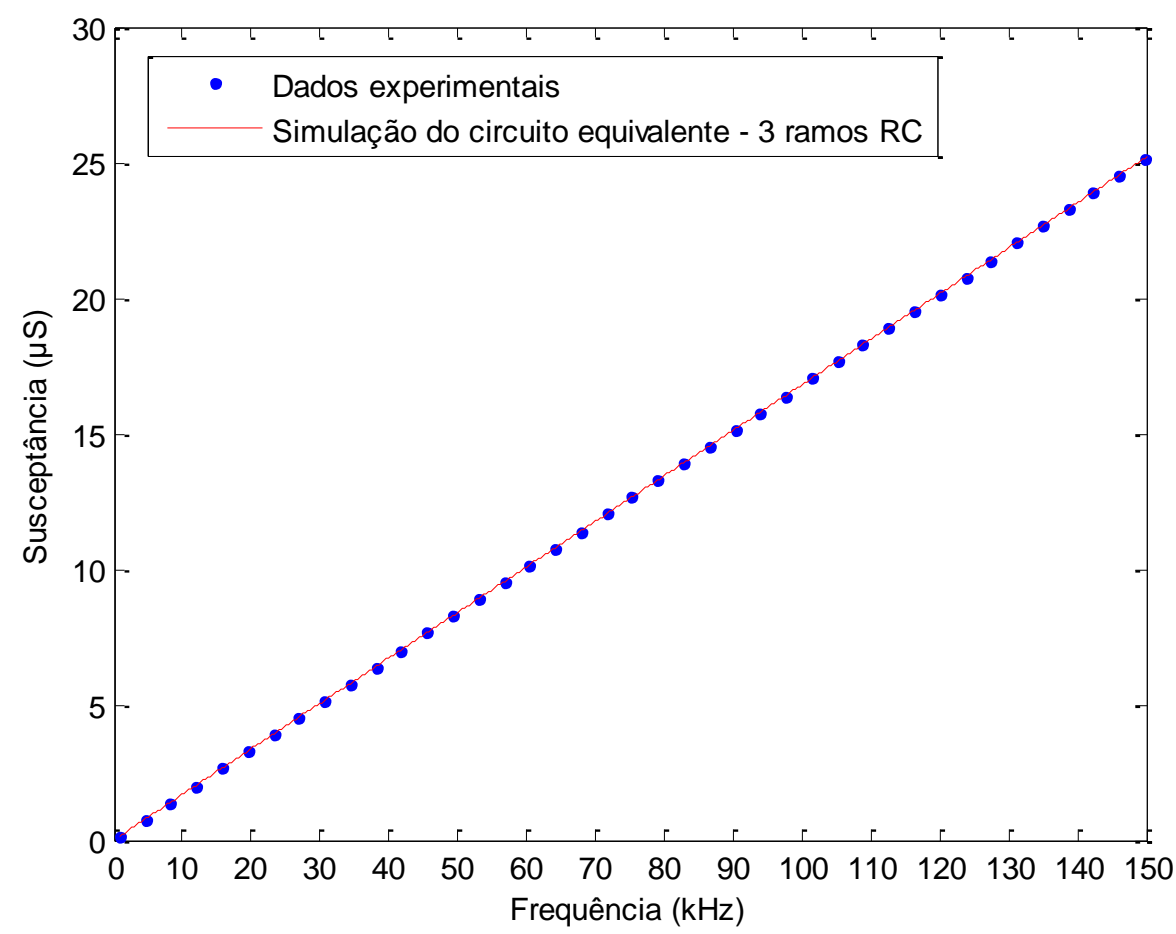

Figura 4.42 - Simulação do circuito equivalente e medição do piezoeletreto de canaletas (50 $\mu \mathrm{m}$ de altura): susceptância. 


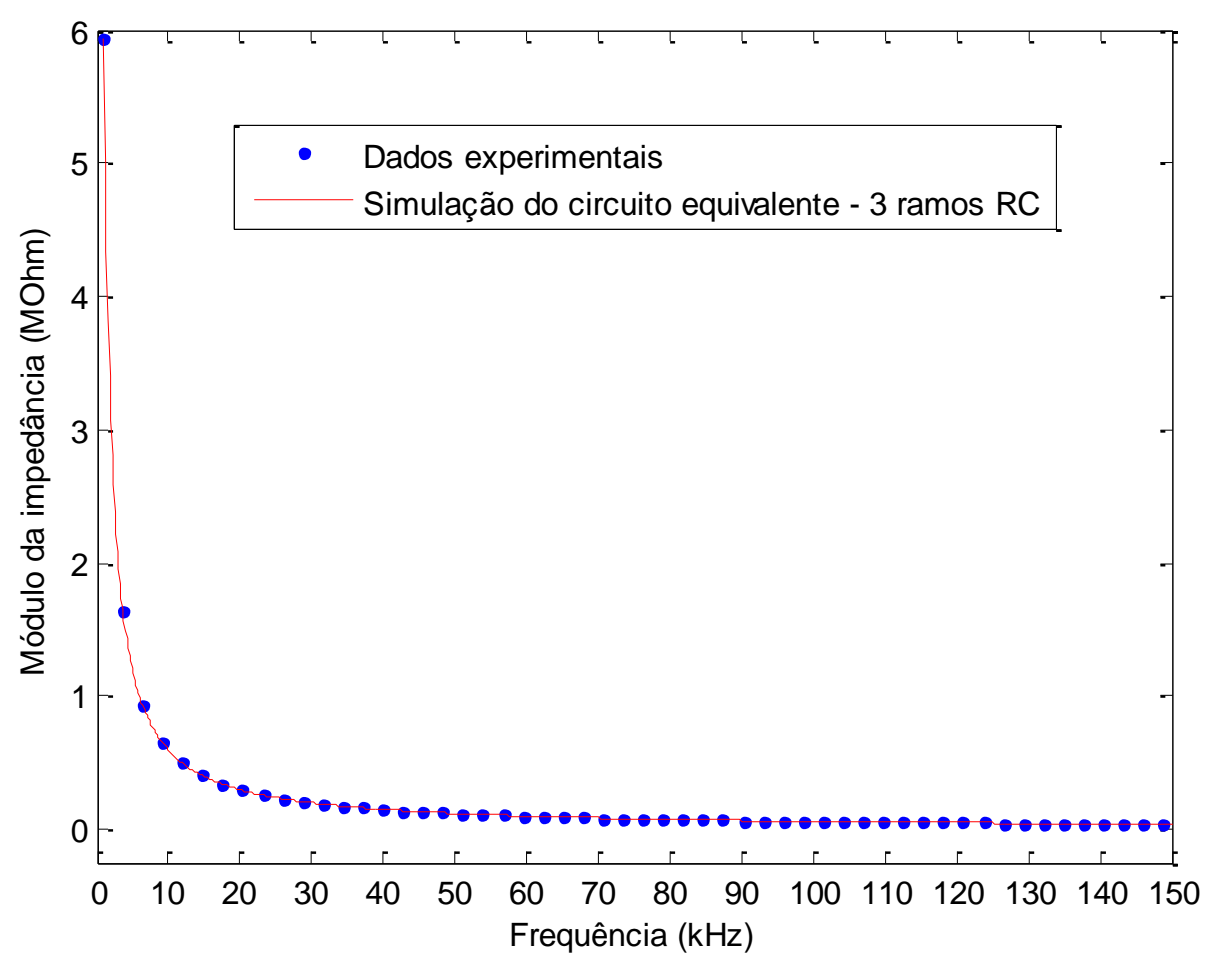

Figura 4.43 - Simulação do circuito equivalente e medição do piezoeletreto de canaletas (50 $\mu \mathrm{m}$ de altura): módulo da impedância.



Figura 4.44 - Simulação do circuito equivalente e medição do piezoeletreto de canaletas (50 $\mu \mathrm{m}$ de altura): fase. 


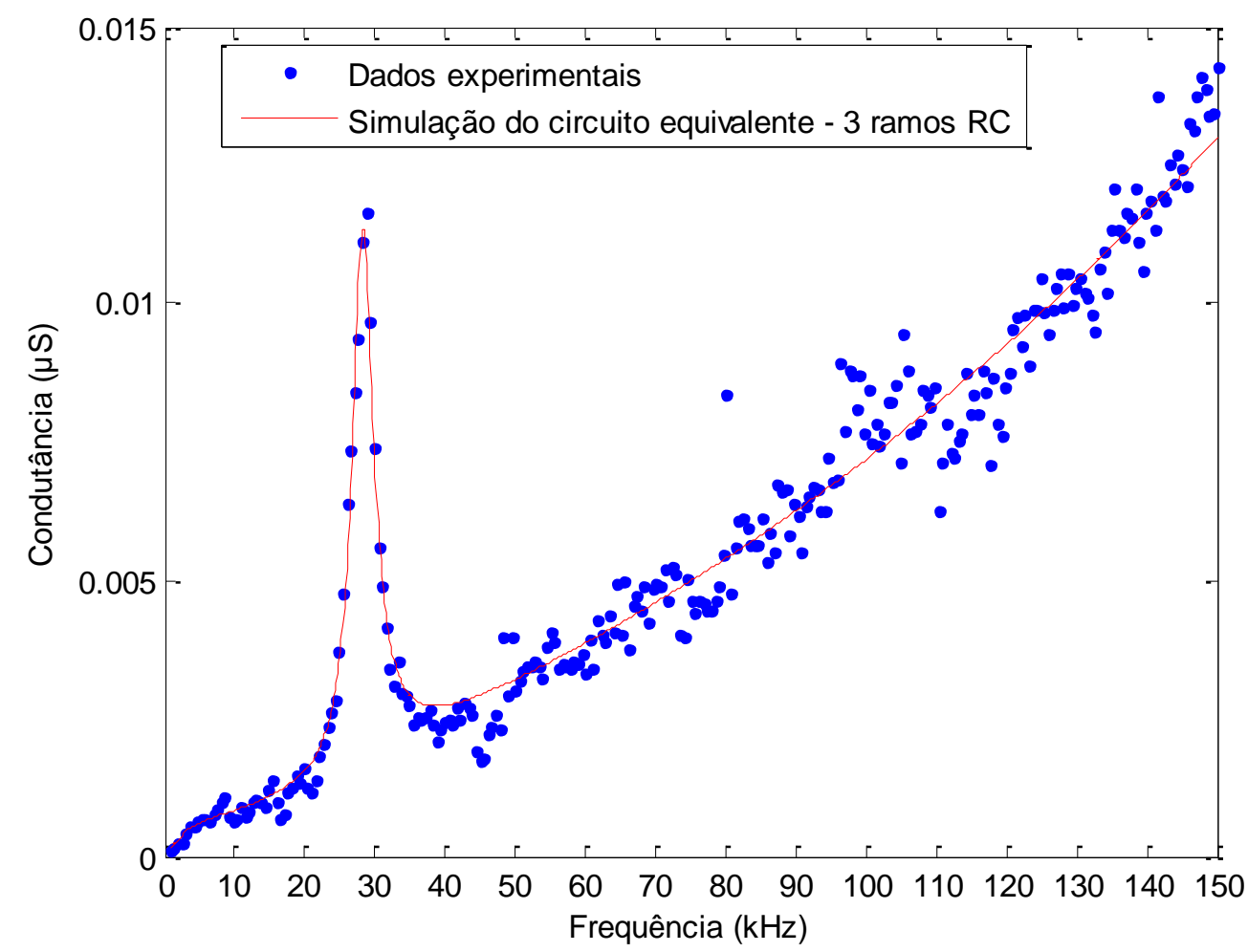

Figura 4.45 - Simulação do circuito equivalente e medição do piezoeletreto de canaletas (70 $\mu \mathrm{m}$ de altura): condutância.

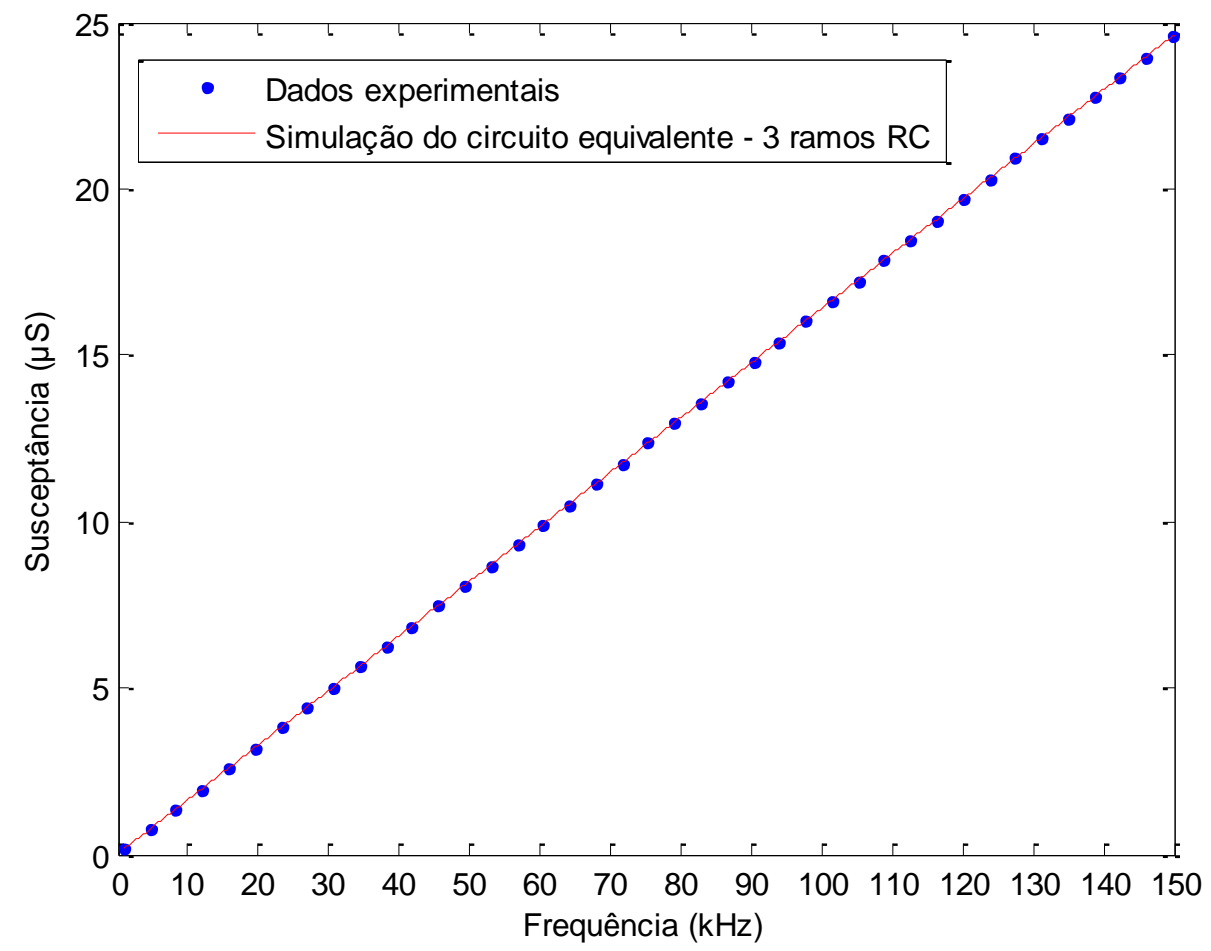

Figura 4.46 - Simulação do circuito equivalente e medição do piezoeletreto de canaletas (70 $\mu \mathrm{m}$ de altura): susceptância. 


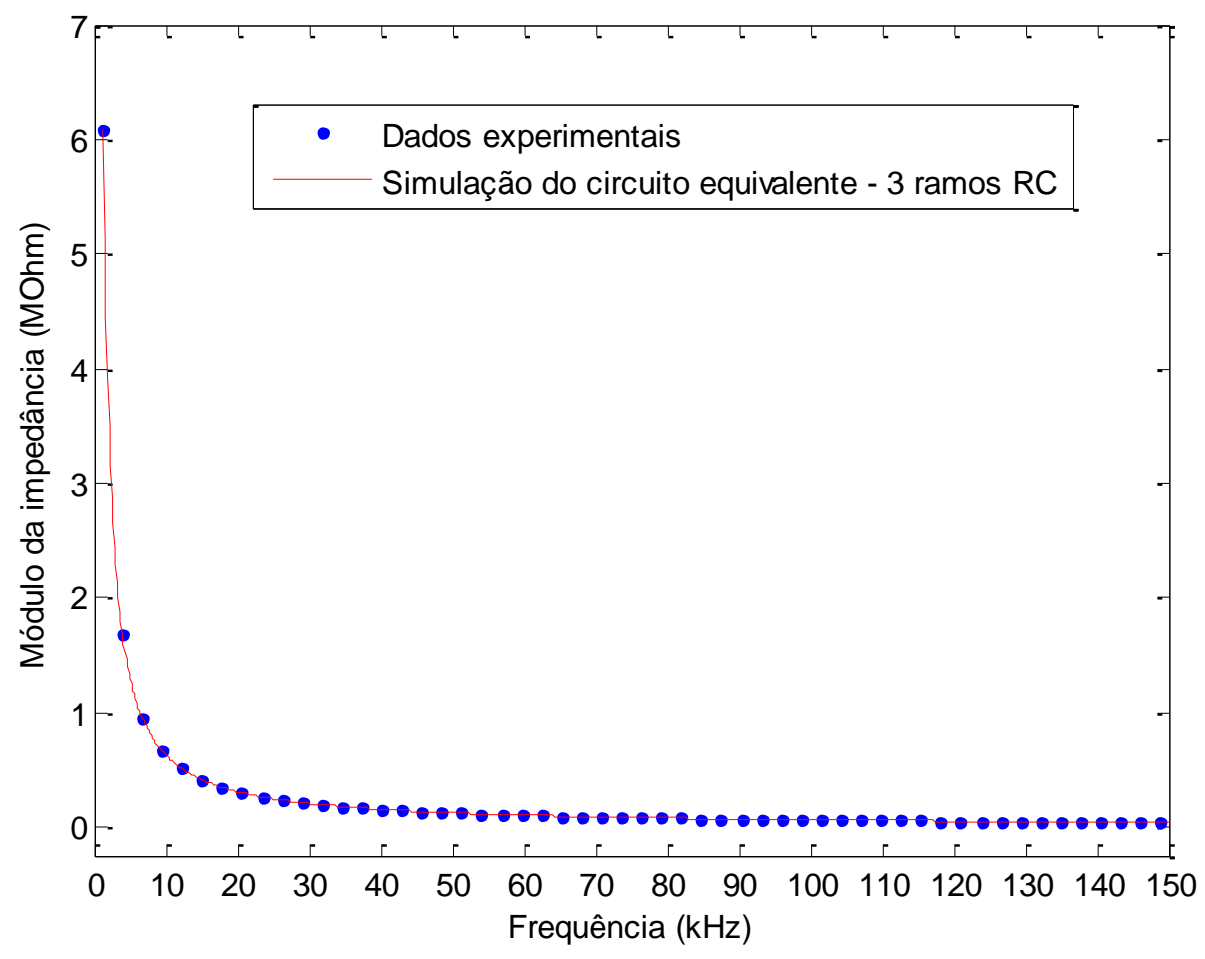

Figura 4.47 - Simulação do circuito equivalente e medição do piezoeletreto de canaletas (70 $\mu \mathrm{m}$ de altura): módulo da impedância.



Figura 4.48 - Simulação do circuito equivalente e medição do piezoeletreto de canaletas (70 $\mu \mathrm{m}$ de altura): fase. 


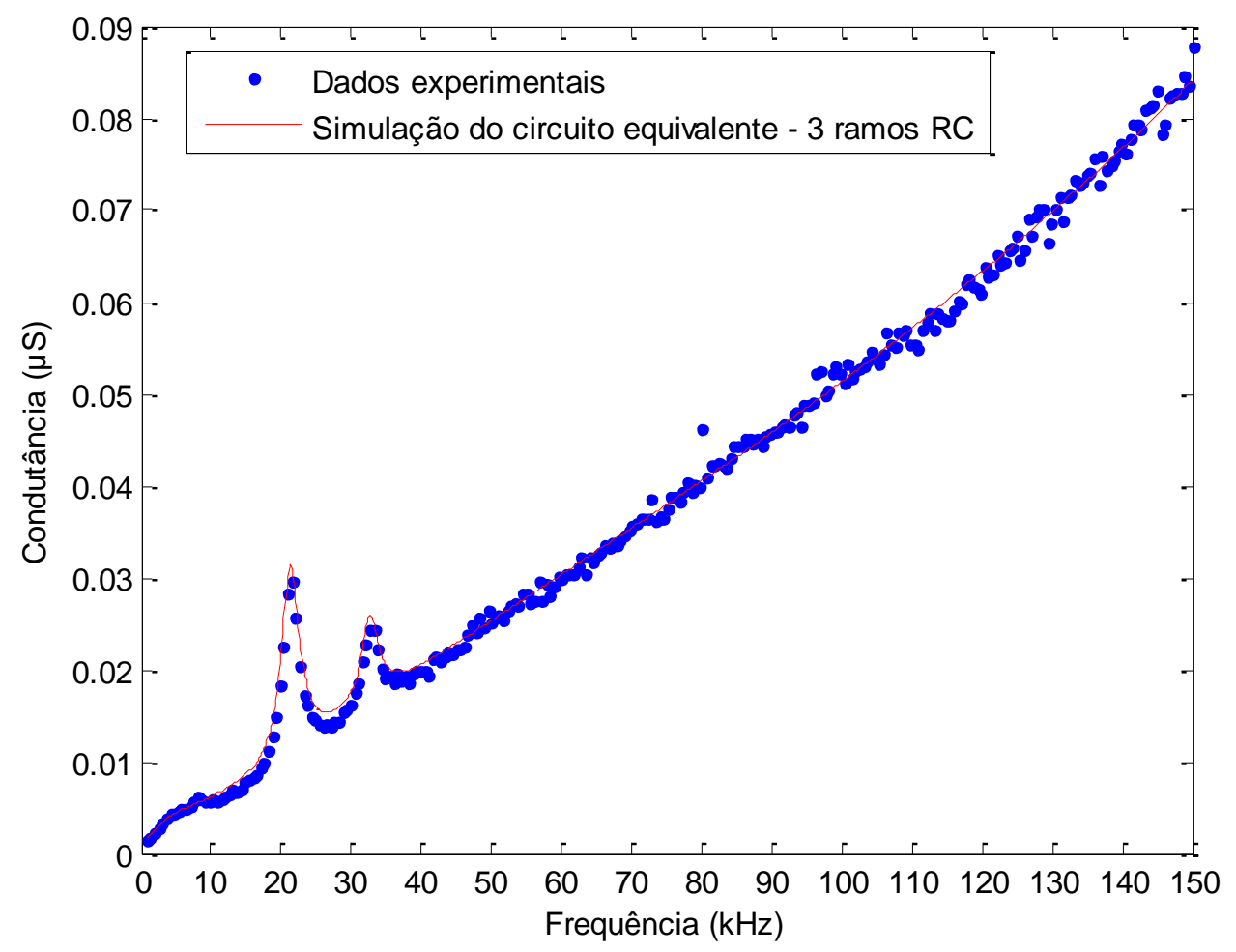

Figura 4.49 - Simulação do circuito equivalente e medição do piezoeletreto de canaletas (2,0-2,5 mm de largura): condutância.

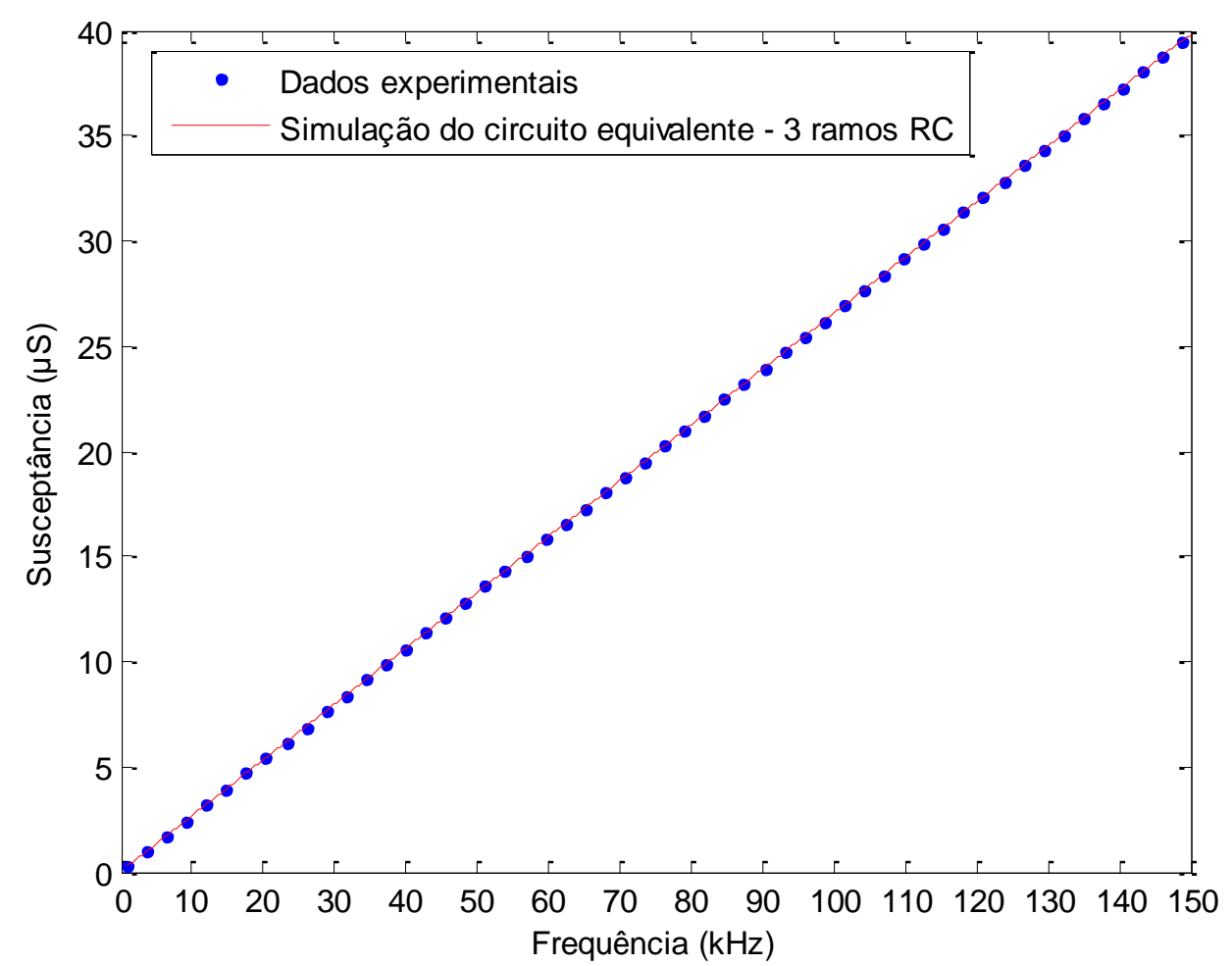

Figura 4.50 - Simulação do circuito equivalente e medição do piezoeletreto de canaletas (2,0-2,5 mm de largura): susceptância. 




Figura 4.51 - Simulação do circuito equivalente e medição do piezoeletreto de canaletas (2,0-2,5 mm de largura): módulo da impedância.

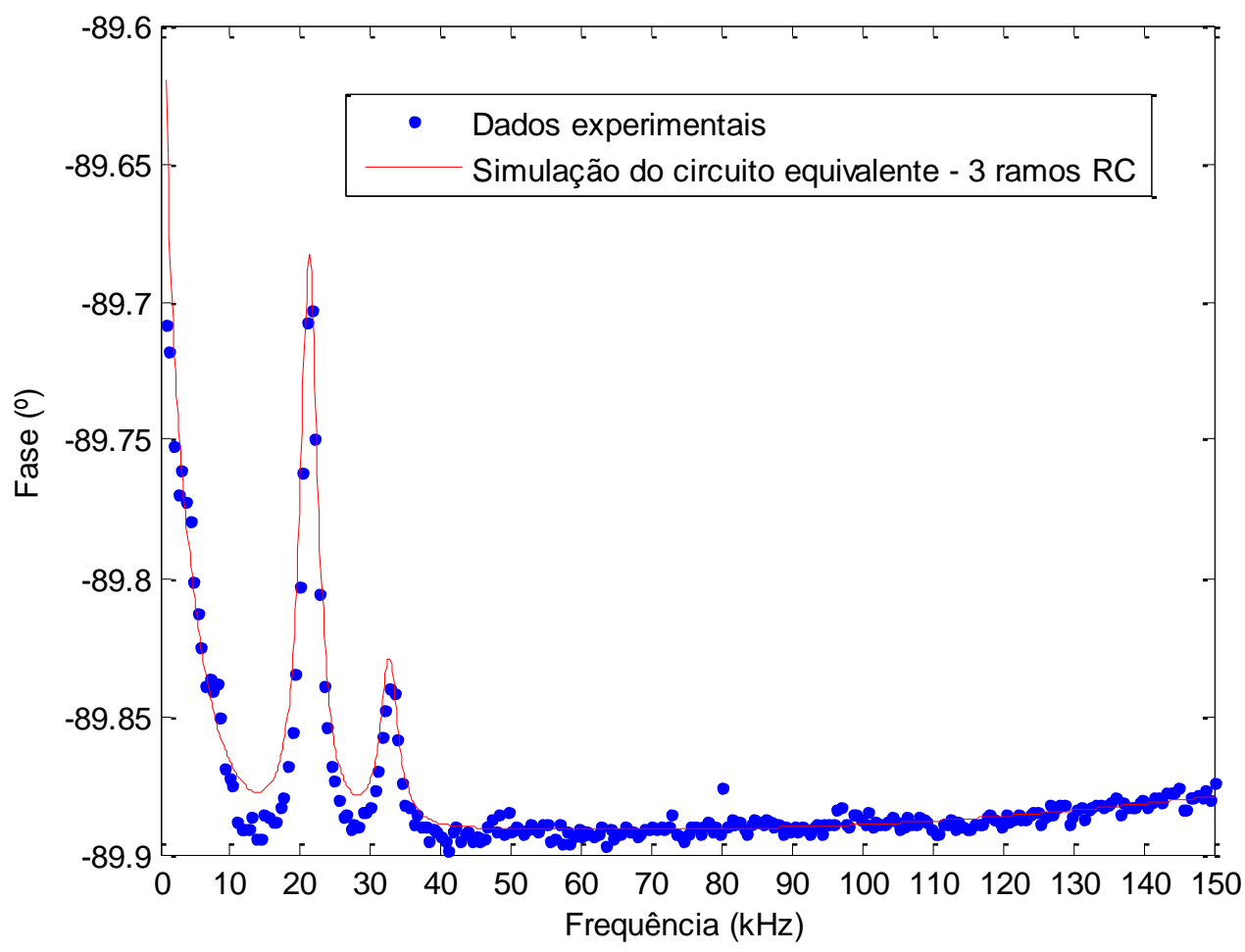

Figura 4.52 - Simulação do circuito equivalente e medição do piezoeletreto de canaletas (2,0-2,5 mm de largura): fase. 


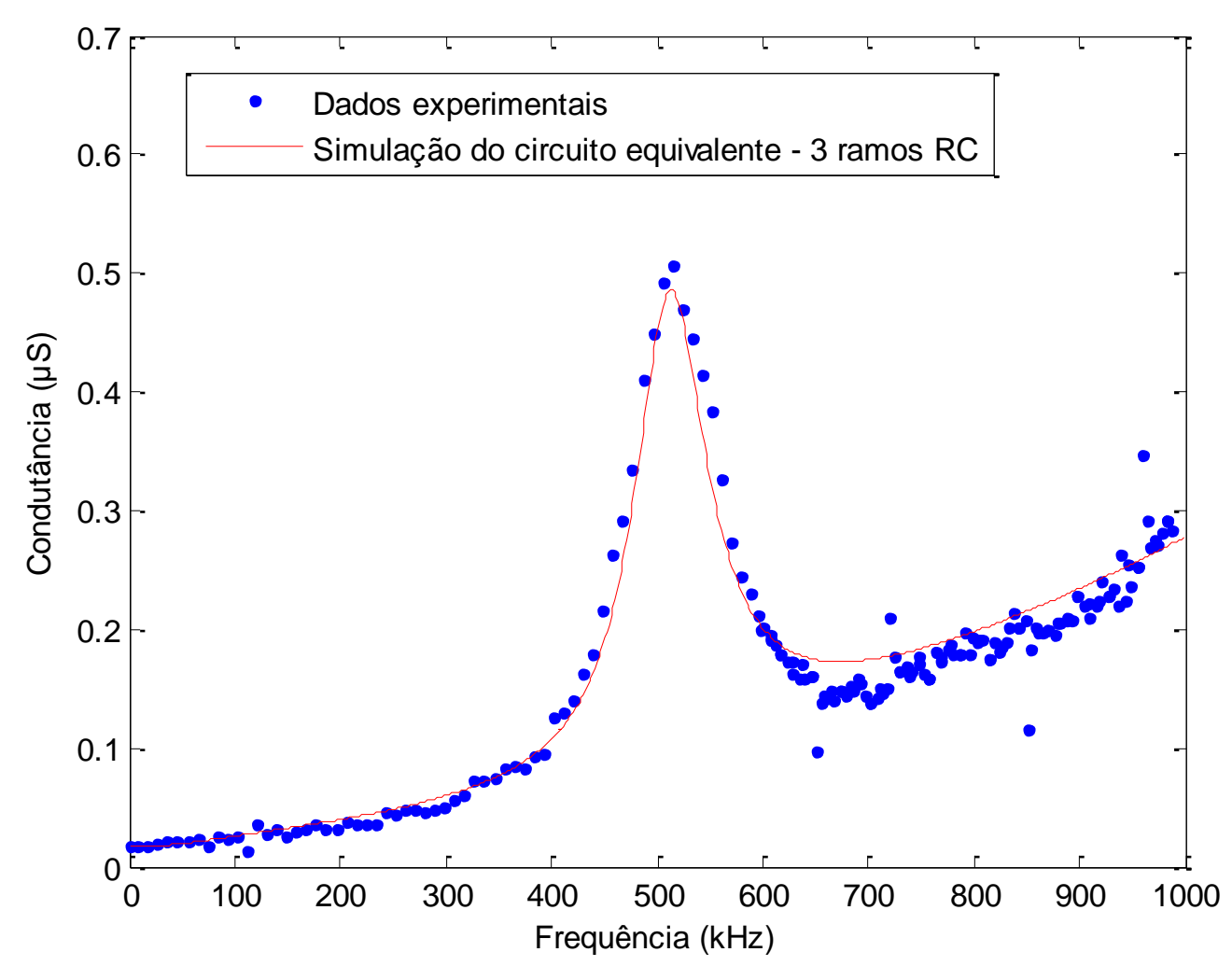

Figura 4.53 - Simulação do circuito equivalente e medição do filme de PP: condutância.

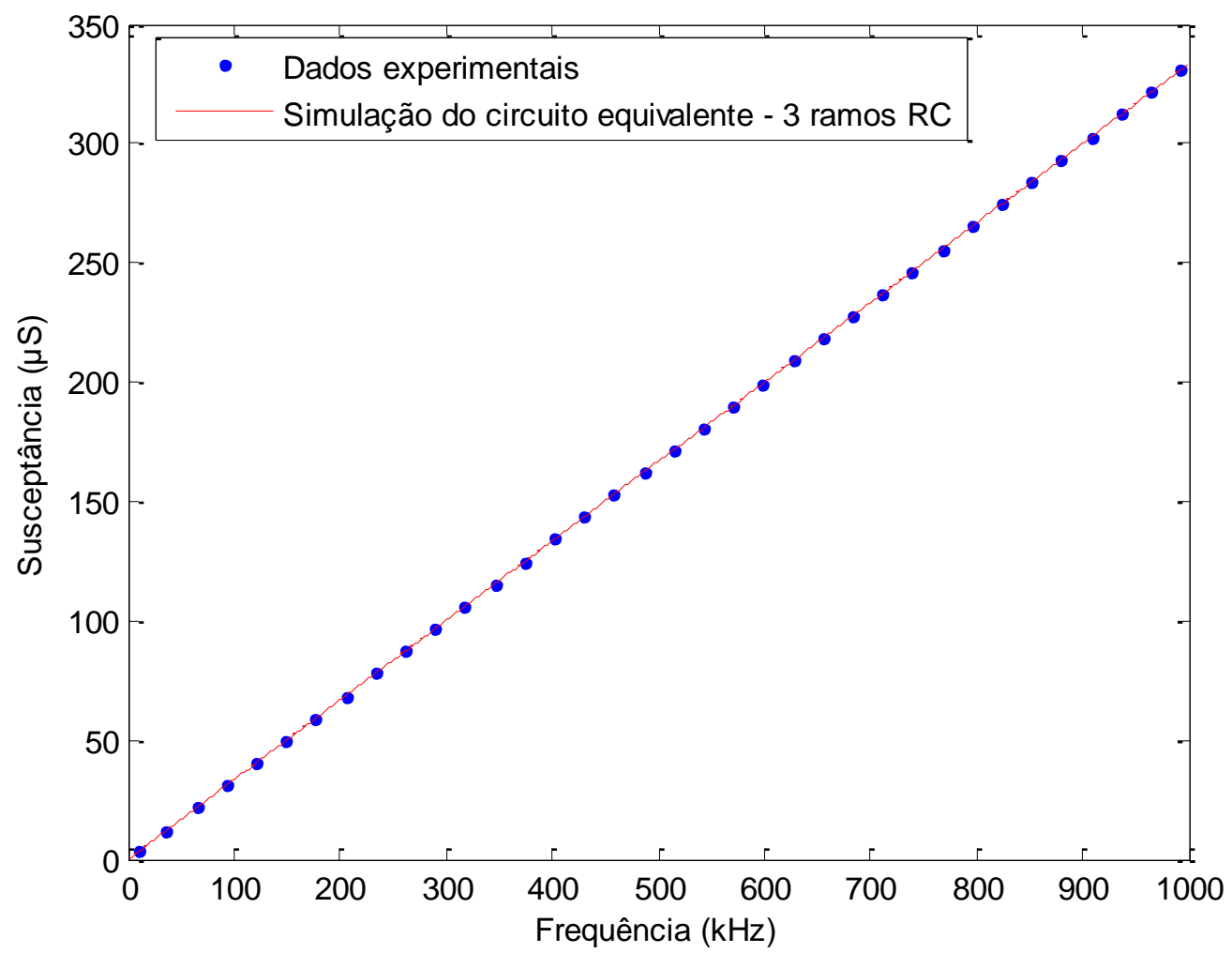

Figura 4.54 - Simulação do circuito equivalente e medição do filme de PP: susceptância. 


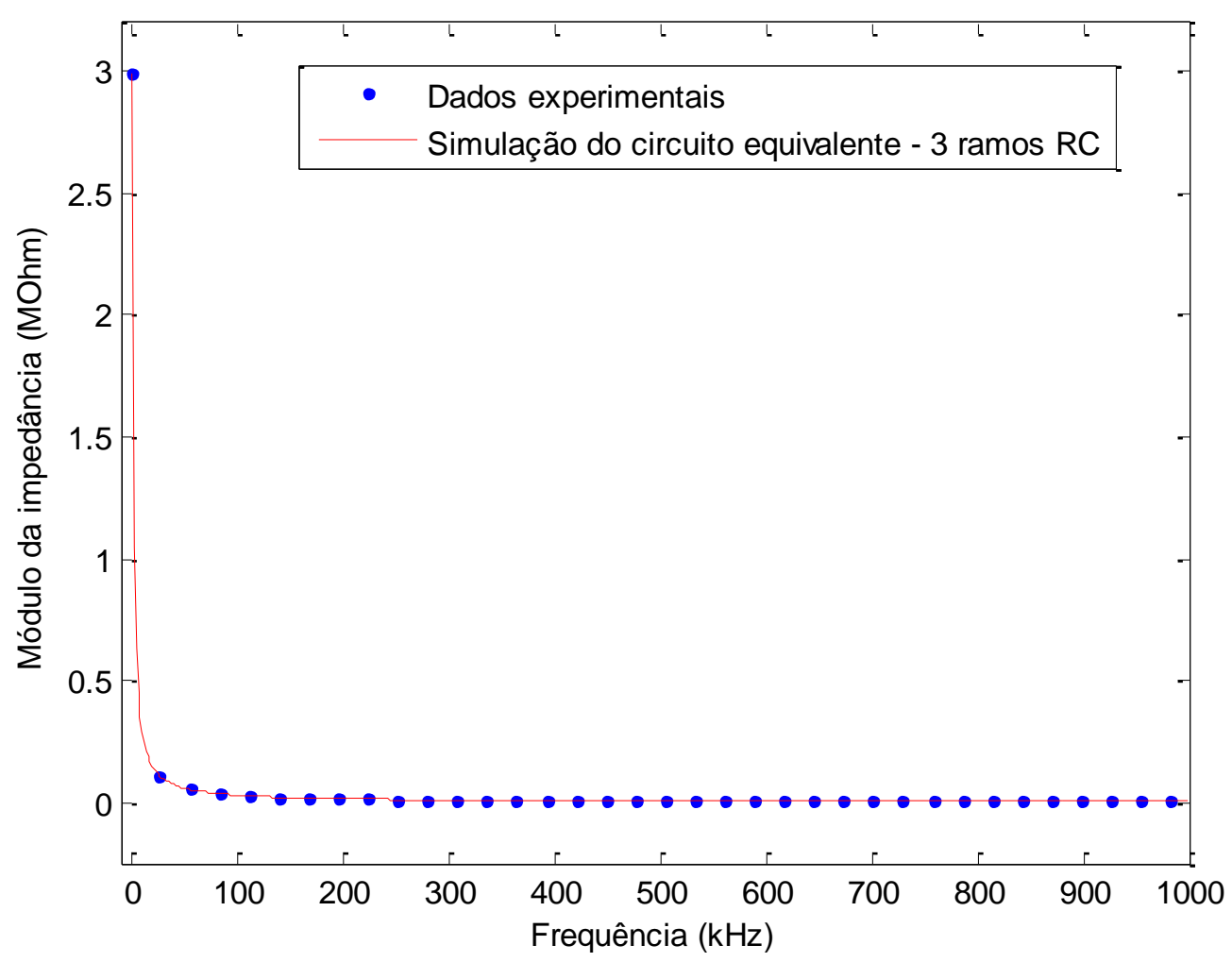

Figura 4.55 - Simulação do circuito equivalente e medição do filme de PP: módulo da impedância.

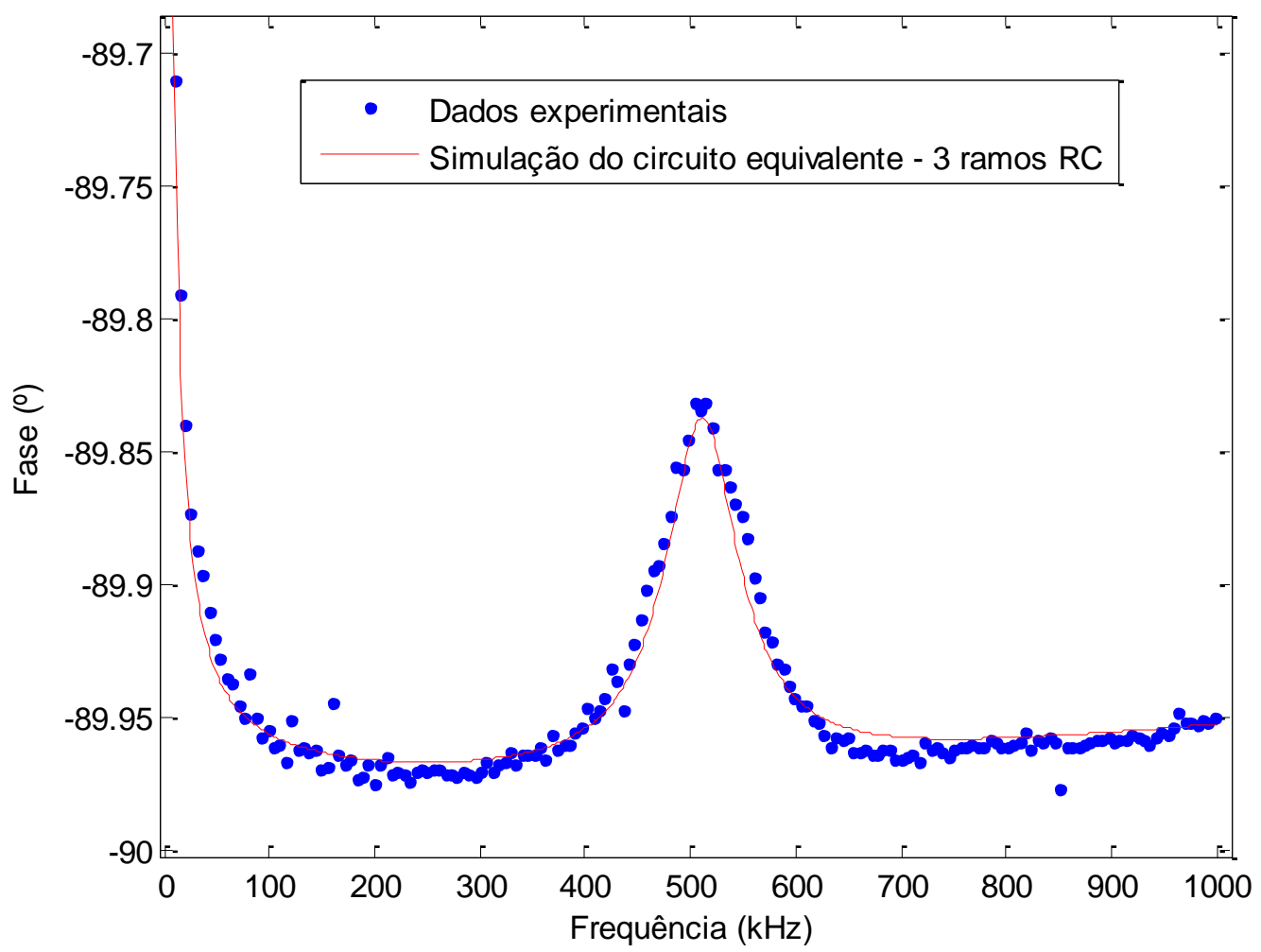

Figura 4.56 - Simulação do circuito equivalente e medição do filme de PP: fase. 


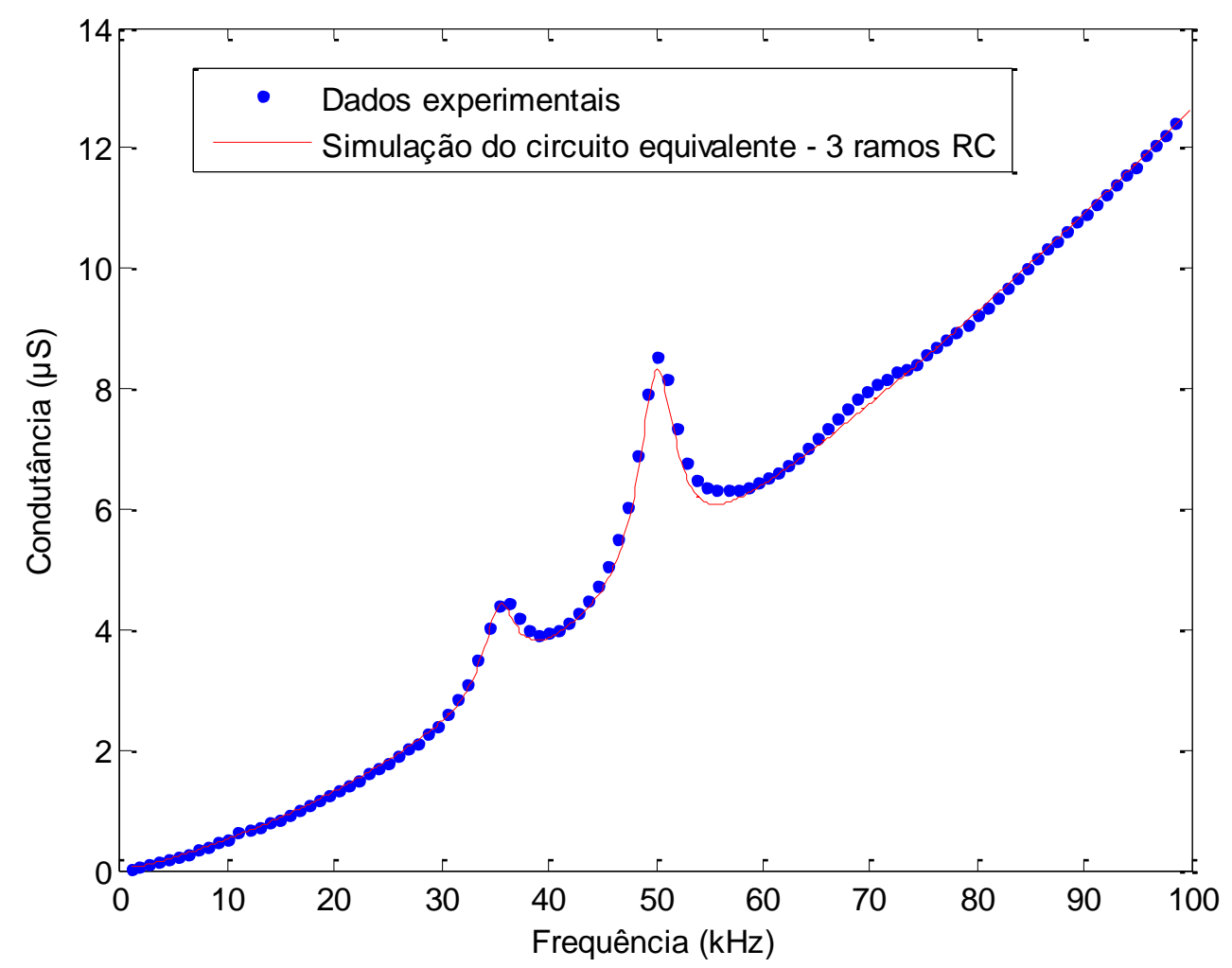

Figura 4.57 - Simulação do circuito equivalente e medição do filme de PVDF: condutância.

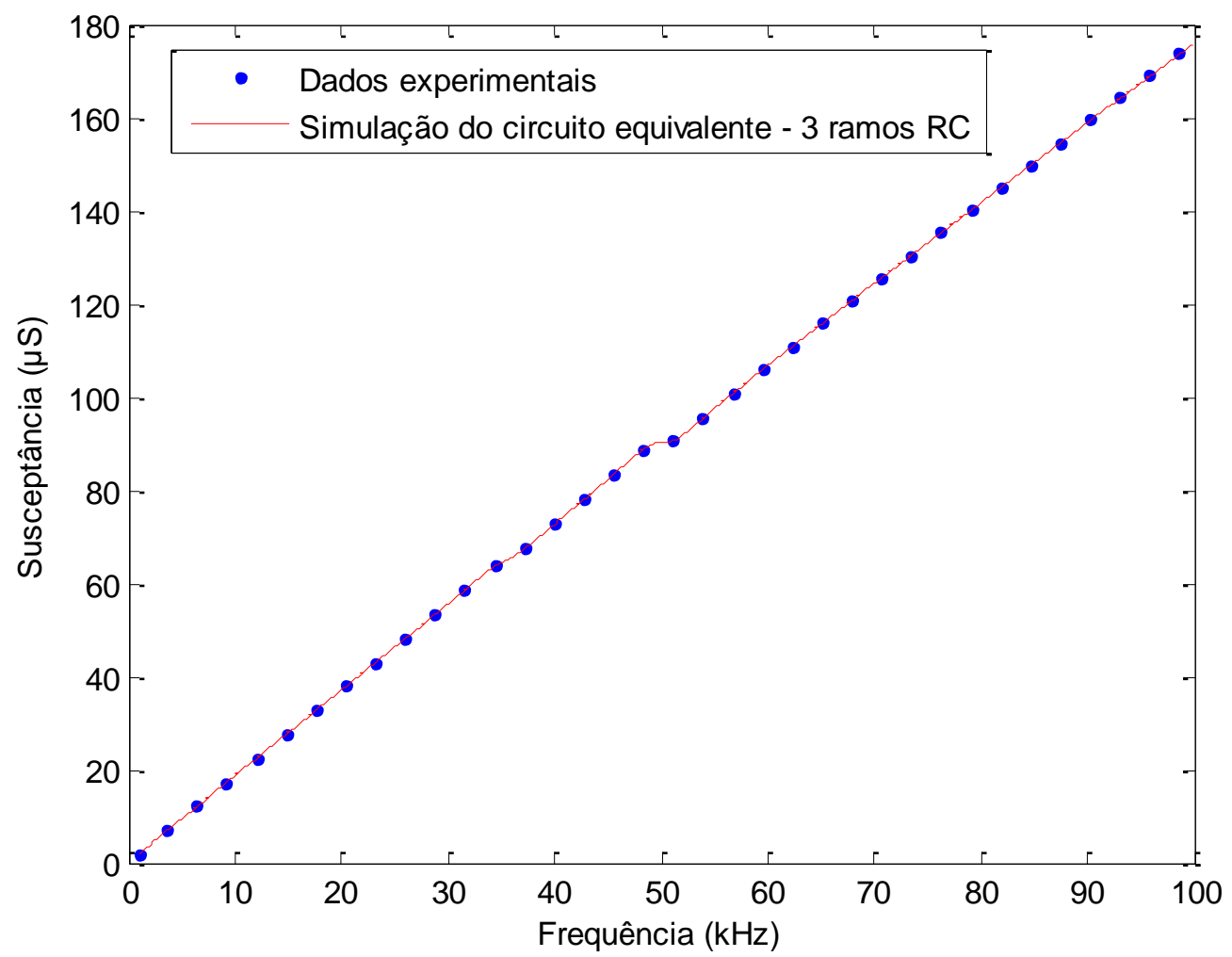

Figura 4.58 - Simulação do circuito equivalente e medição do filme de PVDF: susceptância. 


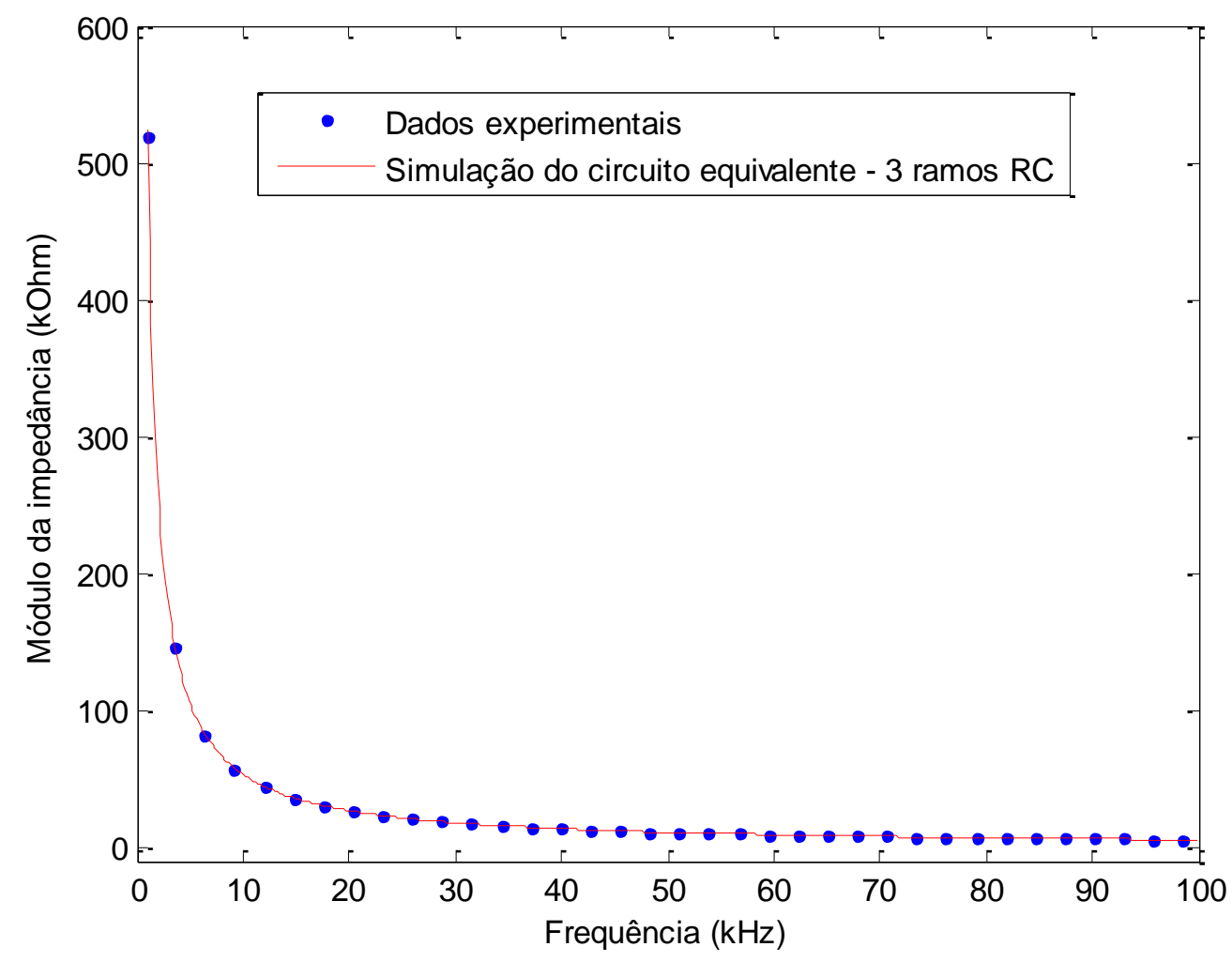

Figura 4.59 - Simulação do circuito equivalente e medição do filme de PVDF: módulo da impedância.

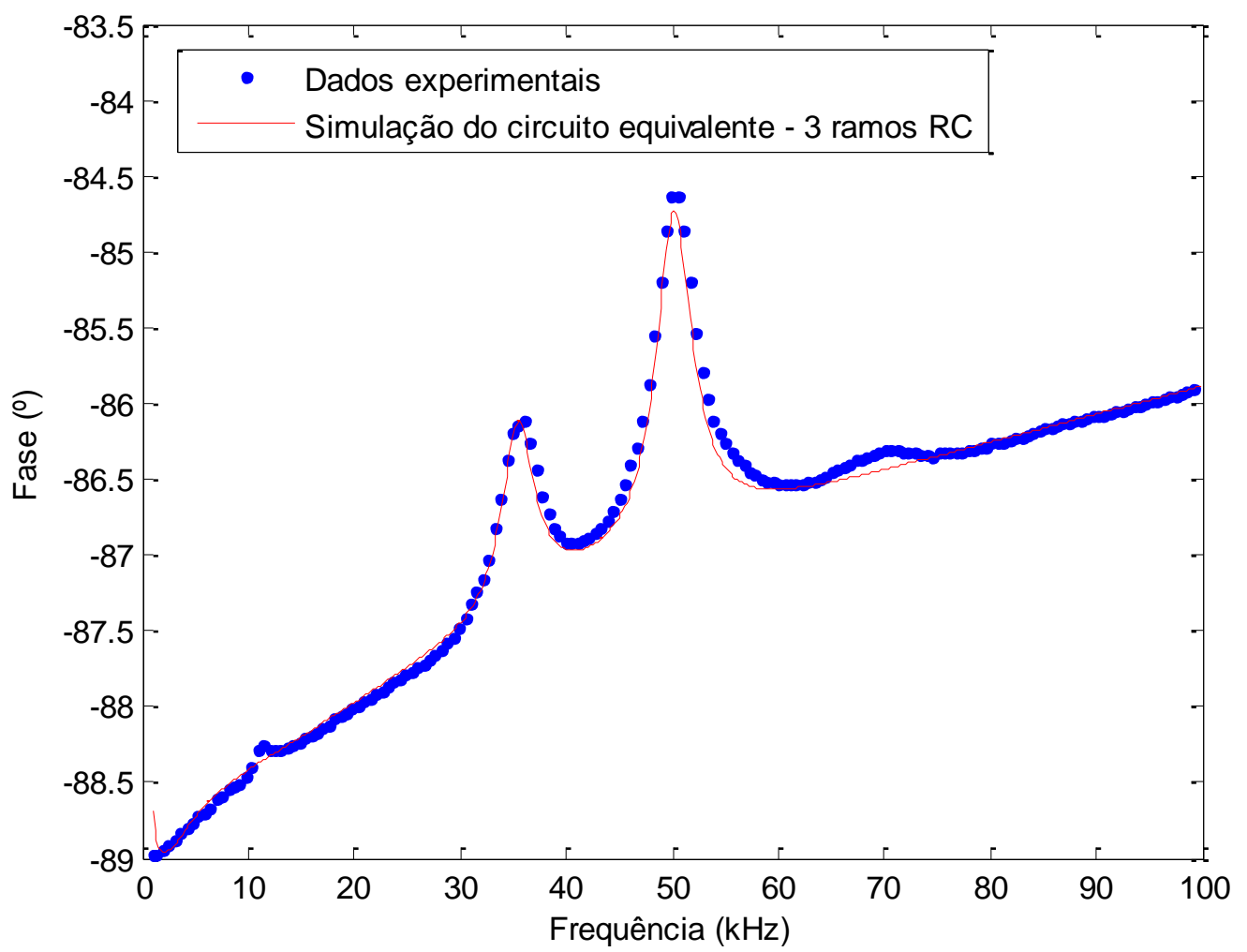

Figura 4.60 - Simulação do circuito equivalente e medição do filme de PVDF: fase. 
Pela análise das comparações gráficas, nota-se um comportamento bastante próximo entre as medições realizadas e as simulações do circuito equivalente. Assim como nas medidas realizadas, os picos ressonantes mostraram-se evidentes nas simulações da condutância e do ângulo de fase do circuito, enquanto que nas curvas de susceptância e do módulo da impedância não é possível determinar tais frequências. Observando-se os valores dos parâmetros dos circuitos equivalentes, percebe-se que tal comportamento decorre principalmente da capacitância $C_{p}$, visto que a reatância capacitiva deste parâmetro é menor do que o módulo da impedância dos demais ramos paralelos dos circuitos nas faixas de frequência analisadas, fato que a torna o termo de maior peso no cálculo da impedância equivalente do circuito. Desta forma, tanto o módulo da impedância quanto a susceptância têm maior influência de $C_{p}$ do que dos outros parâmetros. Além de que, os circuitos da parte mecânica apresentaram valores elevados de $R_{m}$, fato que reflete em picos ressonantes pouco destacados e em baixos fatores de qualidade.

Após as comparações gráficas, as medidas e as simulações foram comparadas numericamente por meio do erro relativo percentual médio, dada pela expressão 3.8. Os resultados dessas comparações, para todos os circuitos e parâmetros analisados estão na tabela 4.6. Pela análise dos resultados, conclui-se que a adição de ramos RC à parte elétrica do modelo diminuiu o valor do erro para as medidas de condutância e de fase para as amostras, com exceção do filme de PP, cujos valores ficaram estáveis para dois e três ramos RC. Já para o módulo da impedância e para a susceptância, não houve uma tendência com relação aos valores dos erros, porém destaca-se que estes apresentaram valores abaixo de $1 \%$. 
Tabela 4.6 - Valores dos erros relativos percentuais médios (\%) entre os parâmetros simulados dos circuitos equivalentes e as medições

\begin{tabular}{|c|c|c|c|c|c|}
\hline Trandutor & $\begin{array}{c}\text { Circuito } \\
\text { simulado }\end{array}$ & Condutância & Susceptância & $\begin{array}{l}\text { Módulo da } \\
\text { impedância }\end{array}$ & Fase \\
\hline \multirow{3}{*}{ FEP $25 \mu \mathrm{m}$} & 1-RC & 27,34 & 0,017 & 0,017 & 0,0056 \\
\hline & 2-RC & 22,28 & 0,016 & 0,016 & 0,0037 \\
\hline & 3-RC & 22,10 & 0,017 & 0,017 & 0,0036 \\
\hline \multirow{3}{*}{ FEP $50 \mu \mathrm{m}$} & 1-RC & 16,95 & 0,013 & 0,013 & 0,0079 \\
\hline & 2-RC & 12,37 & 0,010 & 0,010 & 0,0047 \\
\hline & 3-RC & 10,40 & 0,013 & 0,014 & 0,0037 \\
\hline \multirow{3}{*}{ FEP $70 \mu \mathrm{m}$} & 1-RC & 18,90 & 0,0084 & 0,0085 & 0,006 \\
\hline & 2-RC & 14,95 & 0,010 & 0,010 & 0,0043 \\
\hline & 3-RC & 11,96 & 0,013 & 0,013 & 0,0031 \\
\hline \multirow{3}{*}{$\begin{array}{c}\text { FEP 2,0-2,5 } \\
\text { mm }\end{array}$} & 1-RC & 13,42 & 0,025 & 0,025 & 0,02 \\
\hline & 2-RC & 6,20 & 0,022 & 0,022 & 0,011 \\
\hline & 3-RC & 3,71 & 0,023 & 0,023 & 0,0056 \\
\hline \multirow{3}{*}{ PP } & 1-RC & 12,94 & 0,029 & 0,030 & 0,0081 \\
\hline & 2-RC & 10,31 & 0,023 & 0,024 & 0,0059 \\
\hline & 3-RC & 10,31 & 0,022 & 0,024 & 0,0059 \\
\hline \multirow{3}{*}{ PVDF } & 1-RC & 13,77 & 0,61 & 0,59 & 0,34 \\
\hline & 2-RC & 4,11 & 0,20 & 0,19 & 0,14 \\
\hline & 3-RC & 1,97 & 0,21 & 0,22 & 0,068 \\
\hline
\end{tabular}




\section{Capítulo 5}

\section{Conclusão}

Além da revisão bibliográfica sobre fundamentos da piezoeletricidade e dos modelos elétricos equivalentes piezoelétricos, este trabalho apresentou um circuito equivalente para a simulação de diferentes amostras de piezoeletreto de canaletas, além de um filme de PP e outro de PVDF, e também a metodologia de obtenção de seus parâmetros. Comparações entre medidas e simulações também foram efetuadas.

A metodologia baseou-se em medições da condutância e da susceptância das amostras. Dois eletrodos curvos de latão deixaram as amostras livres e permitiram a realização das medições de sua frequência de ressonância.

A escolha do circuito equivalente base foi resultado de uma extensa pesquisa bibliográfica, que culminou na escolha do modelo de um transdutor polimérico, aplicado para frequências menores que $200 \mathrm{kHz}$. Este circuito foi modificado para melhor modelar os transdutores analisados e todo o procedimento para determinar seus parâmetros também foi apresentado.

De posse do circuito modificado, foram feitas simulações da condutância, da susceptância, do módulo da impedância e do ângulo de fase, que apresentaram relevantes concordâncias com as medições realizadas nas faixas de frequência de interesse. Além das comparações gráficas, foram feitas análises do erro relativo percentual entre as simulações e as medidas, que exibiram numericamente a concordância entre os sinais.

Com relação às amostras dos piezoeletretos de canaletas, nota-se que os componentes de seus circuitos equivalentes apresentaram valores que podem ser relacionados com a geometria das amostras. Por exemplo, os valores de $\mathrm{C}_{\mathrm{p}}$ das amostras aumentaram com a diminuição da altura das canaletas, fato que pode relacionar $C_{p}$ à capacitância geométrica dos piezoeletretos. Com relação aos parâmetros mecânicos, verificou-se que os valores de $\mathrm{L}_{\mathrm{m}} \mathrm{e}$ $\mathrm{R}_{\mathrm{m}}$ aumentaram, enquanto que os de $\mathrm{C}_{\mathrm{m}}$ diminuíram com o aumento da altura das canaletas. De acordo com as expressões dos parâmetros mecânicos do estudo de Van Dyke (1928), é possível dizer que as canaletas das amostras com maiores cavidades possuam massa, rigidez e 
amortecimento maiores do que as amostras com cavidades menores. Entretanto para essa afirmação ser verdadeira, as amostras devem ter constantes piezoelétricas numericamente semelhantes.

Com base nos resultados abrangidos por esta pesquisa, propõe-se como estudos futuros:

- Realizar um estudo mais detalhado sobre a relação dos parâmetros do circuito com a geometria das cavidades dos piezoeletretos;

- Determinar o circuito equivalente para piezoeletretos com cavidades de diferentes geometrias e relacionar os parâmetros do modelo com seus aspectos construtivos;

- Verificar a aplicação do modelo apresentado para frequências maiores, em $\mathrm{MHz}$;

- Verificar a possibilidade de aplicação do modelo na simulação de ensaios transitórios com as amostras;

- Estudar a ocorrência de pequenos picos ressonantes presentes nas medidas de condutância das amostras de piezoeletretos.

\subsection{Artigo}

$\mathrm{O}$ artigo intitulado "Electric circuit model for simulating ferroelectrets with opentubular channels" foi selecionado e será publicado na Conference on Electrical Insulation and Dielectric Phenomena (CEIDP), a ser realizada em Toronto, Canadá, no período de 16 a 19 de outubro de 2016. 


\section{Referências}

ALTAFIM, R.A.C. et al. Piezoelectricity of multi-layers space-charge electrets from teflon FEP film with homogeneous voids distributed on its surface. In: IEEE ANNUAL REPORT CONFERENCE ON ELECTRICAL INSULATION AND DIELECTRIC PHENOMENA, 2003, Albuquerque. Proceeding... Piscataway: IEEE Service Center, 2003. p.225-228.

ALTAFIM, R.A.C. et al. Piezoelectrets from thermo-formed bubble structures of fluoropolymer-electret films. IEEE Transactions on Dielectrics and Electrical Insulation, v.13, n.5, p.979-985, 2006.

ALTAFIM, R.A.P. Análise e implementação de métodos para a caracterização de eletretos termo-formados. 2006. 68 f. Dissertação (Mestrado em Engenharia Elétrica) Escola de Engenharia de São Carlos, Universidade de São Paulo, São Carlos, 2006.

ALTAFIM, R.A.P. Novos piezoeletretos: desenvolvimento e caracterização. 2010. 138 f. Tese (Doutorado em Engenharia Elétrica) - Escola de Engenharia de São Carlos, Universidade de São Paulo, São Carlos, 2010.

ASSAGRA, Y.A.O.; ALTAFIM, R.A.C.; ALTAFIM, R.A.P. Thermo-formed piezoelectrets with open-tubular channels produced from water-filled FEP pads. In: IEEE CONFERENCE ON ELECTRICAL INSULATION AND DIELECTRIC PHENOMENA, 2015.

Proceedings... Piscataway: IEEE, 2015. p.648-651.

BALLATO, A. Modeling piezoelectric and piezomagnetic devices and structures via equivalent networks. IEEE Transactions on Ultrasonics, Ferroelectrics, and Frequency Control, v.48, n.5, p.1189-1240, Sept. 2001.

BERLINCOURT, D. Piezoelectric ceramics: characteristics and applications. Journal of the Acoustical Society of America, v.70, p.1586-1595, Dec. 1981.

BROWN, L.F. Design considerations for piezoelectric polymer ultrasound transducers. IEEE Transactions on Ultrasonics, Ferroelectrics, and Frequency Control, v.47, n.6, p.1377-1396, Nov. 2000.

BROWN, L.F.; CARLSON, D.L. Ultrasound transducer models for piezoelectric polymer films. IEEE Transactions on Ultrasonics, Ferroelectrics, and Frequency Control, v.36, n.3, p.313-318, May 1989.

DAHIYA, R.S.; VALLE, M.; LORENZELLI, L. SPICE model for lossy piezoelectric polymers. IEEE Transactions on Ultrasonics, Ferroelectrics, and Frequency Control, v.56, n.2, p.387-395, 2009. 
EIRAS, J.A. Materiais piezoelétricos. In: ADAMOWSKI, J.C. Sensores - tecnologias e aplicações. Cap.2. Disponível em:

$<$ http://www.atcp.com.br/imagens/produtos/ceramicas/artigos/Sensores_Teoria_e_Aplicacoes .pdf>. Acesso em: 15 fev. 2016.

FALCONI, D.R. et al. Piezoelectric sensor based on electret thermoforming technology. In: IEEE INTERNATIONAL CONFERENCE ON SOLIDS DIELECTRICS, 10., 2010, Potsdam. Proceedings... Piscataway: IEEE Service Center, 2010. p.1-3.

FIORILLO, A.S.; PULLANO, S.A. Ferroelectric polymer for bio-sonar replica. In: LALLART, M.I. (Ed.). Ferroelectrics - applications. Rijeka: InTech, 2011. Cap. 4, p. 75-94.

FIORILLO, A.S. Noise analysis in air-coupled PVDF ultrasonic sensors. IEEE

Transactions on Ultrasonics, Ferroelectrics, and Frequency Control, v.47, n.6, p.14321437, 2000.

GERHARD-MULTHAUPT, R. Less can be more. Holes in polymers lead to a new paradigm of piezoelectric materials for electret transducers. IEEE Transactions on Dielectrics and Electrical Insulation, v.9, n.5, p.850-859, 2002.

GREGÓRIO FILHO, R. Influência das condições de cristalização na morfologia de filmes de polifluoreto de vinilideno (PVDF). Polímeros: ciência e tecnologia , v.3, n.2, p.20-27, jun. 1993.

GUAN, M.; LIAO, W. Studies on the circuit models of piezoelectric ceramics. In: INTERNATIONAL CONFERENCE ON IEEE INFORMATION ACQUISITION, 2004. Proceedings... Piscataway: IEEE, 2004. p.26-31.

GUTMANn, F. The Electret. Reviews of Modern Physics, v.20, n.3, p.457-472, July/Sept. 1948.

HAERTLING, G.H. Ferroelectric ceramics: history and technology. Journal of the American Ceramic Society, v.82, p.797-818, 1999.

KAWAI, H. The Piezoelectricity of poly (vinylidene fluoride). Japanese Journal of Applied Physics, v.8, p.975-976, May 1969.

KIM, J. et al. Electrical modeling of piezoelectric ceramics for analysis and evaluation of sensory systems. In: SENSORS APPLICATIONS SYMPOSIUM, 2008. Proceedings... Piscataway: IEEE, 2008. p.122-127.

KRIMHOLTZ, R.; LEEDOM, D.A.; MATTHAEI, G.L. New Equivalent circuits for elementary piezoelectric transducers. Electronics Letters, v.6, n.13, p.398-399, June 1970.

KYNSLER, L.E. et al. Fundamentals of acoustics. $4^{\text {th }}$ ed. New York: John Wiley, 2000.

LANCEE, C.T. et al. Ferro-electric ceramics versus polymer piezoelectric materials.

Ultrasonics, v.23, n.3, p.138-142, May 1985. 
LEACH, W.M. Contolled-source analogous circuits and SPICE models for piezoelectric transducers. IEEE Transactions on Ultrasonics, Ferroelectrics, and Frequency Control, v.41, n.1, p.60-66, Jan. 1994.

MASON, W.P. An Electromechanical representation of a piezoelectric crystal used as a transducer. Proceedings of the Institute of Radio Engineers, v.23, n.10, p.1252-1263, 1935.

Piezoelectricity, its history and applications. The Journal of the Acoustical Society of America, v.70, n.6, p.1561-1566, 1981.

MEDEIROS, L.J. Hidrofone ultrassônico com piezoeletreto como elemento transdutor. 2014. 109 f. Dissertação (Mestrado em Engenharia Elétrica) - Escola de Engenharia de São Carlos, Universidade de São Paulo, São Carlos, 2014.

MORRIS, S.A.; HUTCHENS, C.G. Implementation of Mason's model on circuit analysis programs. IEEE Transactions on Ultrasonics, Ferroelectrics, and Frequency Control, v.33, n.3, p.295-298, 1986.

OHIGASHI, H. et al. Analysis of frequency response characteristics of polymer ultrasonic transducers. Japanese Journal of Applied Physics, v.27, n.3, p.354-360, 1988.

PALITÓ, T.T.C. Detecção acústica de descargas parciais com transdutor piezoelétrico. 2015. 117 f. Dissertação (Mestrado em Engenharia Elétrica) - Escola de Engenharia de São Carlos, Universidade de São Paulo, São Carlos, 2015.

PÜTTMER, A. et al. SPICE model for lossy piezoceramic transducers. IEEE Transactions on Ultrasonics, Ferroelectrics, and Frequency Control, v.44, n.1, p.60-66, 1997.

QIU, X. et al. Penetration of sulfur hexafluoride into cellular polypropylene and its effect on the electric charging and electromechanical response of ferroelectrets. Journal of Physics D: Applied Physics, v. 38, n. 4, p.649-654, 2005.

REDWOOD, M.; LAMB, J. On the Measurement of attenuation in ultrasonc dealy lines. Proceedings of the IEE-part B: radio and electronic engineering, v.103, n.12, p.773-780, 1956.

ROBERTS, S. Dielectric and piezoelectric properties of barium titanate. Physical Review, v.71, p.890-895, June 1947.

SHERMAN, C.H.; BUTLER, J.L. Transducer and arrays for underwater sound. New York: Springer, 2007.

SHERRIT, S. et al. An Accurate equivalent circuit for the unloaded piezoelectric vibrator in the thickness mode. Journal of Physics D: applied physics, v.30, p.2354-2363, 1997.

TRAINER, M. Kelvin and piezoeletricity. European Journal of Physics, v.24, p.535-542, July 2003. 
VAN DYKE, K.S. The Piezo-electric resonator and its equivalent network. Proceedings of the Institute of Radio Engineers, v.16, n.6, p.724-764, 1928.

WADA, Y.; HAYAKAWA, R. Piezoelectricity and pyroelectricity of polymers. Japanese Journal of Applied Physics, v.15, n.11, p.2041-2057, 1976.

ZAENGL, W.S. Dielectric spectroscopy in time and frequency domain for HV power equipment, part I: theoretical considerations. IEEE Electrical Insulation Magazine, v. 19, n. 5, p. 5-19, Sept./Oct. 2003.

ZHANG, X. et al. Fabrication of fluoropolymer piezoelectrets by using rigid template. Journal of Applied Physics, v.108, n.6, p.064113, 2010.

Fluoroethylenepropylene ferroelectrets with patterned microstructure and high, thermally stable piezoelectricity. Applied Physics A, v.107, n.13, p.621-629, 2012.

ZHANG, X.; HILLENBRAND, J.; SESSLER, G.M. Thermally stable fluorocarbon ferroelectrets with high piezoelectric coefficient. Applied Physics A, v.84, n.1-2, p.139-142, 2006.

Ferroelectrets with improved thermal stability made from fused fluorocarbon layers. Journal of Applied Physics, v.101, n.5, p.054114, 2007. 